\title{
The Generation of Secondary Ice Particles in Clouds
} by Crystal-Crystal Collision

\author{
By \\ Larry Vardiman
}

Department of Atmospheric Science

Colorado State University

Fort Collins, Colorado

This research was supported by the NSF Grant GI-31460, and the State of Colorado,

Weather Modification Research Funds.

Principal investigator: Lewis $\mathrm{O}$. Grant

Fall 1974

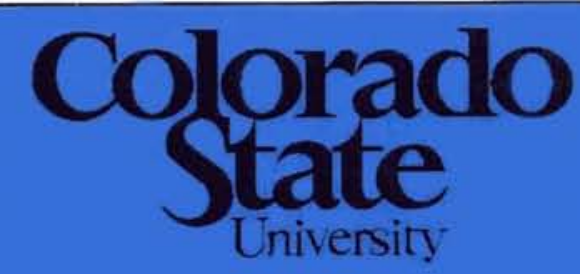

\section{Department of Atmospheric Science}


THE GENERATION OF SECONDARY ICE PARTICLES IN CLOUDS

BY CRYSTAL-CRYSTAL COLLISION

\author{
by \\ Larry Vardiman
}

This report was prepared with support provided by National Science Foundation Grant GI-31460

and the State of Colorado, Weather Modification Research Funds Principal Investigator, Lewis 0 . Grant

Department of Atmospheric Science

Colorado State University

Fort Collins, Colorado

Fall 1974

Atmospheric Science Paper No. 230 


\section{ABSTRACT OF DISSERTATION \\ THE GENERATION OF SECONDARY ICE PARTICLES \\ IN CLOUDS BY CRYSTAL-CRYSTAL COLLISION}

Evidence has accumulated over the last twenty years that in some clouds the concentration of ice crystals may be a factor of four or five orders of magnitude greater than the concentration of observed ice nuclei apparently available to the cloud. A large number of physical mechanisms have been proposed to explain this disparity between the concentration of ice nuclei and ice crystals. This dissertation describes the investigation of one of these mechanisms -the generation of secondary ice particles in clouds by crystal-crystal collision.

The number of fragments generated by crystal collisions in a cloud is a product of the number of fragments produced per collision and the collision frequency. The first term, called the fragment generation function was obtained experimentally by photographing at high speed, collisions of natural ice crystals with a fixed plate. The number of fragments in a collision was found as a function of the change in momentum upon impact with the fixed plate and as a function of crystal type and degree of rime. The difference in the change in momentum for collisions in a cloud compared to the fixed plate is treated theoretically and developed into a mathematical model. The collision frequency is incorporated into the model and rates of fragment generation studied for different crystal combinations, sizes, and concentrations. 
TABLE OF CONTENTS

$\underline{\text { Section }}$

$\underline{\text { Page }}$

ABSTRACT OF DISSERTATION........................ iii

ACKNOWLEDGMENTS $\ldots \ldots \ldots \ldots \ldots \ldots \ldots \ldots \ldots \ldots \ldots \ldots \ldots \ldots \ldots \ldots \ldots \ldots \ldots$

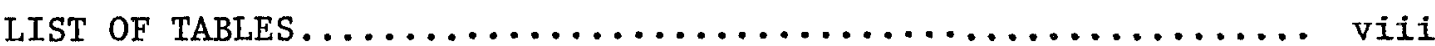

LIST OF FIGURES $\ldots \ldots \ldots \ldots \ldots \ldots \ldots \ldots \ldots \ldots \ldots \ldots \ldots \ldots \ldots \ldots \ldots \ldots \ldots \ldots$

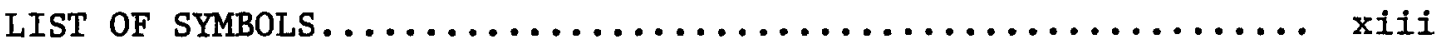

CHAPTER I: INTRODUCTION........................ 1

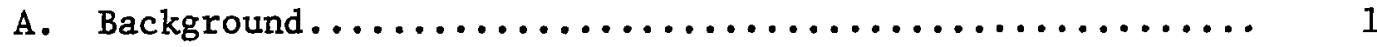

B. The Generation of Secondary Ice Particles............. 2

C. The Need for a Solution....................... 4

D. Suggested Mechanisms for Ice Multiplication.......... 5

1. Mechanisms Related to the Formation of Primary

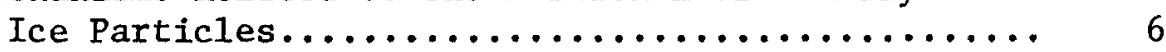

2. Mechanisms Related to the Generation of Secondary

Ice Particles........................... 6

E. Previous Studies on Mechanical Fracturing of Fragile

Crystals in Clouds......................... 8

F. Purpose of this study........................ 10

CHAPTER II: THEORY............................ 12

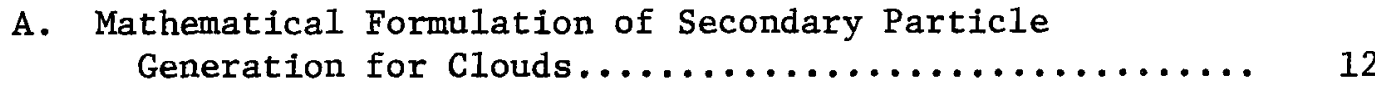

1. Random and Ordered Collisions................. 12

2. Fragment Generation Functions................. 14

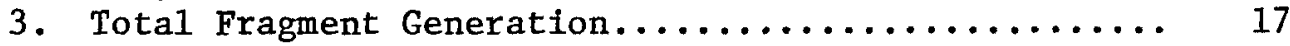

B. Analytic Solutions......................... 19

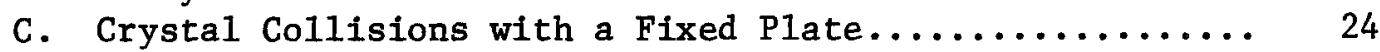

1. Similarity to Collisions in Clouds............. 24

2. Mathematical Formulation of the Change in

Momentum with a Fixed Plate................. 26

3. Determination of the Coefficient of Restitution.... 27

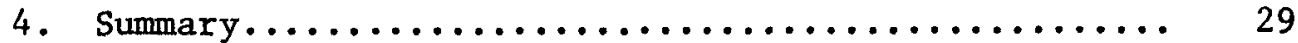

CHAPTER III: EXPERTMENTAL DATA AND PROCEDURES........... 30

A. Description of Experimental Apparatus.............. 30

B. Data Collection and Reduction Procedures............ 37

C. Determination of the Fragment Generation Function....... 40

D. Data Limitations............................ 49 
CHAPTER IV: NUMERICAL MODELING.................. 53

A. Model Description......................... 53

B. Determination of Optimum Rate Constants............ 61

C. Time-Dependent Computations.................... 69

CHAPTER V: MODEL VERIEICATION.................. 78

A. Introduction........................... 78

B. HAO and Wolf Creek Observations................. 79

C. Yellowstone Observations..................... 81

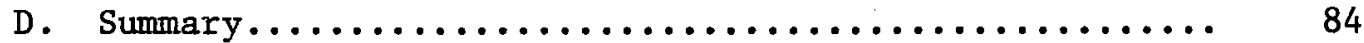

CHAPTER VI: DISCUSSION OF RESULTS................ 85

A. General Comments......................... 85

B. Implications for Natural and Seeded Clouds.......... 86

1. Stratiform Clouds...................... 86

2. Isolated Convective Clouds................ 87

3. Embedded Convective Clouds.................. 88

C. Summary.............................. 89

CHAPTER VII: CONCLUSIONS AND RECOMMENDATIONS............ 90

A. Conclusions............................. 90

B. Implications for Natural and Seeded Clouds.......... 91

C. Recommendations.......................... 92

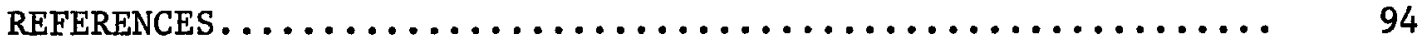

APPENDIX A: DERIVATION OF THE AVERAGE CHANGE IN MOMENTUM.... 99

APPENDIX B: DETERMINATION OF THE COEFFICIENT OF RESTITUTION

IN A COLLISION WITH A FIXED PLATE.......... 104

APPENDIX C: DETERMINATION OF FALL VELOCITIES........... 110

APPENDIX D: METEOROLOGICAL DATA FOR A CASE STUDY AT

YELLOWSTONE NATIONAL PARK.............. 114 
1. Data sources for each of the five crystal types studied.... 38

2. Equations of the fragment generation functions and correlation coefficients for second order least squares fit.......................... 47

3. $\mathrm{N}$ and $\Delta \mathrm{N} / \mathrm{N}$ with a $10 \%$ increase in $\Delta \mathrm{M}$ for the five crystal types studied....................... 51

4. Mass-diameter and terminal fall velocity equations used in the numerical model................. 57

5. Values of $\mathrm{K}_{\mathrm{O}}$ for various size distributions of unrimed plane dendrites colliding with unrimed plane dendrites.. 62

6. Values of $\mathrm{K}_{\mathrm{o}}$ for various size distributions of unrimed plane dendrites colliding with lightly-rimed plane dendrites.................................

7. Values of $k_{o}$ for various size distributions of unrimed plane dendrites colliding with heavily-rimed plane dendrites................................

8. Values of $\mathrm{K}_{\mathrm{O}}$ for varlous size distributions of unrimed plane dendrites colliding with light-moderate rimed

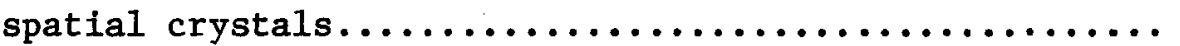

9. Values of $\mathrm{K}_{\mathrm{o}}$ for various size distributions of unrimed

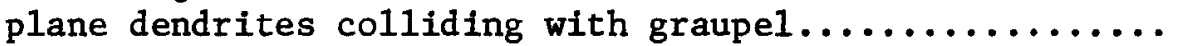

10. Values of $\mathrm{K}_{\mathrm{o}}$ for various size distributions of lightlyrimed plane dendrites colliding with lightly-rimed

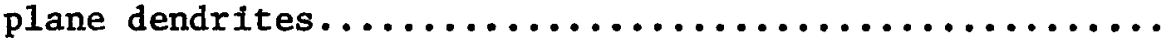

11. Values of $\mathrm{K}_{\mathrm{o}}$ for various size distributions of lightlyrimed planedendrites colliding with heavily-rimed plane dendrites............................. 64

12. Values of $\mathrm{K}_{0}$ for varlous size distributions of lightlyrimed plane dendrites colliding with light-moderate rimed spatial crystals....................... 64

13. Values of $\mathrm{K}_{0}$ for various size distributions of lightlyrimed plane dendrites colliding with graupel......... 64

14. Values of $\mathrm{K}_{\mathrm{o}}$ for various size distributions of heavilyrimed plane dendrites colliding with heavily-rimed

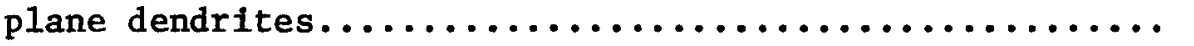


$\underline{\text { Table }}$

15. Values of $\mathrm{K}_{\mathrm{o}}$ for various size distributions of heavilyrimed plane dendrites colliding with light-moderate rimed spatial crystals...................... 65

16. Values of $\mathrm{K}_{\mathrm{o}}$ for various size distributions of heavilyrimed plane dendrites colliding with graupel........ 65

17. Values of $\mathrm{K}_{\mathrm{o}}$ for various size distributions of lightmoderate rimed spatial crystals colliding with lightmoderate rimed spatial crystals................. 66

18. Values of $\mathrm{K}_{\mathrm{o}}$ for various size distributions of lightmoderate rimed spatial crystals colliding with graupel.. 66

19. Values of $\mathrm{K}_{\mathrm{o}}$ for various size distributions of graupel

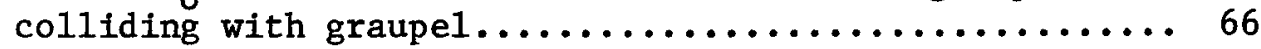

20. Values of $\mathrm{K}_{0}$ for three relatively large distributions of graupel colliding with a broad distribution of four other crystal types.......................... 69 
LIST OF FIGURES

Figure

Page

1. The variation of $\mathrm{C}$ as a function of time for various

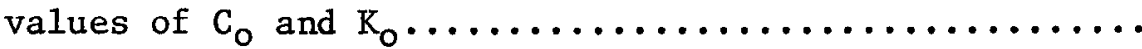

2. The time required to reach a given multiplication ratio for various values of $\mathrm{C}_{0}$ and $\mathrm{K}_{0} \ldots \ldots \ldots \ldots \ldots \ldots$

3. Photograph of the instrument used in the fixed-plate

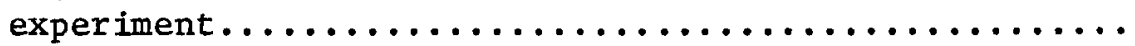

4. A sequence of six frames taken during the collision of a heavily-rimed plane dendrite with the fixed plate. The frames are approximately .01 sec. apart.........

5. Photographs of the data collection procedures and equipment set up in the field at $\mathrm{HAO}$, near Leadville

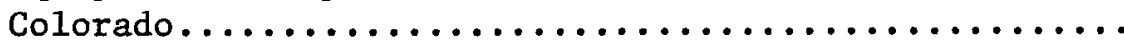

6. Examples of each of the five crystal types studied.......

7. Diagram of the instrument used to determine the number of fragments from unrimed plane dendrites...........

8. Fragment generation function for unrimed plane dendrites. The number of fragments produced per collision, $N$, as a function of the change of momentum in the collision,

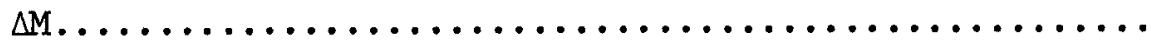

9. Fragment generation function for 1ight-to-moderate rimed plane dendrites. The number of fragments produced per collision, $\mathrm{N}$, as a function of the change of momentum in the collision, $\Delta \mathrm{M} . \ldots \ldots \ldots \ldots \ldots \ldots \ldots \ldots \ldots \ldots$

10. Fragment generation function for heavily-rimed plane dendrites. The number of fragments produced per collision, $\mathrm{N}$, as a function of the change of momentum in the collision $4 M . \ldots \ldots \ldots \ldots \ldots \ldots \ldots \ldots \ldots \ldots \ldots$

11. Fragment generation function for 1ight-to-moderate rimed spatial crystals. The number of fragments produced per collision, $N$, as a function of the change of momentum in the collision, $\Delta \mathrm{M}$.

12. Fragment generation function for graupel. The number of fragments produced per collision, $N$, as a function of the change of momentum in the collision, $\Delta \mathrm{M} . \ldots \ldots \ldots \ldots$

13. Composite fragment generation functions for all five

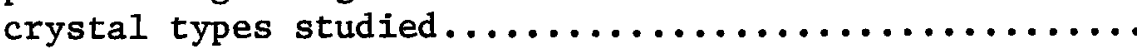


Figure

$\underline{\text { Page }}$

14. Flow diagram of numerical model................ 54

15. Size distributions used in the numerical model......... 56

16. Terminal fall velocities as a function of crystal diameter for the five crystal types studied......... 58

17. Size distribution of fragments from heavily-rimed plane

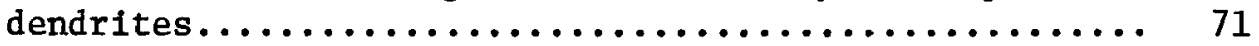

18. Size distributions of fragments from graupe1......... 72

19. Change of concentration of all crystals as a function of time for two different initial crystal concentrations and several different rates of accretion and diffusion.. 73

20. Change in the size distribution of heavily-rimed plane dendrites due to collision with graupel. (a) initial size distribution (b) size distribution after 5 minutes (c) size distribution after 10 minutes (d) composite of sizes distributions for all three time

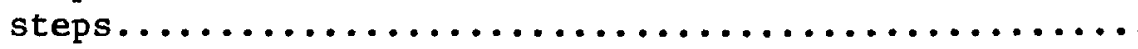

21. Change in the size distribution of graupel due to collision with heavily-rimed plane dendrites. (a) initial size distribution (b) size distribution after 5 minutes (c) size distribution after 10 minutes (d) composite of size distributions for all three time

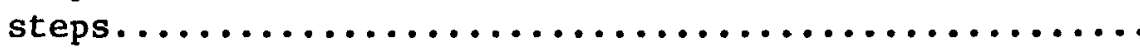

22. Regrown ice crystal collected at HAO near Climax,

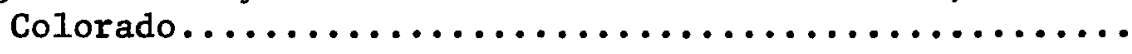

23. P1ot of crystal concentration vs. time for January 26,

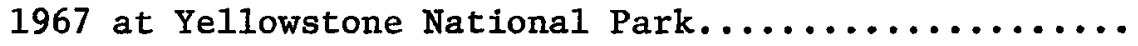

A-1. Collision configuration of two crystals used to determine the most likely change of momentum........ 100

B-1. Collision trajectory with times, angles, and velocities before and for two frames after collision with a

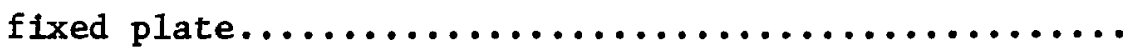

C-1. Observed terminal fall velocities for lightly-rimed plane dendrites. The correlation coefficient for the least-squares fit was .59 . 


\section{LIST OF FIGURES (Cont.)}

Figure

Page

C-2. Observed terminal fall velocities for heavily-rimed plane dendrites. The correlation coefficient for the least-squares fit was $.36 \ldots \ldots \ldots \ldots \ldots \ldots \ldots \ldots . \ldots 112$

D-1. Surface map for $18 \mathrm{Z}$ on 26 January $1967 \ldots \ldots \ldots \ldots \ldots \ldots$

D-2. Surface map for $00 Z$ on 27 January $1967 \ldots \ldots \ldots \ldots \ldots \ldots . . . \ldots$

D-3. Surface map for $06 z$ on 27 January $1967 \ldots \ldots \ldots \ldots \ldots \ldots$

D-4. $\quad 700 \mathrm{mb}$ chart for $00 \mathrm{z}$ on 27 January $1967 \ldots \ldots \ldots \ldots \ldots \ldots .116$

D-5. $500 \mathrm{mb}$ chart for $00 \mathrm{Z}$ on 27 January $1967 \ldots \ldots \ldots \ldots \ldots \ldots$

D-6. Upper-air sounding for Boise, Idaho at $00 \mathrm{z}$ on 27

January $1967 \ldots \ldots \ldots \ldots \ldots \ldots \ldots \ldots \ldots \ldots \ldots \ldots \ldots \ldots \ldots \ldots \ldots \ldots$ 


\section{LIST OF SYMBOLS}

English Letters

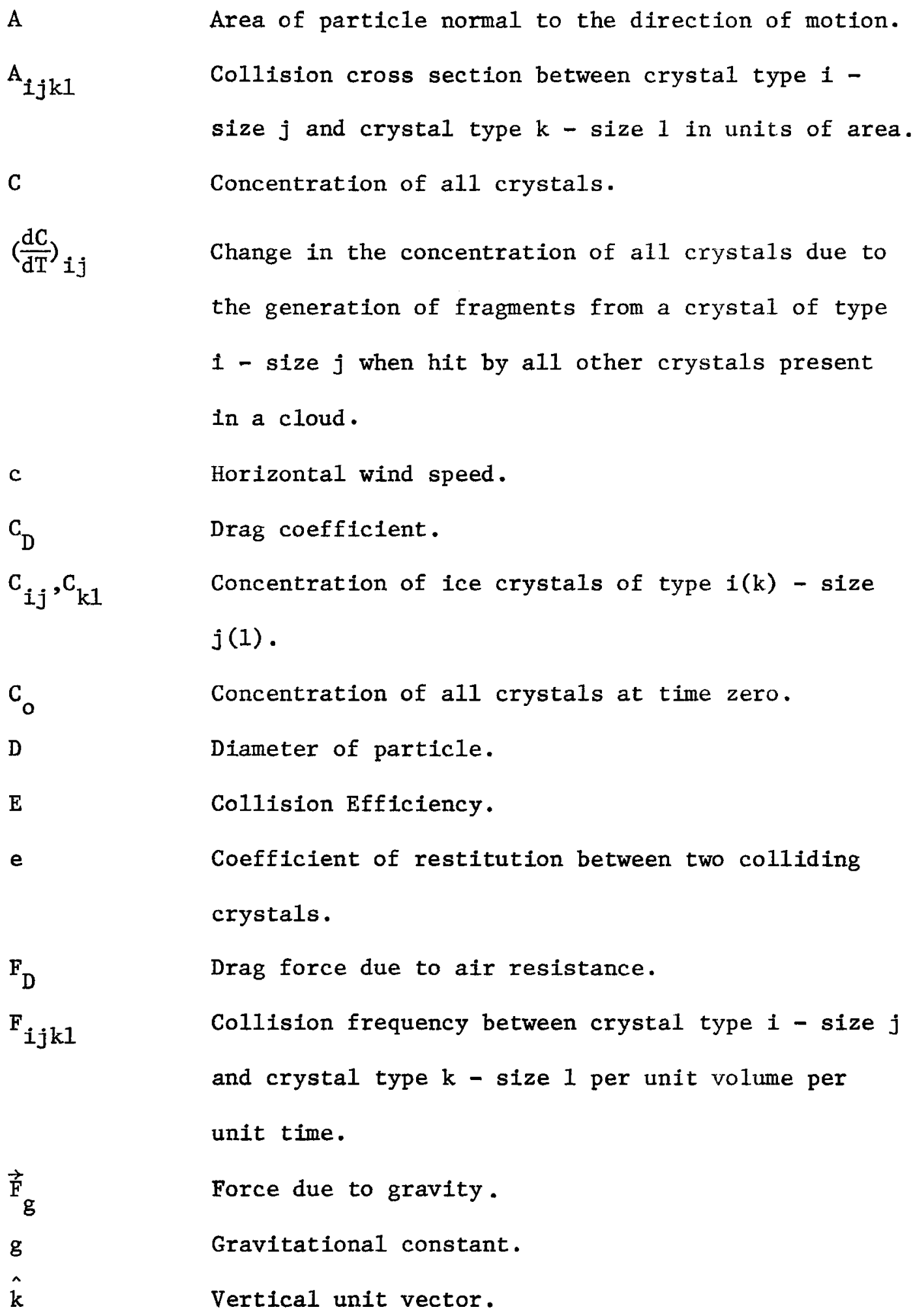




\section{LIST OF SYMBOLS (Cont.)}

English Letters

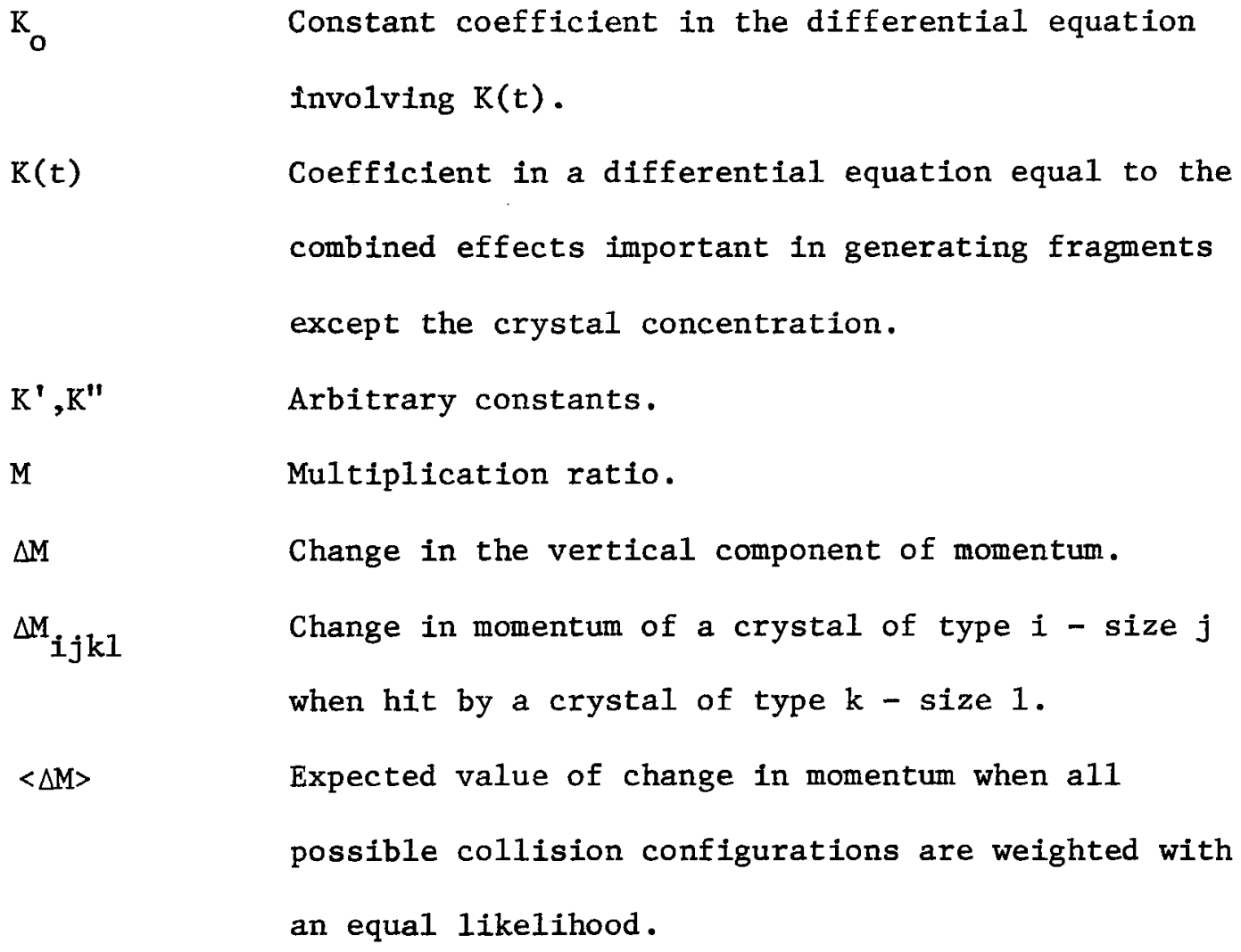


LIST OF SYMBOLS (Cont.)

English Letters

$N_{i j k 1}$

Fragment generation function for a crystal of type

$i$ - size $j$ when hit by a crystal of type $k$ - size 1

in units of number of fragments per collision.

n

Concentration of ice nuclei active at a given

temperature and warmer.

no

Concentration of ice nuclei active at $0^{\circ} \mathrm{C}$.

$P_{i j}, P_{k 1}$

Fraction of all crystals of type $i(k)$ - size $j(1)$.

Re

Reynold's number.

$r_{i j}, r_{k 1}$

Radius of a crystal of type $i(k)$ - size $j(1)$.

$r_{1}, r_{2}$

Radii of colliding particles.

$\Delta \mathrm{T}$

Temperature differential below $0^{\circ} \mathrm{C}$.

$t_{0}, t_{1}, t_{2}$

Time before, time one frame after, and time two

frames after collision respectively.

$\overrightarrow{\mathrm{v}}$

Velocity of a particle.

$\frac{d \vec{v}}{d t}$

Acceleration of a particle.

$\mathrm{v}_{0}, \mathrm{v}_{1}, \mathrm{v}_{2}$

Vertical speed of particle before and one and two frames after collision, respectively.

$\mathrm{v}_{1 \mathrm{R}}, \mathrm{v}_{2 \mathrm{R}}$

Fall velocities of two colliding particles relative

to time of impact.

$v_{i j}, v_{k 1}$

Terminal fall velocity of a crystal of type $i(k)-$ size $j(1)$.

$v_{i j}, v_{R I}{ }^{\circ} \quad$ Velocity of a crystal of type $i(k)-$ size $j(1)$

before a collision. 


\section{LIST OF SYMBOLS (Cont.)}

English Letters

$v_{i j}^{f}, v_{k 1}^{f} \quad$ Velocity of a crystal of type $i(k)-\operatorname{size} j(1)$ after a collision.

$\mathrm{v}_{1 \mathrm{~T}}, \mathrm{v}_{2 \mathrm{~T}}$

w

wo

$\mathrm{w}_{\mathrm{f}}$

${ }^{\mathrm{w}} \mathrm{f}$

$\mathrm{w}_{f i}$

$\frac{d \vec{w}}{d t}$

$\mathrm{X}$

$z$

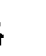

Greek Letters
$\alpha, \beta, \gamma$
Coefficients in least squares fit to fragment generation functions.
Angle between the vertical and the line of impact in a collision between two particles. 


\section{LIST OF SYMBOLS (Cont.)}

Greek Letters

$\begin{array}{ll}\rho & \text { Air density. } \\ \phi_{0}, \phi_{1}, \phi_{2} & \text { Angle between direction of particle motion and the } \\ & \text { horizontal before and one and two frames after } \\ & \text { collision, respectively. } \\ & \text { Coefficient in exponential equation for ice nuclei. } \\ \psi & \text { Summation. }\end{array}$



CHAPTER I

INTRODUCTION

\section{A. Background}

In 1933 Tor Bergeron suggested that precipitation in the majority of extratropical clouds is initiated by the formation of ice crystals and subsequent growth due to the vapor pressure difference between ice and water. Since 1933 it has been found that the coalescence process may a1so be responsible for much precipitation even in extratropical clouds, but the ice phase process is still considered the dominant process. Early in the investigation of the "Bergeron-Findeison" precipitation process it was found that the initiation of the ice phase in clouds was due to the presence of small ice-forming particles in the atmosphere, called ice nuclei. These particles were found to be active in greater concentrations at colder temperatures and varied somewhat in space and time. For many years the concentration of these ice nuclei active at a given cloud-top temperature was equated to the concentration of ice crystals in a cloud. Over the last twenty years, however, evidence has accumulated which shows that in some clouds the concentration of ice crystals may be four or five orders of magnitude greater than the concentration of ice nuclei available to the cloud.

A large number of physical mechanisms have been proposed to explain this disparity between the concentration of ice nuclei and ice crystals. One of the earliest and most persistently-proposed mechanisms has been the mechanical fracturing of fragile ice crystals in a cloud due to collisions between crystals. This dissertation 
describes the investigation of this mechanism and its importance in natural and seeded clouds.

B. The Generation of Secondary Ice Particles

Primary ice crystals are particles of ice which have originated on primary ice nuclei. These ice nuclei may be activated in any of four ways (Mason, 1971). They may form ice crystals by the direct deposition of water vapor; they may first act as condensation nuclei, and then cause the absorbed water to freeze; they may contact supercooled cloud droplets causing them to freeze; or they may be embedded in cloud droplets acting as bulk freezing nuclei. Primary ice crystals are expected to be present in clouds in concentrations equal to the concentration of ice nuclei activated in a cold chamber at a given temperature. The temperature at the cloud top strongly affects the concentration of ice nuclei which becomes active. A world-wide time and space average temperature spectrum of activated ice nuclei has been obtained by Fletcher (1962). It has an exponential form

$$
\mathrm{n}(\Delta \mathrm{T})=\mathrm{n}_{\mathrm{o}} \exp (\psi \Delta \mathrm{T})
$$

where $\Delta T$ is the degree of supercooling, $n(\Delta T)$ is the concentration of activated ice nuclei per liter, and $\mathrm{n}_{\mathrm{o}}$ and $\psi$ are constants. Fletcher found $\psi$ and $n_{0}$ to be about $0.6 /{ }^{\circ} \mathrm{C}$ and $10^{-5} /$ iter respectively. An estimate of the concentration of activated ice nuclei is one per liter at a supercooling of $-20^{\circ} \mathrm{C}$ and a change by a factor of ten for each four degrees of supercooling, the concentration increasing at greater supercooling.

Secondary ice crystals are particles of ice which have been produced in a cloud by the presence of primary ice crystals. These 
secondary ice particles may be "regular" in shape, irregular, rimed or unrimed depending on the formation process and subsequent history.

Early observations of secondary ice particle generation were highly suspect due to the wide fluctuations in the concentration of primary ice crystals from cloud to cloud and due to inaccuracies in the measurement of ice nucleus and ice crystal concentrations. In the last ten years, however, as measurement techniques have improved and observed differences in the concentrations of ice nuclei and ice crystals have become divergent, particularly in clouls with small supercooling, the presence of large concentrations of secondary ice particles has been generally accepted. The observational studies by Koenig (1963, 1968), Mossop $(1968,1971)$, Mossop, et a1 (1967, 1968, 1969, 1970, 1972), Hobbs (1969), Auer, et al (1969), Grant (1968), Gagin (1971), and Vardiman (1972) have provided insight into the general cloud types and conditions which favor ice multiplication and the magnitude of the effect. In general, stratiform clouds do not appear to produce large numbers of secondary ice particles since the concentrations of ice crystals agree closely to the concentrations of ice nuclei. Cumuliform clouds produce secondary ice particles under as yet incompletely-defined conditions and ratios of ice crystals to ice nuclei may range from 1 at cloud-top temperatures of about $-30^{\circ} \mathrm{C}$ to $10^{4}-10^{5}$ at temperatures as warm as $-4^{\circ} \mathrm{C}$. Maritime cumuli seem to produce secondary ice particles much more easily than continental cumuli. 
C. The Need for a Solution

The simple assumption that the initiation and formation of precipitation in a cold cloud is related entirely to the concentration of primary ice nuclei, leads to an underestimate of natural

precipitation. Certain clouds preclpitate much more intensely than would be expected if only the primary ice nuclei were available. In some extreme cases a cloud may precipitate heavily where no precipitation would be expected from the cloud-top temperature and thickness. Forecasting of natural precipitation and simple understanding of a commonly-observed but little-understood phenomena necessitate the study of secondary ice-particle generation in a cloud. Most artificial cold cloud modification is also based on the assumption that the concentration of ice crystals in a cloud is equal to the concentration of measured ice nuclei. If this were true, the less the supercooling in a cloud, the more efficient cloud modification should be in converting the cloud water to ice. However, we know that artificial modification of cold clouds to increase precipitation becomes inefficient at temperatures warmer than about $-10^{\circ} \mathrm{C}$. There are practical constraints such as the reduction in efficiency of seeding devices and the slower growth rates of ice crystals at warmer temperatures which contribute to this inefficiency, but the precipitation efficiency of these clouds does not appear to be helped by seeding. If the concentration of ice crystals in a cloud is equal to the concentration of measured ice nuclei, many of these 
"warm clouds" should not precipitate naturally by the ice crystal process and seeding should increase precipitation efficiency. Grant and E1liott (1974) estimated the "temperature window" for efficient cloud seeding in winter orographic clouds to extend from $-10^{\circ} \mathrm{C}$ to $-24^{\circ} \mathrm{C}$. At the warm end of this "temperature window" they suggested that various effects including "multiplication processes" may impair the seeding efficiency. They were unable to define a "temperature window" for convective clouds or clouds which contain strong dynamic effects. Since it is generally accepted that ice multiplication is greater in convective clouds than in stratiform clouds, the reason a "temperature window" can not be defined may be due to multiplication processes.

Since ice multiplication appears to be a common theme in limiting seeding opportunity for many clouds, it would seem to be easier to attack the problem directly by defining secondary ice particle generation processes, rather than randomly seeding all cloud situations and using statistical evidence to define "temperature windows." The need for a solution to secondary ice particle generation is urgent if artificial cloud modification is to be applied effectively.

\section{Suggested Mechanisms for Ice Multiplication}

Not only may the concentration of ice crystals be increased by the generation of secondary particles but the concentration of ice nuclei may be underestimated in an instrument used to detect them. The conditions in an ice nucleus counter do not completely duplicate those in a cloud. For purposes of this dissertation ice multiplication is defined by the ratio of ice crystals to ice nuclei in a cloud. 
There are two basic classifications of the suggested mechanisms for explaining ice multiplication. Following Henmi (1974), the first category includes those suggested mechanisms which are related to the formation of primary ice particles and the second category includes those suggested mechanisms which generate secondary ice particles.

1. Mechanisms related to the formation of primary ice particles.

a. Ice formation on slow acting ice nuclei (Warner and Newnham, 1958; Takeda, 1968)

b. Ice formation on pre-activated nuclei (Roberts and Hallett, 1968)

c. Contact nucleation by dry particles (Gokhale and Goold, 1968)

d. Freezing of water droplets due to evaporation cooling Hallett, 1970)

e. Electro-freezing or mechanical freezing of supercooled water (Abbas and Latham, 1969)

2. Mechanisms related to the generation of secondary ice particles.

a. Shedding of "whiskers" from evaporating ice particles (Cross, 1969; De Michelli and Licenblat, 1967; Ruskin, 1969; Schaeffer and Cheng, 1974)

b. Mechanical fracturing of fragile ice crystals (Findeisen, 1943; Langmuir, 1948; Mason, 1955; Grant, 1968; Hobbs and Farber, 1972; Vardiman, 1972)

c. "Sp1intering" when drops freeze in the riming growth of ice particles (Brewer and Palmer, 1949; Johnson and 
"warm clouds" should not precipitate naturally by the ice crystal process and seeding should increase precipitation efficiency. Grant and E1liott (1974) estimated the "temperature window" for efficlent cloud seeding in winter orographic clouds to extend from $-10^{\circ} \mathrm{C}$ to $-24^{\circ} \mathrm{C}$. At the warm end of this "temperature window" they suggested that various effects including "multiplication processes" may impair the seeding efficiency. They were unable to define a "temperature window" for convective clouds or clouds which contain strong dynamic effects. Since it is generally accepted that ice multiplication is greater in convective clouds than in stratiform clouds, the reason a "temperature window" can not be defined may be due to multiplication processes.

Since ice multiplication appears to be a common theme in limiting seeding opportunity for many clouds, it would seem to be easier to attack the problem directly by defining secondary ice particle generation processes, rather than randomly seeding all cloud situations and using statistical evidence to define "temperature windows." The need for a solution to secondary ice particle generation is urgent if artificial cloud modification is to be applied effectively.

\section{Suggested Mechanisms for Ice Multiplication}

Not only may the concentration of ice crystals be increased by the generation of secondary particles but the concentration of ice nuclei may be underestimated in an instrument used to detect them. The conditions in an ice nucleus counter do not completely duplicate those in a cloud. For purposes of this dissertation ice multiplication is defined by the ratio of ice crystals to ice nuclei in a cloud. 
There are two basic classifications of the suggested mechanisms for explaining ice multiplication. Following Henmi (1974), the first category includes those suggested mechanisms which are related to the formation of primary ice particles and the second category includes those suggested mechanisms which generate secondary ice particles.

1. Mechanisms related to the formation of primary ice particles.

a. Ice formation on slow acting ice nuclei (Warner and Newnham, 1958; Takeda, 1968)

b. Ice formation on pre-activated nuclei (Roberts and Ha1lett, 1968)

c. Contact nucleation by dry particles (Gokhale and Goold, 1968)

d. Freezing of water droplets due to evaporation cooling Ha1lett, 1970)

e. Electro-freezing or mechanical freezing of supercooled water (Abbas and Latham, 1969)

2. Mechanisms related to the generation of secondary ice particles.

a. Shedding of "whiskers" from evaporating ice particles (Cross, 1969; De Miche11i and Licenblat, 1967; Ruskin, 1969; Schaeffer and Cheng, 1974)

b. Mechanical fracturing of fragile ice crystals (Findeisen, 1943; Langmuir, 1948; Mason, 1955; Grant, 1968; Hobbs and Farber, 1972; Vardiman, 1972)

c. "Splintering" when drops freeze in the riming growth of ice particles (Brewer and Palmer, 1949; Johnson and 
Hallett, 1968; Mossop et al, 1969; Mossop et a1, 1962;

Ono, 1971; Hallet and Mossop, 1974.

d. Shattering of water drops freezing in free fall (Hobbs and Alkezweeny, 1968; Brownscomb and Thorndike, 1968;

Takahashi and Yamashita, 1970)

e. Frost-like growth on ice particles in local supersaturation caused by contact with large drops (Koenig, 1965)

f. Accumulation of ice crystals or ice nuclei at the sampling leve1 (Mossop and Ono, 1969)

g. Seeding by ice particles from higher clouds (Braham, 1967)

h. Disintegration of the surface structure of rimed ice by ventilation in subsaturated air (Henmi, 1974)

The suggested mechanisms have been studied to a greater or lesser degree depending on the likelihood of the mechanism being active in the clouds peculiar to the investigators' interests. Under certain conditions and in particular clouds many of the suggested mechanisms can be eliminated. As of this writing none of the thirteen mechanisms have been shown to be "the" ice crystal multiplication mechanism. In fact, I tend to doubt if a single process will ever be found to explain all of the differences between the concentrations of ice crystals and ice nuclei. If one is found to be generally effective in a great number of clouds, it appears probable that "splintering" is the most likely candidate.

Given the conditions in Colorado where large concentrations of irregular crystals and crystal fragments have been found in the precipitation from convective cells embedded in orographic clouds (Vardiman, 1972), the most likely mechanism would appear to be 
"mechanical fracturing of fragile ice crystals." Orographic clouds which contain embedded convection differ from smooth orographic clouds mainly in the degree of stability. Unless the cloud layer is highly unstable, the convection will constitute only a small portion of the orographic cloud in which it is embedded. The orographic cloud, with or without convection, is generally smooth on top, except in the vicinity of convective cells which nearly always protrude less than 1,000 feet. Upwind and downwind edges are normally well defined. Therefore, all of the mechanisms relating to the formation of primary ice particles can be eliminated due to the relatively good agreement between crystal concentrations in a smooth orographic cloud and expected ice nucleus concentrations. Droplets large enough to produce shattering and splintering effects are seldom present in these clouds. Only occasiona1ly are higher-level clouds present which could seed the lower cloud deck and the accumulation of ice crystals or ice nuclei is unlikely. Finally, the frequently-observed presence of large crystal fragments can only be explained by mechanical fracturing. Therefore, of the mechanisms which are related to the generation of secondary ice particles, mechanical fracturing of fragile ice crystals constitutes a prime prospect to explain the ice multiplication associated with convective cells embedded in such continental orographic clouds. Findings in such a study may have application in many other cloud types.

E. Previous Studies on Mechanical Fracturing of Fragile Crystals in Clouds.

To initiate a study on mechanical fracturing by crystal-crystal collision in a cloud one must determine two main characteristics of a 
given cloud of ice crystals - the collision frequency between crystals and the production rate of fragments per collision. Once these two characteristics are determined the rate of increase in ice crystal concentration with time can be estimated for different cloud conditions and a determination of the importance of this process made.

The collision frequency of raindrops has been treated in detail because of the importance of size distribution in the production of rain from warm clouds (See Twomey, 1966 and Berry, 1967), but the collision frequency of ice crystals has received little attention. What work has been done was related not to the breakup of ice crystals, but rather to their aggregation. One such study, from which the basic mathematical model for collision frequency was obtained in this work, was that of Austin and Kraus (1968). One of the basic conclusions of their research, which applied to aggregation, was that a threshold in conditions must be reached before the process becomes significant. For Austin and Kraus the threshold was a function of temperature and size of crystals. The threshold in this study was found to be crystal concentration and the degree of rime.

The production rate of fragments per collision has never been studied in more than a cursory manner. Findeisen (1943), Langmuir (1948), and Mason (1955), although discussing the need for fragments to be produced by collisions among fragile crystals, never went beyond estimates of the average number of fragments which would have to be produced. They obtained these estimates by dividing the concentration of particles at the ground by an assumed initial concentration of particles at the top of the cloud. Langmuir (1948) discussed the 
possibility of changes in the fragmentation rate in his famous "Chain Reaction" paper but never treated it in a quantitative manner. Grant (1968) using data from Climax, Colorado discussed the presence of crystal fragments in the precipitation from general orographic clouds and concluded that on the average fragmentation only caused a maximum tenfold increase in the concentration. Vardiman (1972) conducted a study at the same location but emphasized only crystal concentrations from embedded convective cells. In this study it was found that ratios of ice crystals to ice nuclei from these embedded cells could reach $10^{4}$ at cloud-top temperatures as warm as $-15^{\circ} \mathrm{C}$.

The first reported attempt at assessing the strength of ice crystals and their susceptibility to fracture was that of Hobbs and Farber (1972). Theirs was essentially a theoretical study using measured tensile strengths and elastic moduli for pure ice. They obtained critical kinetic energies for given moment arms to determine if crystals falling at relative velocities, such as observed in a cloud, should produce fragments. For large relative velocities, moment arms, and masses they found that some fragmentation would be expected. A warning was provided at the end of their paper regarding the collision frequency but only a rough evaluation of this point was made, indicating that even though fragmentation does occur it is probably so infrequent as to nullify the effect.

F. Purpose of this Study

If mechanical fracturing by crystal-crystal collision in a cloud is to be formulated in detail, two problems should be resolved: (1) An experimentally-determined fragment-generation function (number of fragments produced per collision) must be obtained and (2) this 
function must be integrated with the collision frequency. A theoretically-derived fragment generation function, such as that of Hobbs and Farber (1972), is not really suitable because of the many variations in crystal type, orientation of fall, and degree of rime. One needs a measure of the number of fragments which would be generated in a collision which is more closely tied to real collisions rather than to theoretical deductions based on elastic crystal streng ths.

The purpose of this study, then, is to determine experimentally a fragment generation function for a number of different crystal types and integrate these fragment generation functions with the respective theoretical collision frequencies. The magnitude of ice particle generation by crystal-crystal collision is to be estimated for various cloud conditions and the effects on natural and seeded clouds predicted. 
CHAPTER II

THEORY

A. Mathematical Formulation of Secondary Particle Generation for Clouds.

1. Random and Ordered Collisions.

In a cloud of particles varying in size, two basic types of collision processes are possible - random collisions and ordered collisions. Random collisions are associated with turbulent motions in the air caused by vertical and horizontal wind shear. Ordered collisions are caused by the difference in terminal velocity between particles. The component to the total collision frequency in a cloud due to ordered collisions can be visualized as the total collision frequency between particles in a quiescent environment where the particles fall without fluttering or being deflected in the wake of other particles. If wake effects are to be considered, a factor called the collision efficiency must be multiplied times the computed collision frequency.

Although it is possible that random collisions may outnumber ordered collisions in highly-turbulent clouds and the collisions could be more "forceful", only ordered collisions will be treated in this study due to the inability to formulate random collisions in an analytic manner. This assumption should not be too restrictive as the number of random collisions should be of the same order as the number of ordered collisions in non-severe cloud situations. For smooth orographic clouds, the number of ordered collisions should outnumber the random collisions. 
The ordered collision frequency between crystals has been shown by Austin and Kraus (1968) to be:

$$
F_{i j k 1}=E C_{i j} C_{k 1} A_{i j k 1}\left|V_{i j}-V_{k 1}\right|
$$

where $F_{i j k I}$ is the collision frequency per unit volume between crystal type $i$ - size $j$ and crystal type $k$ - size $1, E$ is the collision efficiency, $C_{i j}$ is the concentration of crystal type $i$ - size $j$, $C_{k I}$ is the concentration of crystal type $k$ - size $1, A_{i j k l}$ is the collision cross section between crystal type $i$ - size $j$ and crystal type $k$ - size 1 , and $\left|v_{i j}-v_{k 1}\right|$ is the relative fall velocity between crystal type $i$ - size $j$ and crystal type $k$ - size 1 . Because the majority of crystals studied in this research are large enough to be outside the range of interaction effects and those that are in the range of wake effects have such small relative fall velocities, which contribute little or nothing to secondary particle generation, E will be assumed equal to 1 .

The collision cross section $A_{i j k 1}$ can be approximated by a disc with diameter equal to the sum of the maximum dimensions of the two colliding particles. For the crystal types studied in this paper the initial crystal shapes are close to circular discs when viewed vertically and the approximation is quite adequate. For other crystal shapes such as columns or needles, however, a different collision cross section is required. The equation for $A_{i j k 1}$ is:

$$
A_{i j k 1}=\pi\left(r_{i j}+r_{k 1}\right)^{2}
$$

where $r_{i j}$ and $r_{k 1}$ are the maximum radil of the two particles. 


\section{Fragment Generation Functions}

In general, the number of fragments generated in a collision is a function of the type and size of both crystals involved in the collision. However, the task of obtaining the necessary information to predict the number of fragments generated for all of the various combinations of types and sizes of crystals in a cloud is prohibitive. It is far simpler and should not be too bad an assumption to find a predictor for the number of fragments generated as a function of some single parameter of the collision. The most appropriate parameter would seem to be the maximum force exerted during a collision. The number of fragments generated in a given collision should be proportional to the maximum force exerted. However, the maximum force exerted in a collision is a function of many parameters of a collision, such as the coefficient of restitution, the masses of the two particles, the relative velocities, the contact time of the collision, and the collision force as a function of time. Most of these parameters could be taken into account except for the contract time and the collision force. Unfortunately, these parameters are unknown and probably vary greatly. Even if the contact time is assumed constant for all collisions and the collision force is assumed to be normally distributed with time, the error in the estimated maximum force would still be extreme. Two other logical parameters come to mind - the kinetic energy of impact and the change in momentum. Neither of these parameters is as basic as the maximum force but they have the advantage that most of the variables upon which they depend can be reasonably treated. Hobbs and Farber (1972) used kinetic energy as a parameter since the elastic properties of a theoretical study naturally lend themselves to this treatment. However, for this study 
the change in momentum due to the collision between particles was used because it was found to be conservative while kinetic energy is non-conservative. This is true since momentum is conserved even in a non-elastic collision while energy is not. Crystal collisions are necessarily inelastic if fracturing is to occur since the fracturing process requires the absorption of energy.

The change in momentum is similar to the maximum force because it is the integral of force over time. It can not distinguish a short, hard collision from a long, soft collision. However, if the contact time is similar for all collisions, it will approximate the maximum force quite well.

The change in momentum of a particle when hit by another particle can be obtained by solving two equations with two unknowns. The two equations are the equation for the conservation of momentum for the system and the equation for the coefficient of restitution. From Sears and Zemansky (1957) these equations are:

$$
\begin{aligned}
& m_{i j}\left(v_{i j}^{f}-v_{i j}{ }^{o}\right)=-m_{k 1}\left(v_{k 1}^{f}-v_{k 1}{ }^{o}\right) \\
& e=-\frac{v_{i j}^{f}-v_{k 1}^{f}}{v_{i j}{ }^{\circ}-v_{k 1}{ }^{\circ}}
\end{aligned}
$$


where $m_{i j}$ and $m_{k 1}$ are the masses of the two particles, $v_{i j}{ }^{0}$ and $v_{k 1}{ }^{0}$ are the initial velocities, $v_{i j} f$ and $v_{k l} f$ are the final velocities, and $e$ is the coefficient of restitution. The two unknowns are $v_{i j} f$ and $v_{k 1} f$ given that the coefficient of restitution, $e$, is known. Since only two particles are involved, the change in momentum of one particle must equal the change in momentum of the other. Therefore,

$$
\Delta M_{i j k I}=m_{i j}\left(v_{i j}^{f}-v_{i j}{ }^{\circ}\right)=-m_{k I}\left(v_{k I} f-v_{k I}{ }^{\circ}\right)
$$

where $\Delta M_{i j k l}$ is the change in momentum of a particle of type $i$ - size $j$ when hit by a particle of type $k$ - size 1 . Solving Equations (4) and (5) simultaneously for $v_{i j} f$ gives:

$$
v_{i j}^{f}=\frac{1}{m_{i j}}+m_{k 1}\left\{m_{i j} v_{i j}^{0}+m_{k 1} v_{k 1}^{o}+e m_{k 1}\left(v_{k I}^{o}-v_{i j}^{o}\right)\right\}
$$

Substituting $v_{i j} f$ into Equation (6) and simplifying gives:

$$
\Delta M_{i j k 1}=\frac{m_{i j} m_{k 1}}{m_{i j}+m_{k 1}}\{1+e\}\left\{v_{k 1}{ }^{o}-v_{i j}^{o}\right\} \text {. }
$$

This change in momentum $\Delta \mathrm{M}_{i j k l}$ is the maximum possible change because Equation (8) assumes that the particles collide center-tocenter. However, in a real cloud the particles have an equal probability of colliding in all configurations between center-to-center and a grazing blow. The most likely change in momentum is then the expected value of $\Delta M_{i j k l}$ obtained by integrating over all possible 
configurations. In Appendix A the derivation for the most likely $\Delta M_{i j k l}$ is given. The end result is that $\Delta M_{i j k l}$ in Equation (8) must be multiplied by $\pi / 4$. Therefore, the statistical change in momentum of a particle hit by another becomes:

$$
\Delta M_{i j k 1}=\frac{\pi}{4}\left\{\frac{m_{i j} m_{k 1}}{m_{i j}+m_{k 1}}(1+e)\left(v_{k 1}-v_{i j}\right)\right\}
$$

where $v_{i j}{ }^{\circ}$ and $v_{k 1}{ }^{\circ}$ have been replaced by the observed terminal velocities.

If the number of fragments generated can be determined as a function of the change in momentum, then the total fragment generation rate can be found. This "fragment generation function" has been found for each of five different crystal types and will be described in Chapter III. Suffice it to say the "fragment generation functions" take the form as follows:

$$
N_{i j k l}=\alpha+\beta \log \Delta M_{i j k 1}+\gamma\left(\log \Delta M_{i j k l}\right)^{2}
$$

where $N_{i j k l}$ is the number of fragments per collision for crystal type $i$ - size $j$ hit by crystal type $k$ - size $I$ and are constants determined for each of the five crystal types studied.

It should again be re-emphasized that $\mathrm{N}_{i j k l}$ is an approximation due to the prohibitive task of obtaining a true $\mathrm{N}_{i j k I}$.

\section{Total Fragment Generation}

The fragment generation rate for collisions between crystal type $i$ - size $j$ and crystal type $k$ - size 1 is:

$$
\left(\frac{d C}{d t}\right)_{i j k 1}=F_{i j k l} \cdot N_{i j k l}
$$


where $\mathrm{C}$ is the concentration of all crystals in a cloud, $t$ is time, $(d C / d t)_{i j k 1}$ is the contribution to the total fragment generation rate due to collisions between crystal type $i$ - size $j$ and crystal type $k$ size 1, $F_{i j k I}$ is the collision frequency, and $N_{i j k 1}$ is the fragment generation function.

The total fragment generation rate for crystal type $i$ - size $j$ colliding with all other crystals in a cloud is:

$$
\left(\frac{d C}{d t}\right)_{i j}=\sum_{k} \sum_{i} F_{i j k 1} \cdot N_{i j k I} .
$$

The total fragment generation rate for all crystal types and sizes in a cloud is:

$$
\frac{\mathrm{dC}}{\mathrm{dt}}=\sum_{i} \sum_{j} \sum_{k} \sum_{1} F_{i j k 1} \cdot \mathrm{N}_{i j k 1} .
$$

From Equation (2), letting $\mathrm{E}=1, \mathrm{dC} / \mathrm{dt}$ becomes:

$$
\frac{d c}{d t}=\sum_{1} \sum_{j} \sum_{k} \sum_{1} C_{i j} C_{k 1} A_{i j k l}\left|v_{i j}-v_{k l}\right| N_{i j k l}
$$

Now, if we define a distribution function for crystal type and size:

$$
P_{i j}=\frac{C_{i j}}{C} \text { and } P_{k I}=\frac{C_{k I}}{C} \text {. }
$$

Then,

$$
\frac{\mathrm{dC}}{\mathrm{dt}}=\sum_{i} \sum_{j} \sum_{k} \sum_{1} C P_{i j} \mathrm{CP}_{k 1} \mathrm{~A}_{i j k 1}\left|\mathrm{v}_{i j}-\mathrm{v}_{\mathrm{k} 1}\right| \mathrm{N}_{i j k 1}
$$

where $C$ is a function of time. Since $C$ is not an explicit function of crystal type or size, it may be removed from the summations.

$$
\frac{d C}{d t}=C^{2} \sum_{i} \sum_{j} \sum_{k} \sum_{1} P_{i j} P_{k l} A_{i j k l}\left|v_{i j}-v_{k l}\right| N_{i j k l} .
$$


The terms in the summations are functions completely of crystal type and size distributions. These may change in time but are independent of the concentration $\mathrm{C}$.

B. Analytic Solutions

Define:

$$
K(t)=\sum_{i} \sum_{j k} \sum_{1} P_{i j} P_{k 1} A_{i j k l}\left|v_{i j}-v_{k I}\right| N_{i j k 1}
$$

Substituting into Equation (17):

$$
\frac{\mathrm{dC}}{\mathrm{dt}}=\mathrm{K}(\mathrm{t}) \mathrm{C}^{2}
$$

In general $K(t)$ changes with time because the distributions change as fragments are produced. The production of fragments will cause the distributions to have fewer crystals at large sizes and more crystals at small sizes. The effect of this should be to cause $K(t)$ to decrease with time.

As a first approximation $K(t)$ can be assumed to be constant.

$$
\mathrm{K}(\mathrm{t})=\mathrm{K}_{\mathrm{O}}
$$

Integrating Equation (19) with the assumption in Equation (20) gives the following solution:

$$
c=\frac{c_{0}}{1-C_{0} K_{0} t}
$$

where $\mathrm{C}_{0}$ is the initial total concentration of crystals. This solution is plotted in Figure 1. It has the following characteristics:

1. If $\mathrm{K}_{\mathrm{o}}$ is 0 the concentration does not change with time and there is no secondary particle generation. 


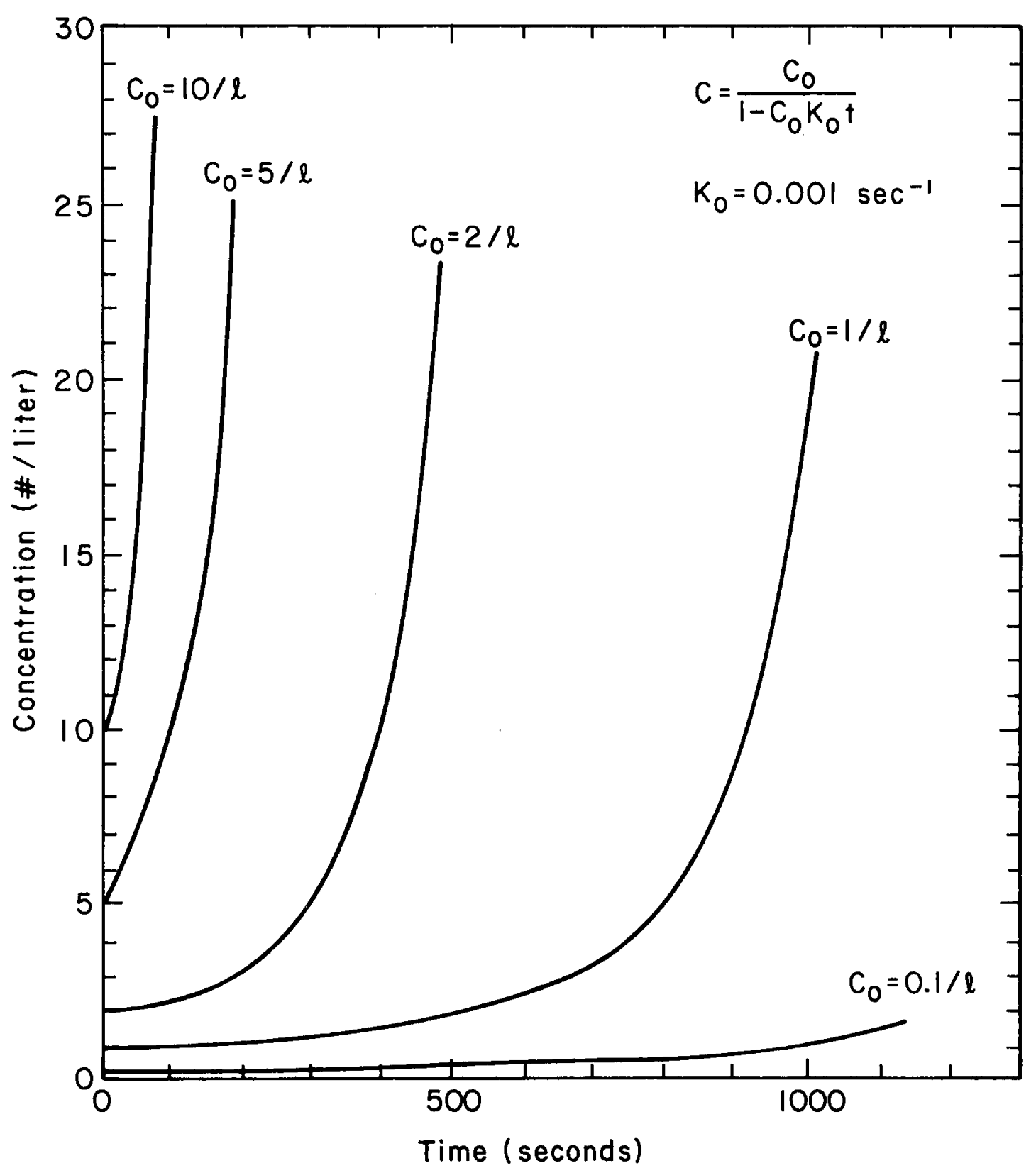

Figure 1. The variation of $\mathrm{C}$ as a function of time for various values of $\mathrm{C}_{\mathrm{o}}$ and $\mathrm{K}_{\mathrm{o}}$. 
2. If $\mathrm{K}_{\mathrm{o}}$ is negative the concentration decreases w1th time. However, from Equation (18) we can see that $\mathrm{K}_{0}$ can never be less than 0 .

3. If $\mathrm{K}_{\mathrm{o}}$ is positive the concentration increases with time. In fact, it increases at a rate greater than an exponential increase because it approaches infinity at some finite time.

4. The greater $\mathrm{K}_{0}$ and $\mathrm{C}_{\mathrm{o}}$ the faster the concentration increases. From the foregoing characteristics, it is apparent that $\mathrm{C}_{0}$ and $\mathrm{K}_{\mathrm{o}}$ should be maximized to obtain the greatest effect of secondary particle generation.

Equation (21) can also be solved to stress the time required to reach a desired ice multiplication ratio. If the ice multiplication ratio is defined as:

$$
\mathrm{M}=\frac{\mathrm{C}}{\mathrm{C}_{\mathrm{o}}} \text {. }
$$

Then, solving (21) for $t$ gives:

$$
t=\frac{1-1 / M}{C_{0} K_{0}} \text {. }
$$

This relation is plotted in Figure'2. This solution shows the rapid rate of increase in concentration during the last portion of time. It takes 15 minutes to obtain the first tenfold increase in concentration at an initial concentration of .1/1iter and a $k_{0}$ of .01 , but it only takes an additional 1.5 minutes to obtain the next tenfold increase. The solution also shows the inverse relation of time to initial concentration and $\mathrm{K}_{0}$. If either $\mathrm{C}_{0}$ or $\mathrm{K}_{0}$ is increased by a factor 


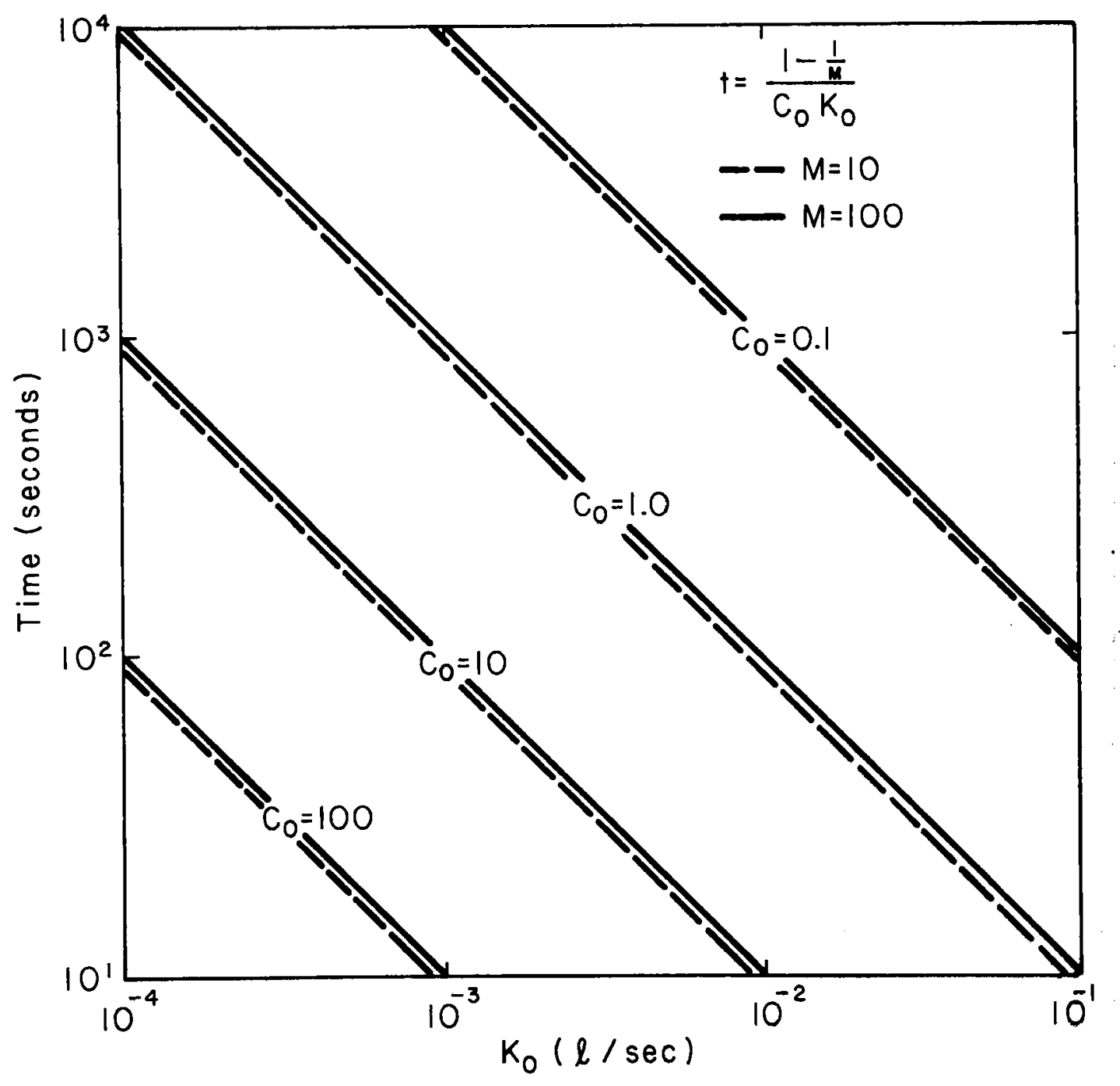

Figure 2. The time required to reach a given multiplication ratio for various values of $\mathrm{C}_{0}$ and $\mathrm{K}_{\mathrm{o}}$. 
of ten, the period of time required to reach a given multiplication ratio is decreased by a factor of ten. This shows the strong dependence of the fragment generation rate on the crystal concentration. Now let:

$$
K(t)=K_{0}+\lambda t
$$

Solving (19) again but with the assumption in (24):

$$
C=\frac{C_{0}}{I-C_{0}\left(K_{0} t+\frac{1}{2} \lambda t^{2}\right)}
$$

This solution is similar to the previous solution but allows for a linear increase or decrease in $K(t)$. If $\lambda$ is 0 this solution simplifies to Equation (21). If $\lambda$ is positive the rate of change in concentration becomes even greater than before and increases with time. If $\lambda$ is negative the rate of change in concentration becomes less with time, and may become zero. This solution again allows for the concentration to decrease with time if $\lambda$ and $t$ are large enough. Equation (18) prohibits this. This solution maximizes the effect of secondary particle generation if $\mathrm{K}_{\mathrm{o}}$ and $\lambda$ are maximized.

The actual solution to Equation (18) can only be found if $K(t)$ is known as a function of time. However, $k(t)$ will vary depending on the initial crystal type and size distributions and on the size distributions of the fragments which are produced in the cloud. Therefore, this solution can only be approximated by numerical methods. A general estimate of the magnitude of secondary particle production can be obtained by calculating $\mathrm{K}_{0}$ for various crystal combinations and size distributions. This has been done and will be discussed in Chapter IV. 


\section{Crystal Collisions with a Fixed Plate}

1. Similarity to Collisions in Clouds

Various methods of observing or simulating crystal collisions in a cloud were attempted including sterophotography of collisions between falling ice crystals and the artificial collision of ice crystals in an electric field. The observation of collisions between crystals falling in the atmosphere was found to be extremely difficult due to the infinetesimal probability of photographing a collision in a reasonable amount of time and collision of cryscals in an electric field was found to be impractical. Field measurements of crystal concentrations in space and time were attempted with an airborne ice crystal counter to identify fragment generation zones in and around convective clouds, but instrumental difficulties and problems in interpretation led to the abandonment of this line of investigation.

One frequently suggested method is to catch or grow an ice crystal, mount it in some manner, and bombard it with an object of known mass and velocity. Two main objections may be given to this method: (1) in catching and mounting the crystal, its properties may be changed because the most fragile elements on the crystal may be broken off or sublimated in the subsaturated environment of the handling equipment and (2) mounting the crystal is difficult, at best, and detracts from the reality of collision similarity because the mount will absorb a portion of the collision energy and effect the collision in unknown ways.

It was finally decided that a more suitable experiment was to photograph with a high speed camera the collisions of natural ice crystals falling at terminal velocity on a fixed plate. The 
objections cited above are not present and a large statistical sample of collisions may be obtained. The immediate reaction is that a collision of an ice crystal with a fixed plate in no way simulates a crystal-crystal collision in a cloud because of the fixed surface and the extreme impact. A mathematical treatment of the change in momentum, however, shows such a treatment to be possible. When the fragmentation is studied as a function of the change in momentum the only remaining differences are collision orientation, shape effects and the coefficient of restitution. Shape effects and collision orientation may be different when a falling crystal hits a flat plate of infinite extent because the crystal will tend to take a "double bounce" when it hits. This is especially true of plate-like crystals because the leading edge may hit first, rotating the crystal so that the back edge hits before complete rebound. This is not true of more spherical particles such as graupel. The shape of the flat surface is clearly different that that of another crystal and for spatial crystals this is probably important. These crystals have burr-1ike protrusions which could intermesh with another crysta1, but cannot do so on a flat surface. This effect would cause spatial crystals to produce more fragments on a flat surface than a similar collision with another crystal. The coefficient of restitution will also be different but will be treated in the following sections.

These limitations and approximations are estimated to be of second-order importance when compared to the degree of fragmentation in actual collisions. A sensitivity analysis on the numerical model in Chapter IV will show the effect of overestimate or underestimate in the fragment generation function. 
2. Mathematical Formulation of the Change in Momentum with a Fixed Plate.

The equations for the change in momentum between two colliding particles were treated earlier in Section A.2 of this chapter. In this section we now want to treat the inelastic collision of a particle with a fixed plate. Equation (6) is a general equation for any inelastic collision. It may be rewritten as follows:

$$
e=\frac{v_{k 1}^{f}-v_{i j}^{f}}{v_{i j}^{o}-v_{k 1}{ }^{\circ}}
$$

where $v_{i j} f$ and $v_{k 1} f$ are final velocities, $v_{i j}{ }^{\circ}$ and $v_{k 1}{ }^{\circ}$ are initial velocities, and $\mathrm{e}$ is the coefficient of restitution.

For the case where one of the objects is of very large mass, say object $k l$, the velocity after the collision is equal to the velocity before the collision. If the velocity before the collision is also zero, as in the case of the fixed plate, the following relation holds.

$$
\mathrm{v}_{\mathrm{k} 1}{ }^{\mathrm{O}}=\mathrm{v}_{\mathrm{k} 1}^{\mathrm{f}}=0
$$

Therefore, Equation (26) becomes:

$$
e=-\frac{v_{i j}^{f}}{v_{i j}^{\circ}}
$$

Assuming object ij has an initial velocity greater than zero, e can take the values from 0 to 1 . If object ij sticks to object $k 1$ it has a final velocity of zero and $e=0$. This is the case of a perfectly inelastic collision. If object $i j$ rebounds from object $k I$ with a 
final velocity equal and opposite to its initial velocity, $v_{i j}{ }^{f}=$ $-v_{i j}{ }^{\circ}$ then $e=1$. This is the case of a perfectly elastic collision. In the majority of cases the collisions between two ice crystals or an ice crystal and a fixed plate lie somewhere in between.

The change in momentum of a crystal hitting a plate is:

$$
\Delta M=M_{i j}^{f}-M_{i j} 0=m_{i j} v_{i j} f-m_{i j} v_{i j} 0
$$

where $\Delta M$ is the change in momentum, $M_{i j}{ }^{\circ}$ and $M_{i j} f$ are the momentum of particle ij before and after the collision, respectively, and $m_{i j}$ is the mass of the crystal. Solving Equation (28) for $v_{i j} f$ and substituting into Equation (29),

$$
\Delta M=-m_{i j} v_{i j}^{o}(1+e) \quad
$$

It can be seen from this equation that the change in momentum can be calculated for the collision of a particle of known mass and velocity with a fixed plate if the coefficient of restitution is known. The coefficient of restitution between ice crystals or between an ice crystal and other materials has not been determined, however. One of the first objects of the experimental work, then, must be the determination of the coefficient of restitution, e.

3. Determination of the Coefficient of Restitution

A reasonable estimate of the coefficient of restitution would appear to be quite straightforward. It would seem that all one must do is evaluate Equation (28) for a number of collisions and determine e. This is not the case, however. First, the coefficient of restitution is a measure of the elastic properties of both objects 
which collide. Therefore, an ice crystal colliding with another ice crystal will give a different coefficient of restitution than colliding with some other material. The material selected for the fixed plate in the experiment was plexiglass which has a different elasticity than ice. Secondly, each ice crystal has a different coefficient of restitution depending on its structure and degree of rime. The crystals which produce the most fragments are those with the lowest coefficient of restitution. This is consistent with the concept that energy is absorbed by the fracturing process. Thirdly, the high-speed photography system used to obtain a large statistical sample did not permit extremely high speeds to obtain the particle velocities immediately before and after impact. An involved integration of particle trajectories before and after impact was required to obtain these velocities.

Fortunately, a precise determination of the coefficient of restitution is not vital. If one were to assume all the collisions were elastic when, in fact, they were all inelastic, the error would be a factor of two in the change of momentum as can be seen in Equation (30). However, the measured changes in momentum ranged over four orders of magnitude and the dependence of the fragment generation function on the change in momentum is relatively weak.

Appendix $B$ describes the mathematical method of obtaining e for a given collision. The ratio of vertical velocities immediately before and after impact were studied for a number of collisions. Using this method e was found to average .37 for graupel. Since the determination of $e$ by this method severely limited the data available for reduction, e was determined only for graupel and assumed to be the 
same for other crystal types colliding in a cloud as well as with the fixed plate. Except for unrimed plane dendrites, this assumption is felt to be an overestimate of e for all other crystals, at least for collisions with the plate. This overestimate of e results in a slight underestimate of the efficiency of fragment generation on the plate. However, since $e$ is also assumed to be the same in the cloud, the efficiency of fragment generation in a cloud should be overestimated to the same extent.

\section{Summary}

Once the coefficient of restitution is determined, the change in momentum can be obtained for a given collision. Therefore, the number of fragments produced can be related to the change in momentum for a given collision. Provided a large sample of collisions is available, a fragment generation function can be obtained for each crystal type desired. The fragment generation functions can then be substituted into Equation (18) from which the rate of change in crystal concentration can be studied with time.

The next chapter will describe in detail the apparatus and procedures used to obtain the fragment generation functions. 


\section{CHAPTER III}

\section{EXPERIMENTAL DATA AND PROCEDURES}

\section{A. Description of Experimental Apparatus}

The determination of the fragment generation functions require the observation of ice crystals colliding with a fixed plate. The instrument designed to make these observations is shown in Figure 3. It consisted of a $16 \mathrm{~mm}$ movie camera mounted to view parallel to the surface of a black plexiglass plate. An optically-black background was constructed behind the plate to allow photography during daylight hours. A high-intensity light source was mounted to one side of the plate to illuminate the falling crystals. The entire instrument was secured to a heavy adjustable tripod which allowed the instrument to be rotated so that the wind was perpendicular to the optic axis of the camera.

The camera used was a model DMB 4, $16 \mathrm{~mm}$ high-speed movie camera manufactured by the D. B. Milliken Company of Arcadia, California. It had a film magazine which permitted the use of $400^{\prime}$ rolls of film. A $\mathrm{f} / 1.8$ lens with a 5-mm extension was used to observe the crystals. The depth of field was about $1 \mathrm{~cm}$ at $10 \mathrm{~cm}$ from the front of the lens. This configuration allowed the image size on the film to be about $1 / 3$ actual size and permitted a magnification of $40 \mathrm{X}$ actual size by projection later. The film used was Kodak 4-X Reversal black and white film with an ASA rating of 320 . Better resolution could have been obtained with slower film but the light intensity with a continuous lamp was limited by the heat produced. At temperatures near freezing, the heat from very high intensity lamps would cause 


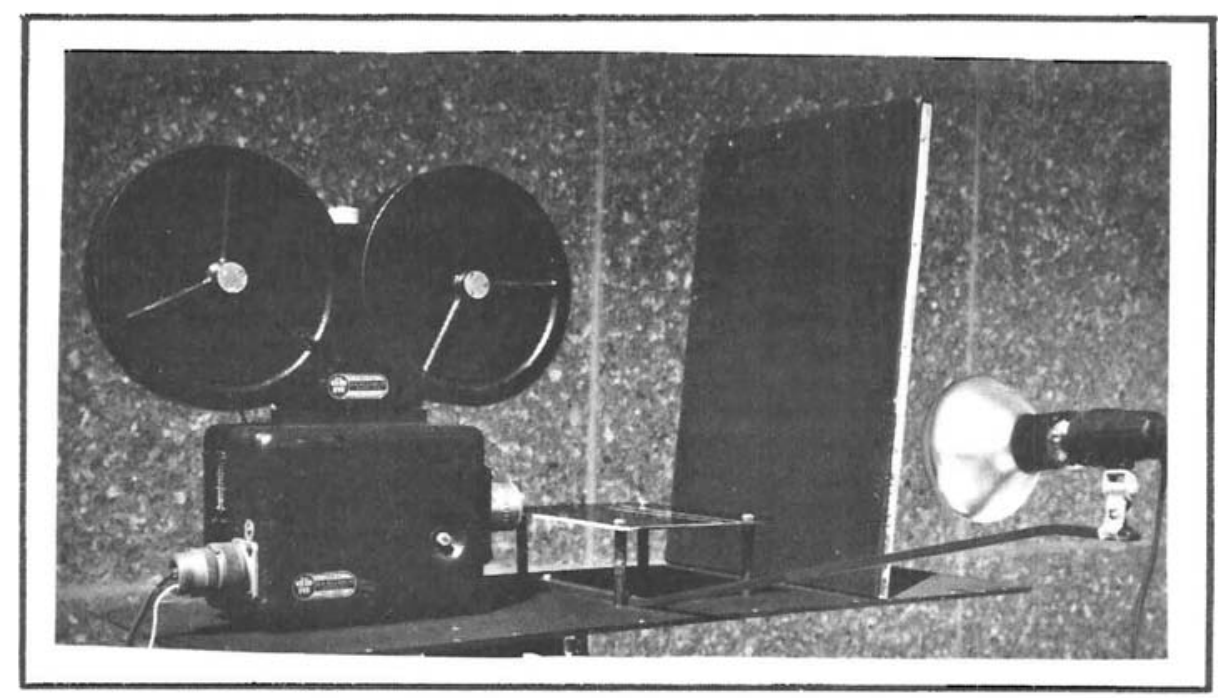

Figure 3. Photograph of the instrument used in the fixed-plate experiment.

the crystals to melt and stick upon hitting a warm surface. Strobes were not attempted because of the complications in synchronizing the camera and strobes at the high frame rates. The camera was found to have a normal frame rate of 101.7 frames per second. When the camera was kept heated between operations and no film transport problems occurred, the camera functioned accurately at this frame rate. When the camera malfunctioned and the frame rate was questionable the data were not used.

Figure 4 shows a sequence of six frames taken during the collision of a heavily-rimed plane dendrite with the plate. This particular crystal produced 15 fragments. The quality of the photographs in Figure 4 are not as good as the direct projection of the original film on a screen. Consequently, some of the smaller fragments can not be distinguished in this sequence. The minimum detectable size 


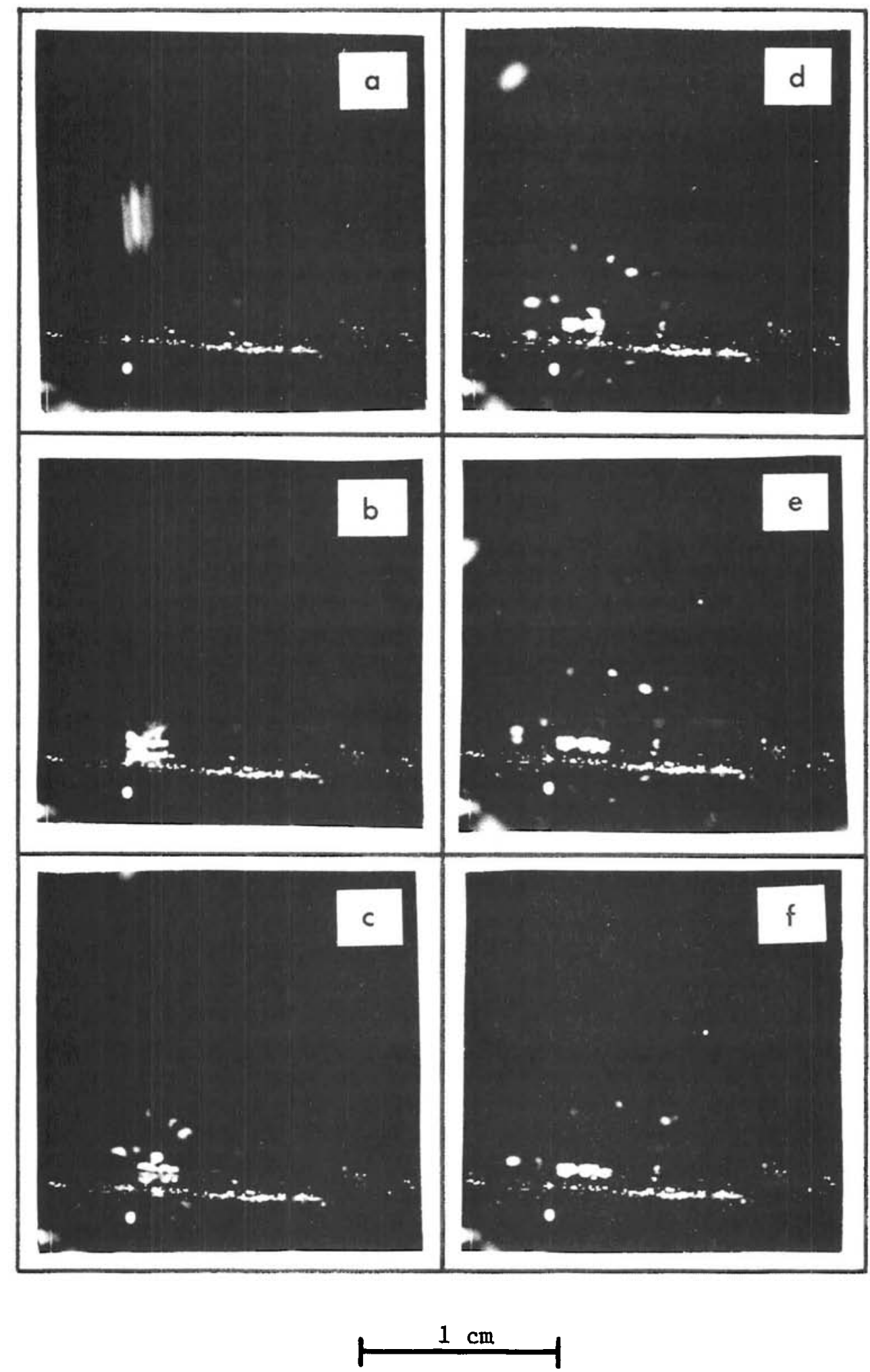

Figure 4. A sequence of six frames taken during the collision of a heavily-rimed plane dendrite with the fixed plate. The frames are approximately $.01 \mathrm{sec}$. apart. 
of fragment which could be detected with this instrument was estimated to be 50 microns.

Since the resolution from the $16 \mathrm{~mm}$ film was too coarse to allow detailed classification of crystal types and degree of rime, a microscope with an attached camera was used to determine crystal structure. Ice crystals were collected in cooled hexane immediately before and after a sequence of $16 \mathrm{~mm}$ film was taken. This technique for collecting ice crystals in hexane was suggested by Dr. Charles Knight (personal communication). The hexane prevents the crystals from metamorphosizing for short periods of time and increases the contrast in and around a crystal. Ice crystals were collected as shown in Figure 5 and photographed a short time later. The microscope was equipped with a cold stage to allow greater investigation of a sample of crystals before the heat from the microscope lamp changed the crystals. Figure 6 shows an example of each of the five crystal types studied in this manner.

The data obtained during the winter of 1973-74 were collected with the camera system described. In the previous winter a completely different instrument was used as a preliminary study to this. Unrimed plane dendrites were the predominate crystals studied that first winter and since little data were obtained for this crystal type the second winter, these data were included in this study. The instrument shown in Figure 7, consisted of a humidified cold chamber with a hole in the top and a tray of supercooled sugar solution in the bottom. Mounted about $25 \mathrm{~cm}$ below the upper hole and about $10 \mathrm{~cm}$ above the sugar solution was a $1-\mathrm{mm}$ mesh copper screen. Ice crystals were allowed to fall through the upper hole, preferably one at a time, and impinge 


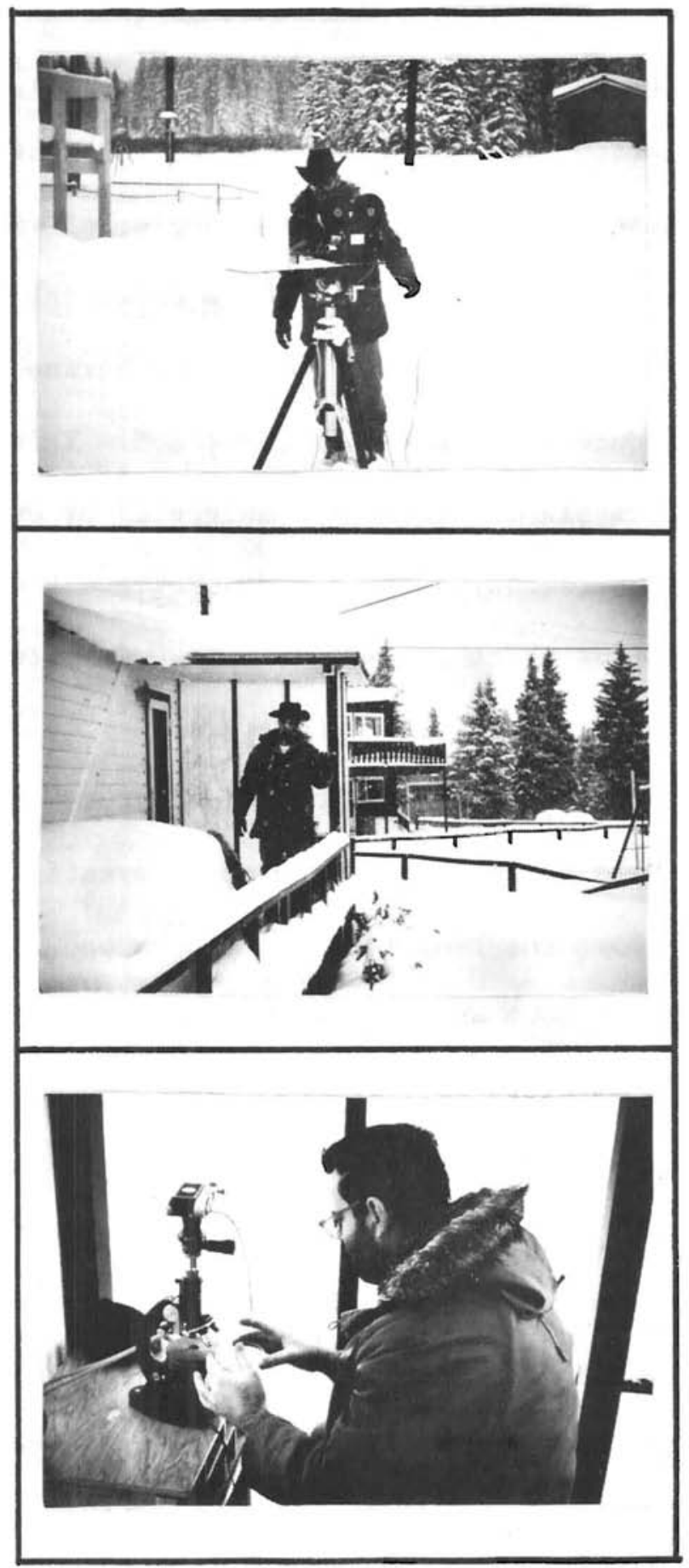

Figure 5. Photographs of the data collection procedures and equipment set up in the field at HAO, near Leadville, Colorado. 


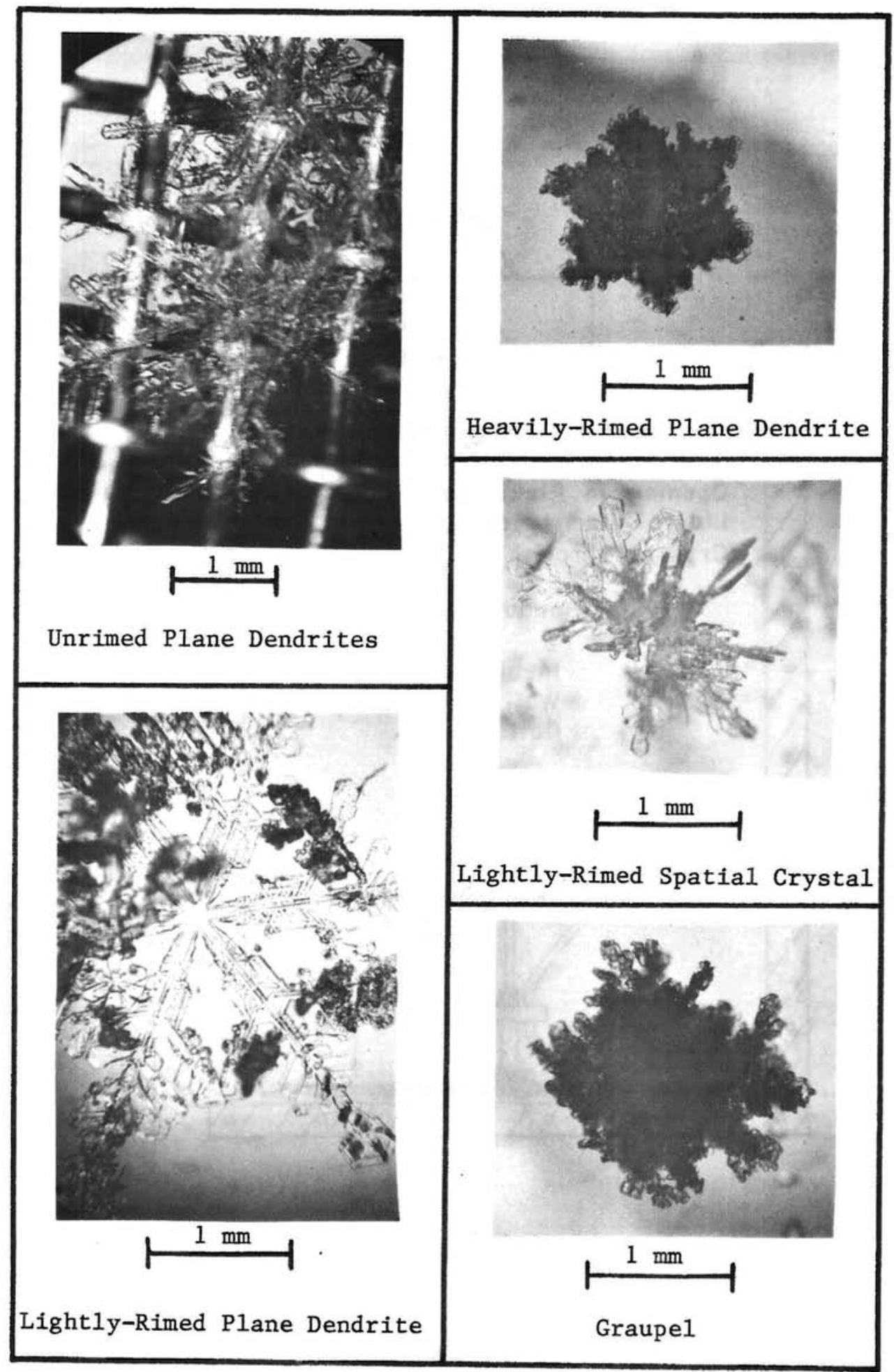

Figure 6. Examples of each of the five crystal types studied. 


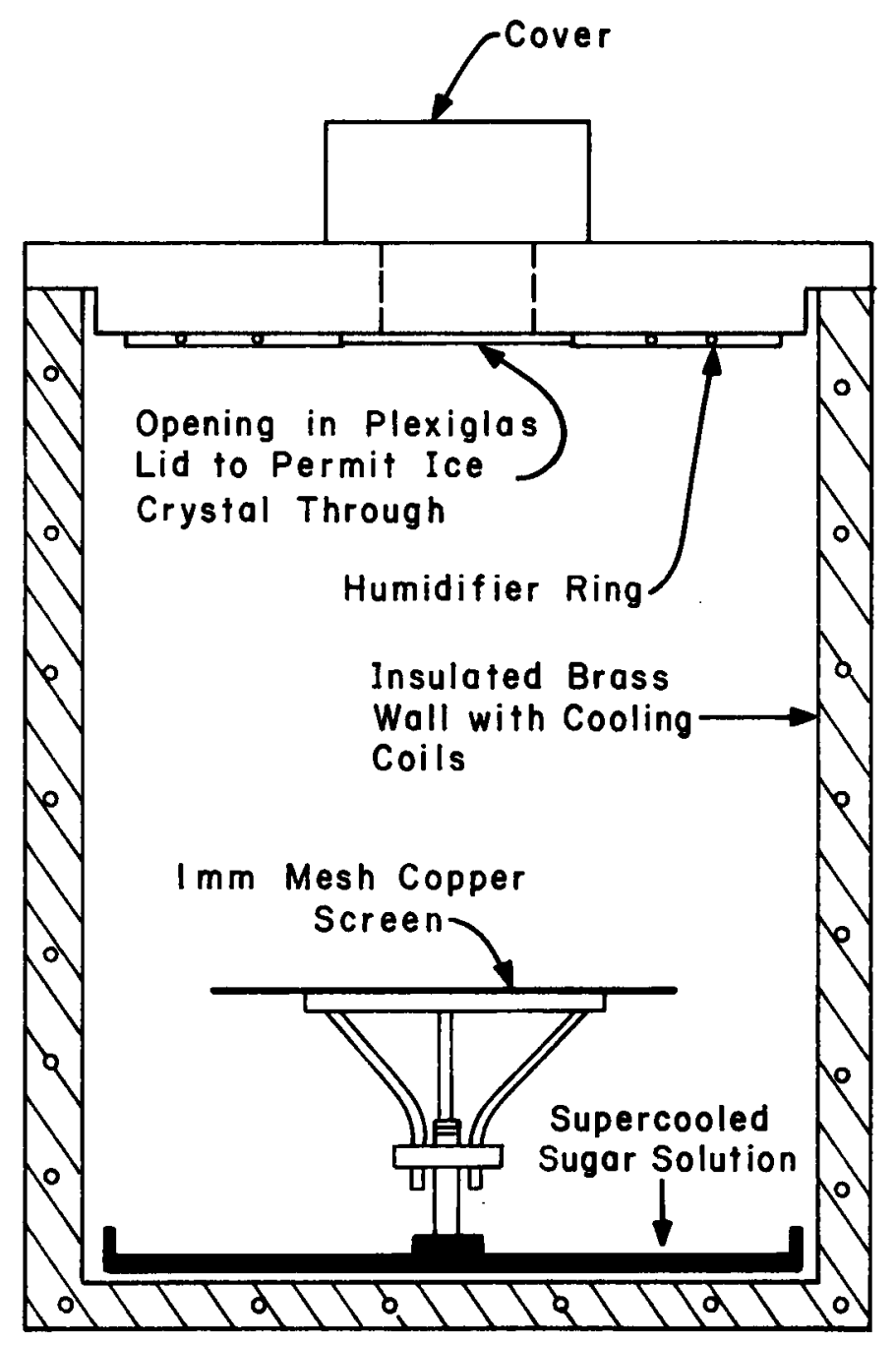

Figure 7. Diagram of the instrument used to determine the number of fragments from unrimed plane dendrites. 
on the screen. The fragments produced in the collision would filter through the screen and fall into the sugar solution, growing to detectable sizes for counting. The chamber was humidified to prevent small fragments from sublimating before reaching the sugar solution. The data obtained from this instrument were qualitative because no measure of the impact velocity was made. Therefore, the camera and fixed plate system was designed for the following winter. One advantage the cold chamber had, however, was the detection of very small fragments. The qualitative agreement between the two systems for similar crystals leads me to believe that most of the fragments produced by mechanical fracturing are fairly large - large enough to be detected by the camera system. The photograph of unrimed plane dendrites in Figure 6 shows the screen used in the cold chamber instrument.

B. Data Collection and Reduction Procedures. Suitable data were collected for five crystal classifications. These data were obtained over a period of two years from three locations in the State of Colorado. The cloud conditions were generally orographic in nature with occasional embedded convection. Table 1 shows the data sources for each of the crystal types. Wolf Creek Pass is at an elevation of about 10,000 feet in the San Juan mountains of Southern Colorado; the High Atltiude Observatory is at an elevation of 11,300 feet on the Continental Divide near Leadville, Colorado; and Fort Collins is at an elevation of about 5,000 feet in northeastern Colorado. The equipment was assembled at each of these sites and leveled carefully to insure 
Table 1. Data sources for each of the five crystal types studied.

\begin{tabular}{|c|c|c|c|}
\hline CRYSTAL TYPE & DATES & LOCATIONS & INSTRUMENT \\
\hline $\begin{array}{l}\text { Unrimed Plane } \\
\text { Dendrites }\end{array}$ & $\begin{array}{ll}3 & \text { Jan } \\
7 & \text { Feb } 73\end{array}$ & $\begin{array}{l}\text { Fort Collins } \\
\text { Fort Collins }\end{array}$ & $\begin{array}{l}\text { Cold Chamber } \\
\text { Cold Chamber }\end{array}$ \\
\hline $\begin{array}{l}\text { LGT-MDT Rimed } \\
\text { Plane Dendrites }\end{array}$ & $26 \operatorname{Jan} 74$ & $\begin{array}{l}\text { Wolf Creek } \\
\text { Pass }\end{array}$ & Fixed Plate \\
\hline $\begin{array}{l}\text { HVY Rimed Plane } \\
\text { Dendrites }\end{array}$ & 2 Nov 73 & Fort Collins & Fixed Plate \\
\hline $\begin{array}{l}\text { LGT-MDT Rimed } \\
\text { Spatial Crystals }\end{array}$ & $13 \mathrm{Dec} 73$ & $\begin{array}{l}\text { Climax } \\
\text { High Altitude } \\
\text { Observatory }\end{array}$ & Fixed Plate \\
\hline \multirow[t]{2}{*}{ Graupel } & 13 Dec 73 & $\begin{array}{l}\text { Climax } \\
\text { High Altitude } \\
\text { Observatory }\end{array}$ & Fixed Plate \\
\hline & $26 \operatorname{Jan} 74$ & Wolf Creek Pass & Fixed Plate \\
\hline
\end{tabular}

similar collection procedures at all three sites. No data were used when the wind exceeded five knots or when it was gusty. The camera and plate were rotated as needed to keep the optic axis perpendicular to the wind direction. Continuous sequences of $30-60$ seconds duration were shot to allow the camera to reach and maintain a constant frame rate. The camera normally came up to speed in less than five seconds and data in the accelerating or decelerating sections were not used. In heavy snowfalls the plate would become covered with crystals in about ten seconds, so the plate was cleaned periodically during shooting. Occasionally, the surface temperature was warmer than $25^{\circ} \mathrm{F}$. In these cases the plate would become too warm because of heating from diffuse sunlight and artificial lighting. When the surface became wet or "sticky" from this effect the data were not used. 
The data were reduced by projecting the film onto a screen at a known magnification and the mass, impact velocity, and number of fragments were measured. Vertical velocity was obtained by measuring the length of the blur as a crystal approached the plate and multiplying by the sine of the angle between the trajectory of the particle and the plate. The mass was calculated by assuming the particles obeyed the mass-diameter relationships of Nakaya (1954) for the different crystal types. The diameter was obtained from the width of the blur. The number and diameter of the fragments was obtained after a collision by viewing from one to five frames after the collision for evidence of fragments. When many fragments were produced and the background was cluttered by snow on the plate or fragments from other nearby collisions, this process became extremely difficult. However, by viewing more than one frame after the collision, the motion of the fragments normally betrayed their source and allowed their identification.

The reduction procedure for graupel was a bit more complicated because not only the number and size of the fragments after collision were required but also the velocity in two successive frames. A similar process was used as before but was more exacting. Since graupel produced relatively few fragments and normally rebounded in a higher trajectory than the other crystal types, the task was somewhat easier. However, a large percentage of collisions were eliminated because of the requirement for two consecutive frames to contain all of the fragments after a collision. For this reason and the increasing difficulty for greater numbers of fragments, this detailed procedure 
was attempted only for graupel. From this analysis an average coefficient of restitution was determined as described in Chapter II and Appendix B.

Data reduction for the unrimed plane dendrites was done simply by counting the number of crystal fragments left on the screen and produced in the sugar solution. No fall velocity or fragment size was obtained except for the few left on the screen. For this reason an assumption was made that the initial crystals fell at the theoretical fall velocity for unrimed plane dendrites and the fragment distribution was the same as that measured for 1ight-moderate rimed plane dendrites.

C. Determination of the Fragment Generation Function. We are now in a position to show how the fragment generation function was determined. Given, that the change in momentum can be determined for a number of collisions with a fixed plate and that this change of momentum may be applied to collisions in a cloud by proper mathematical treatment, the number of fragments generated may be determined as a function of the change in momentum. Each crystal type has a different relationship between the number of fragments generated and the change in momentum due to different likelihoods of fragmentation. Figures 8 through 12 show plots of the number of fragments versus the change in momentum for each of the five crystal types studied. A least-squares curve fit was applied to each of the plots to determine the most-likely fragment generation function. Figure 13 shows all five curves plotted together and Table 2 gives the equations, correlation coefficients, number of collisions, and critical values for each of the crystal types. The critical value 


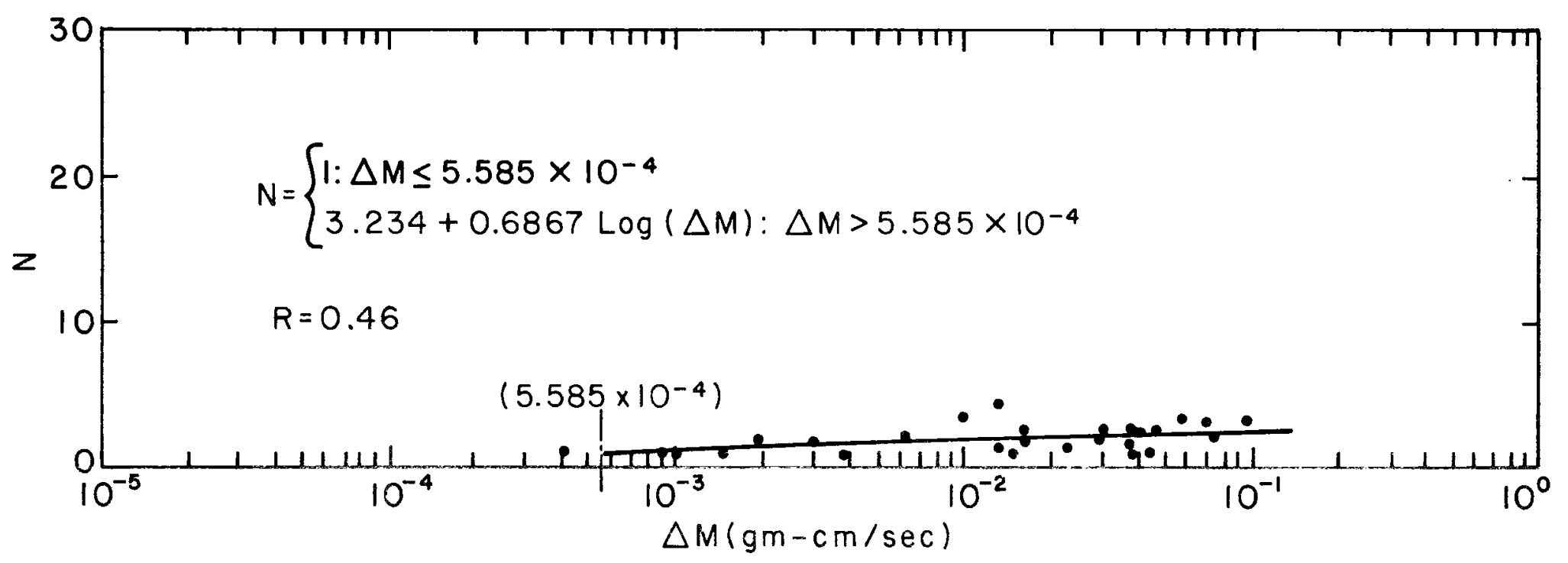

Figure 8. Fragment generation function for unrimed plane dendrites. The number of fragments produced per collision, $N$, as a function of the change of momentum in the collision, $\Delta M$. 


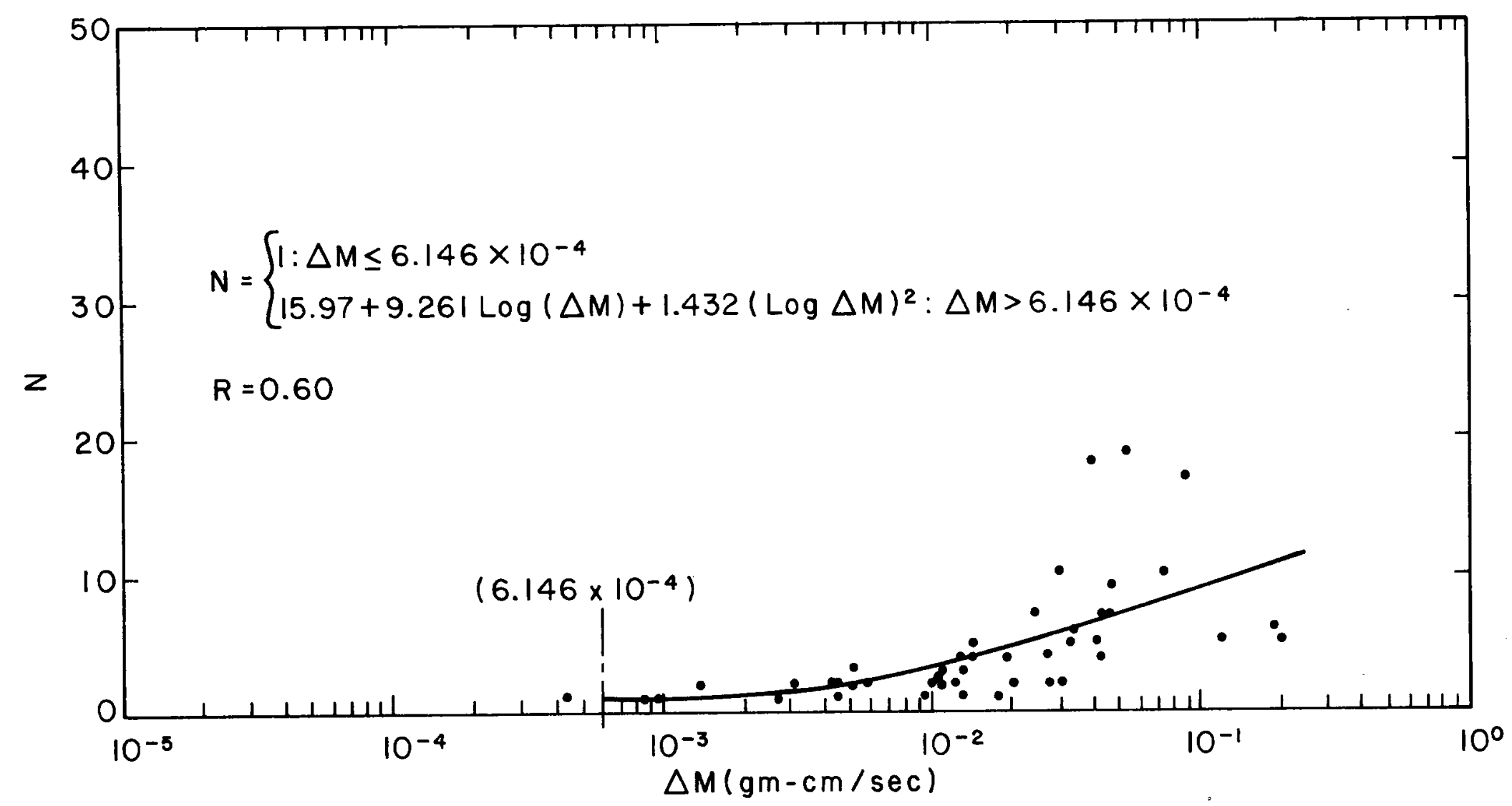

Figure 9. Fragment generation function for light-to-moderate rimed plane dendrites. The number of fragments produced per collision, $N$, as a function of the change of momentum in the collision, $\Delta \mathrm{M}$. 


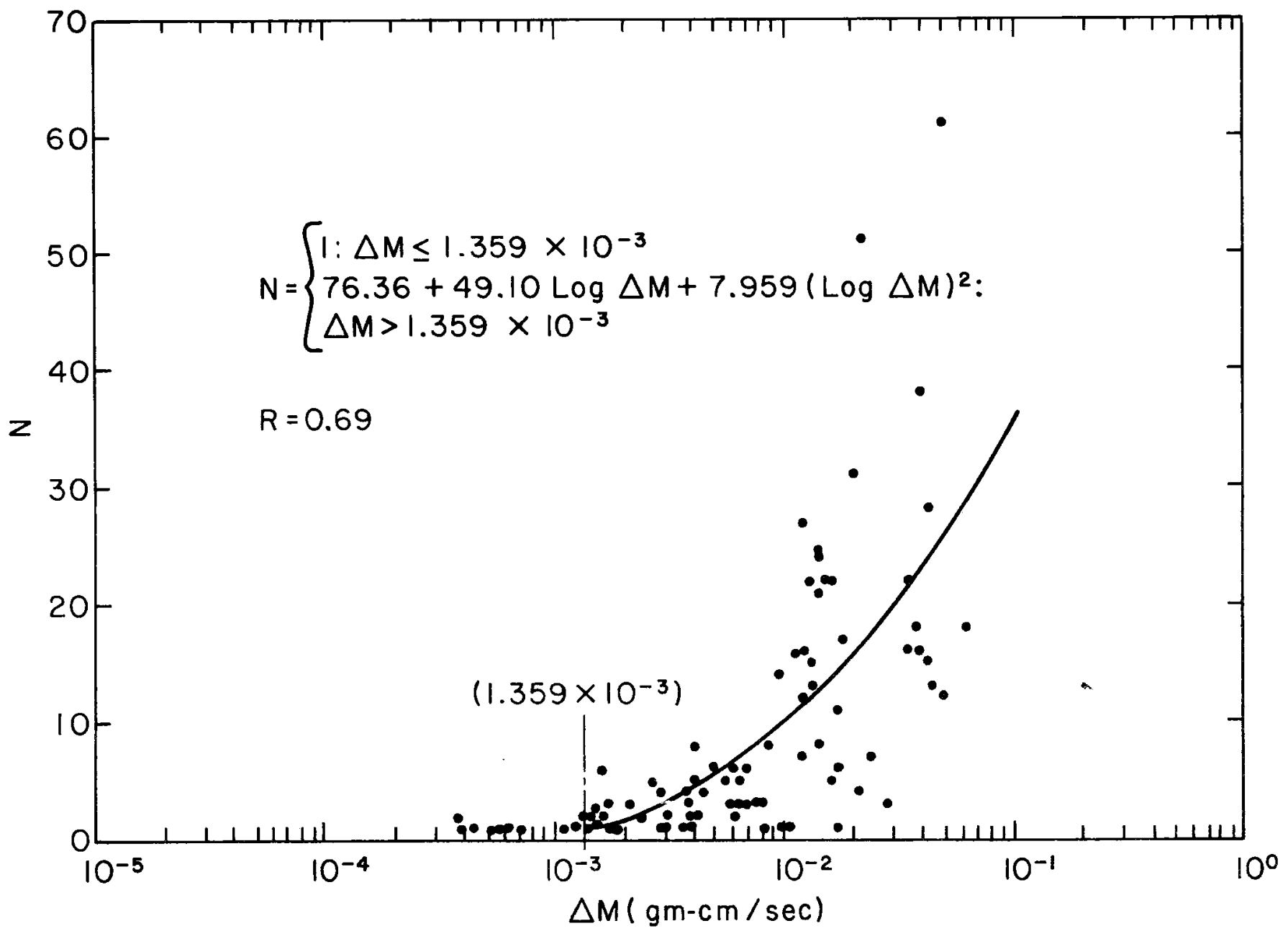

Figure 10. Fragment generation function for heavily-rimed plane dendrites. The number of fragments produced per collision, $N$, as a function of the change of momentum in the collision $\Delta M$. 


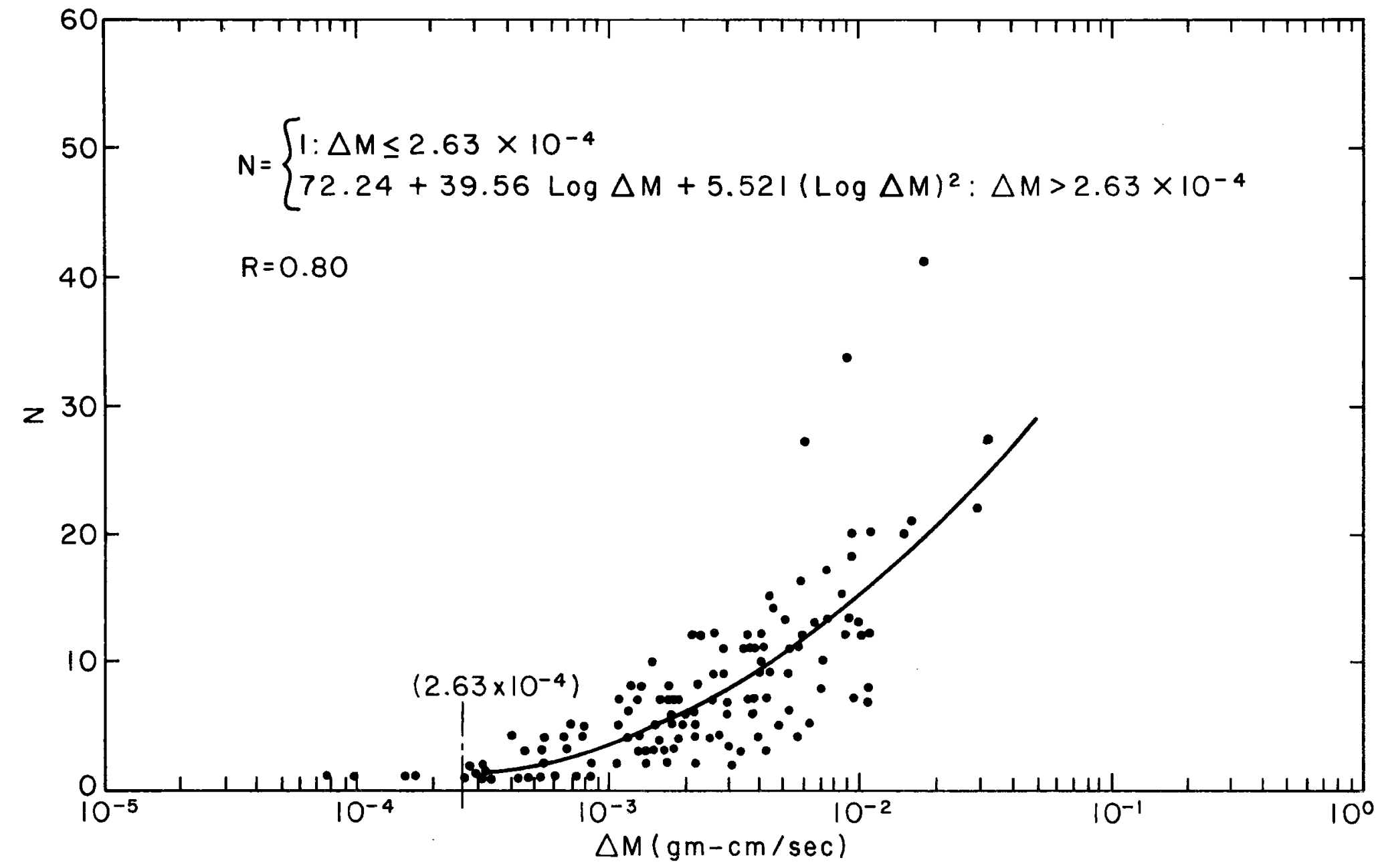

Figure 11. Fragment generation function for 1ight-to-moderate rimed spatial crystals. The number of fragments produced per collision, $N$, as a function of the change of momentum in the collision, $\Delta \mathrm{M}$. 


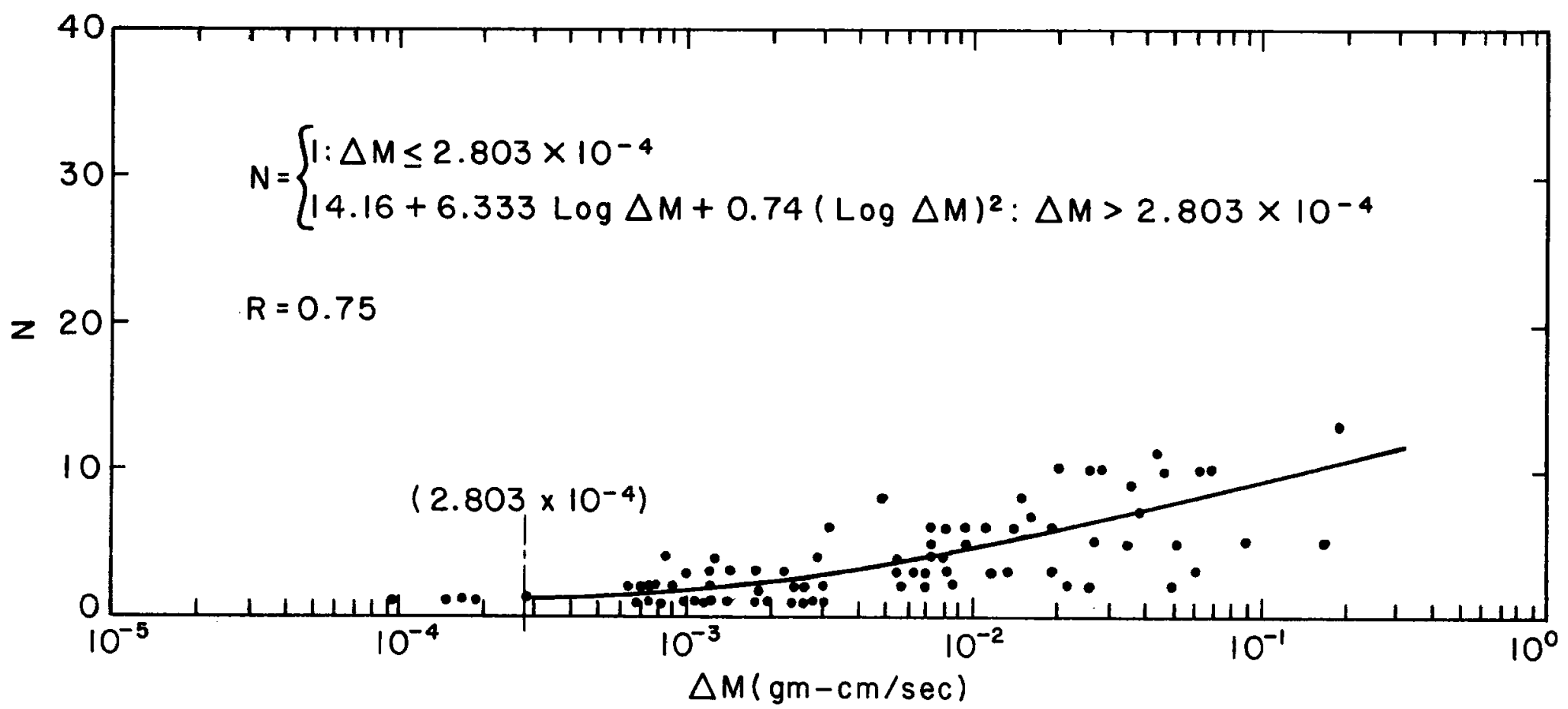

Figure 12. Fragment generation function for graupel. The number of fragments produced per collision, $\mathrm{N}$, as a function of the change of momentum in the collision, $\Delta M$. 


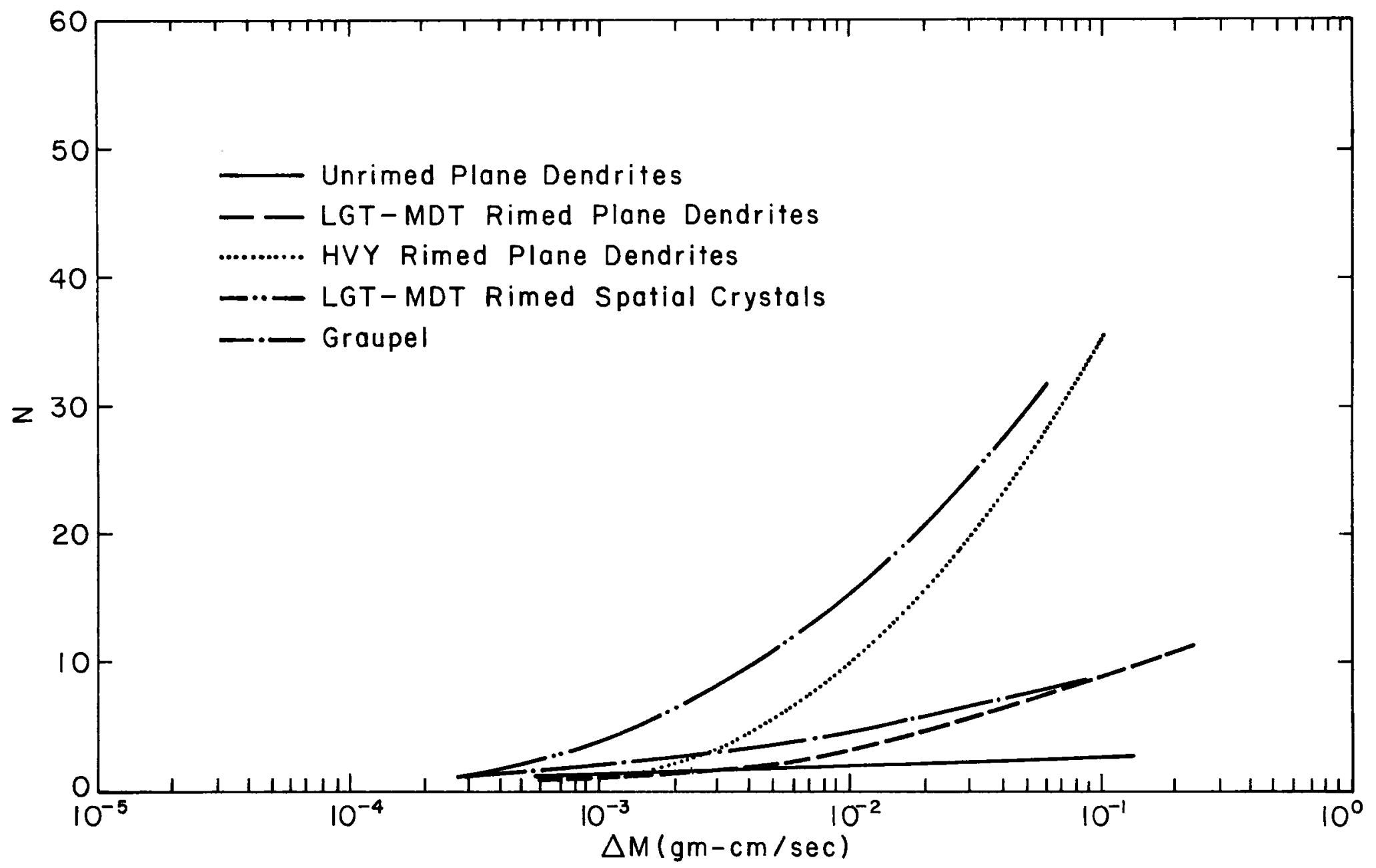

Figure 13. Composite fragment generation functions for all five crystal types studied. 
Table 2. Equations of the fragment generation functions and correlation coefficients for second order least squares fit.

\begin{tabular}{|c|c|c|c|c|}
\hline CRYSTAL TYPE & EQUATION & $\begin{array}{l}\text { CORRELATION } \\
\text { COEFFICIENT }\end{array}$ & $\begin{array}{l}\text { NUMBER OF } \\
\text { COLLISIONS }\end{array}$ & $\begin{array}{l}\text { CRITICAL VALUE } \\
(\mathrm{gm} \mathrm{cm} / \mathrm{sec})\end{array}$ \\
\hline $\begin{array}{l}\text { Unrimed Plane } \\
\text { Dendrites }\end{array}$ & $3.234+.6867 \log \Delta M$ & .46 & 27 & $5.585 \times 10^{-4}$ \\
\hline $\begin{array}{l}\text { LGT-MDT Rimed } \\
\text { Plane Dendrites }\end{array}$ & $\begin{array}{l}15.97+9.261 \log \Delta M \\
+1.432(\log \Delta M)^{2}\end{array}$ & .60 & 44 & $6.146 \times 10^{-4}$ \\
\hline $\begin{array}{l}\text { HVY Rimed Plane } \\
\text { Dendrites }\end{array}$ & $\begin{array}{l}76.36+49.10 \log \Delta M \\
+7.959(\log \Delta \mathrm{M})^{2}\end{array}$ & .69 & 90 & $1.359 \times 10^{-3}$ \\
\hline $\begin{array}{l}\text { LGT-MDT Rimed } \\
\text { Spatial Crystals }\end{array}$ & $\begin{array}{l}72.24+39.56 \log \Delta M \\
+5.52(\log \Delta M)^{2}\end{array}$ & .80 & 130 & $2.63 \times 10^{-4}$ \\
\hline Graupe1 & $\begin{array}{l}14.16+6.333 \log \Delta M \\
+.74(\log \Delta M)^{2}\end{array}$ & .75 & 88 & $2.803 \times 10^{-4}$ \\
\hline
\end{tabular}


for a crystal type is the value for the change in a momentum at which the number of fragments becomes one. This means that no secondary particles are produced but the final particle after collision is the same as the initial particle before collision. At all values of the change in momentum below the critical value, the number of fragments is equal to one.

Some interesting facts are evident in Figure 13 and Table 2.

1. For plane dendrites, the greater the degree of rime, the greater the fragmentation.

2. Also for plane dendrites, the greater the degree of rime, the greater the critical value. This seems to be the opposite of the expected effect since if the statement in 1 above is true, the critical value would be expected to be less for greater rime. This result may be an effect due to curve fitting.

3. Light-moderate rimed spatial crystals are the most effective crystals studied for generating fragments. This may be due to the greater likelihood of fracturing the burr-1ike protrusions from a spatial crystal when it collides with a flat surface. This effect may not be quite as important in a cloud for co1lisions between crystals.

4. Graupel are surprisingly ineffective in generating fragments. Since graupel may originate on spatial crystals, the comparison between the results for graupel and spatial crystals is striking. It would appear that rime causes a crystal to become more fragile until the rime begins to "fill-in" the spaces of a crystal sufficiently that a "cementing" effect 
becomes predominate. At this point, the crystal appears to become stronger again and only weakly-bonded surface rime may break off, rather than fracturing of the internal structure.

5. Unrimed plane dendrites which have been proposed for so many years as a possible source of secondary ice crystals are dramatically ineffective in generating fragments. This statement will be qualified somewhat, however, when the collision frequency is studied in Chapter V. Plane dendrites contribute an unproportionate amount to the total fragment production because of the large cross-sectional area and relative fall velocity compared to other crystals.

\section{Data Limitations}

A strict error analysis will not be attempted for this study because statistical techniques are not adequate where order of magnitude changes are occurring. However, some indications of error sources will be discussed and effects on the results estimated.

The basic equation for estimating the number of fragments for a given change in momentum can be derived from Equation (30) of Chapter II.

$$
\Delta M=m_{i j} w(1+e)
$$

where $\Delta M$ is the change of momentum in the vertical direction, $\mathrm{m}_{i j}$ is the mass of the particle, $w$ is the initial vertical velocity, and $e$ is the coefficient of restitution. The mass, $m$, is determined by the appropriate equation of Nakaya (1954) using a measured diameter. The error in the measurement of diameter is approximated to be $10 \%$ but Nakaya's equation contains unknown errors. Therefore, m will not 
be analyzed by components but a total maximum error approximated to be $50 \%$. The coefficient of restitution, e, involves a complicated series of dependent computations. It will also be left intact and the error approximated by its standard deviation which is about $50 \%$. The vertical velocity may be broken into the measurcutent of the length of the blur in the photographs which has a matum errot of $10 \%$ and the frame rate which has an error of $1 \%$. Therafore, logarithmically differentiating Equation (31):

$$
\left|\frac{\mathrm{d} \Delta \mathrm{M}}{\Delta \mathrm{M}}\right|=\left|\frac{\mathrm{dm}}{\mathrm{m}}\right|+\left|\frac{\mathrm{dz}}{\mathrm{z}}\right|+\left|\frac{\mathrm{dt}}{\mathrm{t}}\right|+\left|\frac{\mathrm{de}}{1+\mathrm{e}}\right|
$$

where $z$ is the length of the blur and $t$ is the exposure time for a single frame. Substituting the estimated maximum errors in rquation (32) gives:

$$
\left|\frac{\mathrm{d} \Delta \mathrm{M}}{\Delta}\right|=0.5+0.1+0.01+0.5 \text {. }
$$

The total error in $\Delta M$ is approximately $\pm 110 \%$ with the major source being the estimate of mass and the coefficient of restitution. Fortunately, the fragment generation function is dependent on the logarithm of the change in momentum as follows:

$$
N=\alpha+\beta \log \Delta M+\gamma(\log \Delta M)^{2}
$$

The coefficients $\alpha, \beta$, and $\gamma$ were found by the method of least squares and their contribution to the error can be estimated from the correlation coefficients found in Table 2. The effect of an error in $\Delta M$ depends on these coefficients, however. Assuming a $110 \%$ error in $\Delta \mathrm{M}$ the effect on $\mathrm{N}$ varies depending on the crystal type because the coefficients are different. Table 3 shows this effect for the five different crystal types. 
Table $3 . \quad N$ and $\Delta N / N$ with a $10 \%$ increase in $\Delta M$ for the five crystal Types studied.

\begin{tabular}{lccc} 
CRYSTAL TYPE & $\mathrm{N}$ for $\Delta \mathrm{M}=1 \times 10^{-2}$ & $\Delta \mathrm{N}$ for $\Delta \mathrm{M}=1.1 \Delta \mathrm{M}$ & $\frac{\Delta \mathrm{N}}{\mathrm{N}}$ \\
\hline $\begin{array}{l}\text { Unrimed Plane } \\
\text { Dendrites }\end{array}$ & 1.86 & \pm .22 & \pm .12 \\
\hline $\begin{array}{l}\text { LGT-MDT Rimed } \\
\text { Plane Dendrites }\end{array}$ & 3.18 & \pm 1.28 & \pm .40 \\
\hline $\begin{array}{l}\text { Hvy Rimed } \\
\text { Plane Dendrites }\end{array}$ & 10.00 & \pm 6.38 & \pm .64 \\
$\begin{array}{l}\text { LGT-MDT Rimed } \\
\text { Spatial Crystals }\end{array}$ & 31.58 & \pm 21.41 & \pm .68 \\
\hline Graupel & 4.45 & \pm 1.17 & \pm .26 \\
\hline
\end{tabular}

From Table 3 it is evident that the greatest effect of error in the experiment is on the crystal types that produce the most fragments. Even here, however, the effect is to change $N$ by a maximum of $68 \%$ for a $110 \%$ change in $\Delta \mathrm{M}$.

The observation of $\mathrm{N}$ for the plots in Figures 8-12 was estimated to be in error by less than $10 \%$. Other sources of error may be due to the limited sample available. Although a large number of collisions were analyzed for each of the five crystal types, it is possible that cloud conditions peculiar to Colorado or the sample of data obtained may have biased the results. Samples from different locations and times in Colorado gave consistent results, however, giving more confidence in the results.

The total error in the fragment generation function is estimated to be well within a factor of two. Since the rate of change in the crystal concentration, $\mathrm{dC} / \mathrm{dt}$, is directly proportional to the fragment 
generation function, $\mathrm{N}$, (See Equation 17), a given error in $\mathrm{N}$ produces a directly related error in $\mathrm{dC} / \mathrm{dt}$. This effect will be shown to be unimportant in the final results. 
CHAPTER IV

NUMERICAL MODELING

\section{A. Model Description}

The general solution to Equation (18) can only be found if $k(t)$ is known as a function of time. $K(t)$ will vary, depending on the initial crystal type and size distributions, on the size distributions of the fragments which are produced in the cloud, and on the rate of accretion and diffusion which takes place on the original crystals and fragments. Since these factors change in a time-dependent manner, a general analytic function for $K(t)$ is not obtainable. Therefore, a numerical model has been constructed to approximate the change in $K(t)$ and integrate Equation (18) in time.

The flow diagram for the numerical model is shown in abbreviated form in Figure 14. This model was used in two modes: (1) to determine the best crystal combinations and size distributions for generating secondary particles and (2) to determine the magnitude of secondary particle generation for a specific time-dependent case. In the first mode the model was run for one time step for each of 252 different crystal types and size distributions combinations. $\mathrm{K}_{0}$ was determined for each combination. The largest $\mathrm{K}_{0}$ 's indicated the best crystal types and size distributions for generating secondary particles. In the second mode the model was run for fifteen time steps for special cases. In these computations $K(t)$ varied with time and, consequently, $C(t)$ had a different form, from that when $K(t)$ was equal to a constant, $\mathrm{K}_{\mathrm{O}}$. The magnitude of secondary particle generation was found to be 


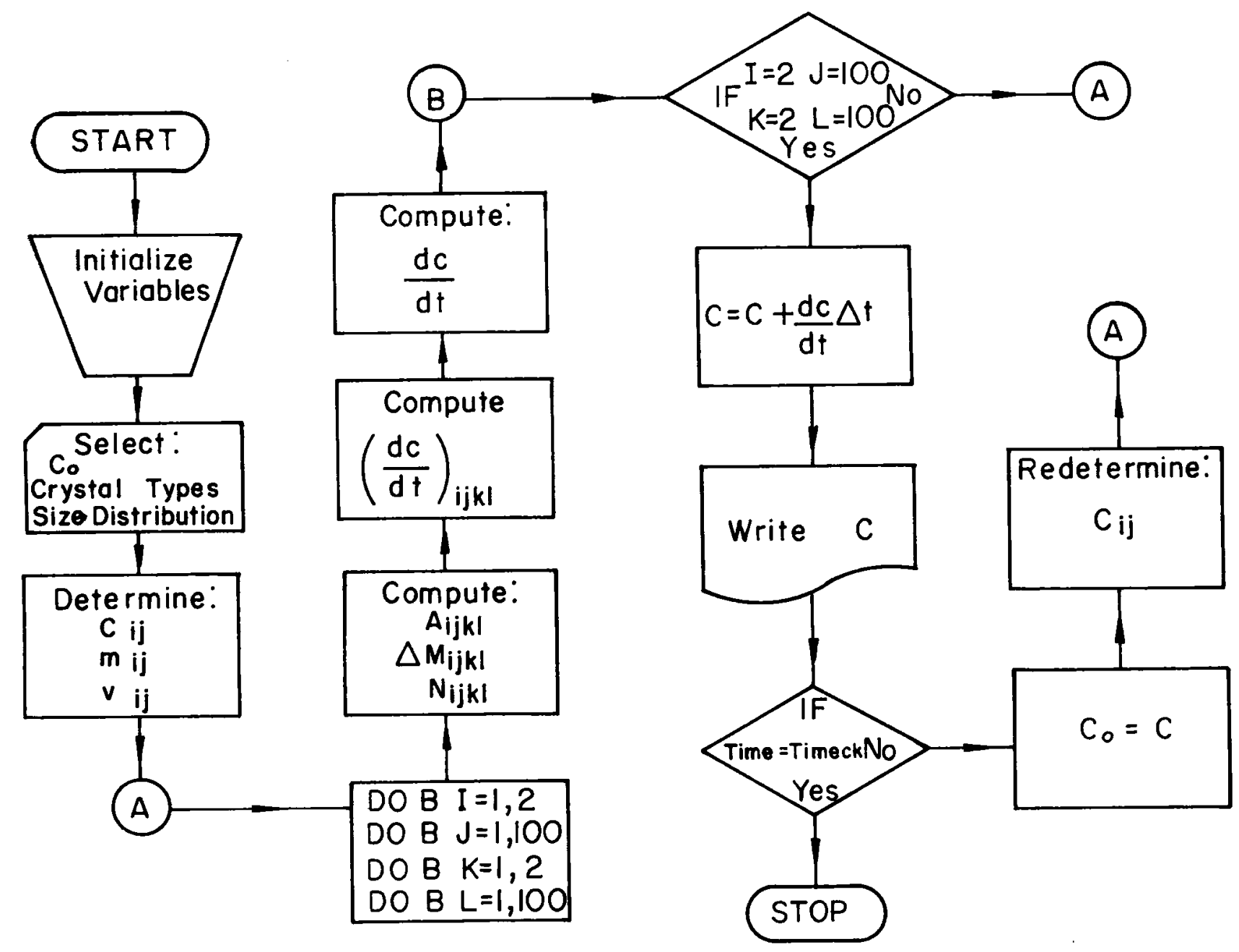

Figure 14. Flow diagram of numerical mode1. 
less than the case for $K(t)=K_{0}$ with some assumptions and greater for other assumptions.

The model allowed the selection of five crystal types and eight size distributions. The five crystal types were unrimed plane dendrites, lightly-rimed plane dendrites, heavily-rimed plane dendrites, lightly-rimed spatial crystals, and graupel. The eight size distributions are shown in Figure 15. Since the crystal concentration can be treated as an independent variable separate from $K(t), C_{0}$ was set equal to .1 crystal per liter in most cases. Since two crystal types were treated at any one time, each crystal type was assumed to contribute half of the total crystal concentration. This assumption maximizes the interaction between crystals and is an important assumption in determining $K(t)$. $K(t)$ will be less for the case where two crystal types are present but one crystal type contributes less than half of the total concentration.

The model builds three two-dimensional arrays for use in later computations. The first array is the concentration of each crystal type in 100 size categories. The size categories were selected $50 \mu \mathrm{m}$ wide and, consequently, the size range was from 0 to $5000 \mu \mathrm{m}$. The concentrations by size category are called $C_{i j}$ 's where $i$ is the crystal type and $j$ is the size category. The sum of all $C_{i j}$ 's at any time must equal $C$. For time zero $C_{0}$ normally equaled .1 crystal/liter. The second array was the crystal mass per category, $m_{i j}$. These masses were determined from Nakaya's (1954) mass-diameter equations shown in Table 4. The mass for a given category was computed for the mid-size in the category. The third array was the terminal fall velocities 


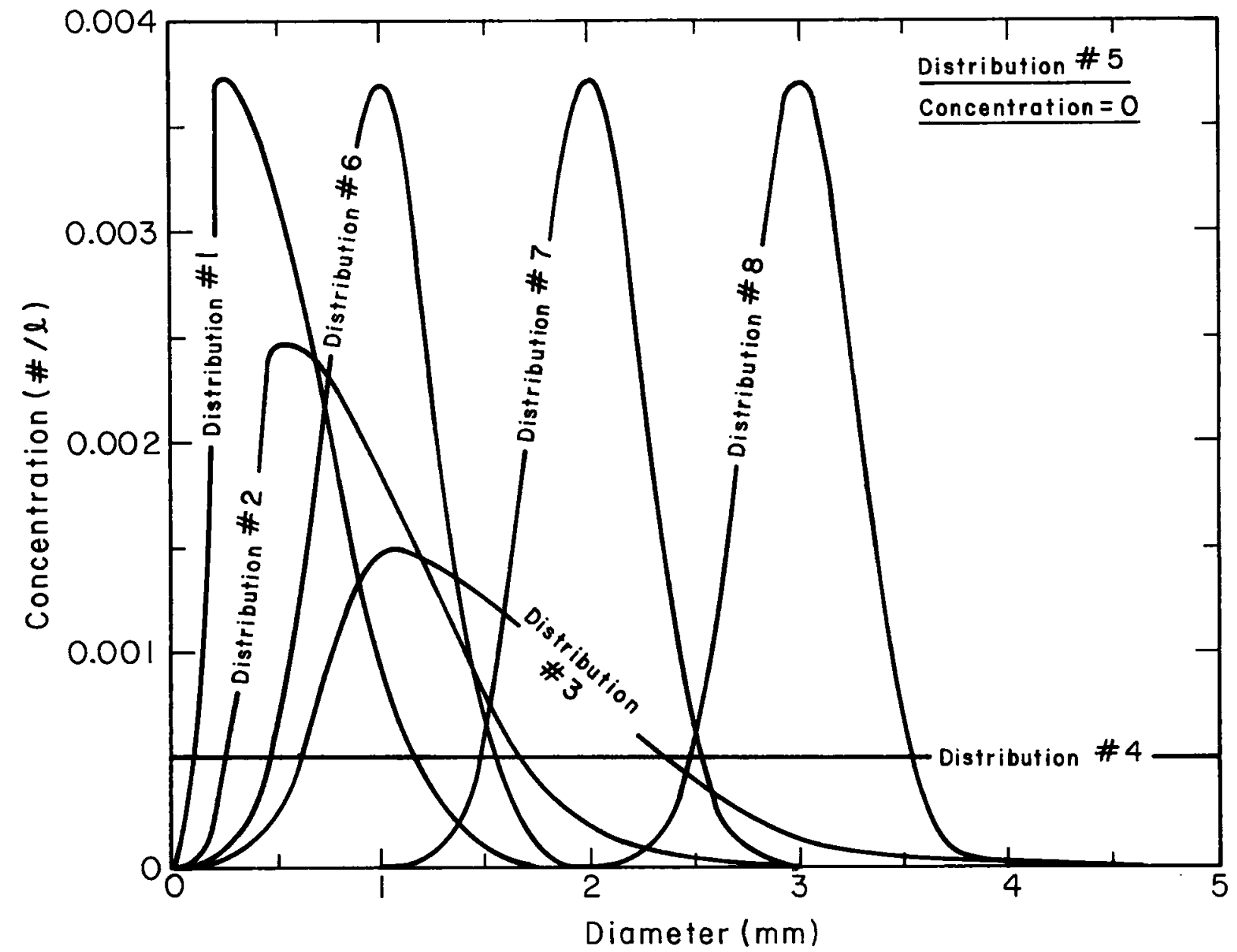

Figure 15. Size distributions used in the numerical model. 
Table 4. Mass-diameter and terminal fall velocity equations used in the numerical model.

\begin{tabular}{l|c|c} 
CRYSTAL TYPE & MASS-DIAMETER EQUATION & FALI VELOCITY EQUATION \\
\hline UNRM PDEN & $\left(3.8 \times 10^{-12}\right) \times D^{2}$ & $8.4 \mathrm{D} \cdot 217$ \\
\hline MDT-RM PDEN & $\left(2.7 \times 10^{-11}\right) \times D^{2}$ & $9.4 \mathrm{D} \cdot 301$ \\
\hline HVY-RM PDEN & $\left(2.7 \times 10^{-11}\right) \times D^{2}$ & $25.5 \mathrm{D} .206$ \\
\hline LGT-MDT RM BCRY & $\left(1.0 \times 10^{-11}\right) \times D^{2}$ & $25.5 \mathrm{D} \cdot 206$ \\
\hline GRAUPEL & $\left(6.5 \times 10^{-14}\right) \times \mathrm{D}^{3}$ & $-267+138 \log _{10} \mathrm{D}$ \\
\hline
\end{tabular}

obtained from different sources. The fall velocities for the five crystal types vs. size are shown in Figure 16. The fall velocities for unrimed plane dendrites and graupel were obtained from Brown (1970) and Zikmunda and Vali (1972) respectively. I felt Nakaya's data for various degrees of rime were inadequate for accurate determination of fall velocities. Therefore, I used the data obtained in association with the fragment generation functions to compute fall velocities. The determination of the fall velocity equations for lightly-rimed plane dendrites, heavily-rimed plane dendrites, and lightly-rimed spatial crystals is discussed in Appendix C.

The next step in the model was to compute the collision cross section and the number of fragments generated in a given collision. The collision cross section was approximated by the area of a disc with diameter equal to the sum of the diameters of the two colliding particles. The number of fragments produced per collision is obtained by evaluating Equations (9) and (10), given the data in Table 2 . 


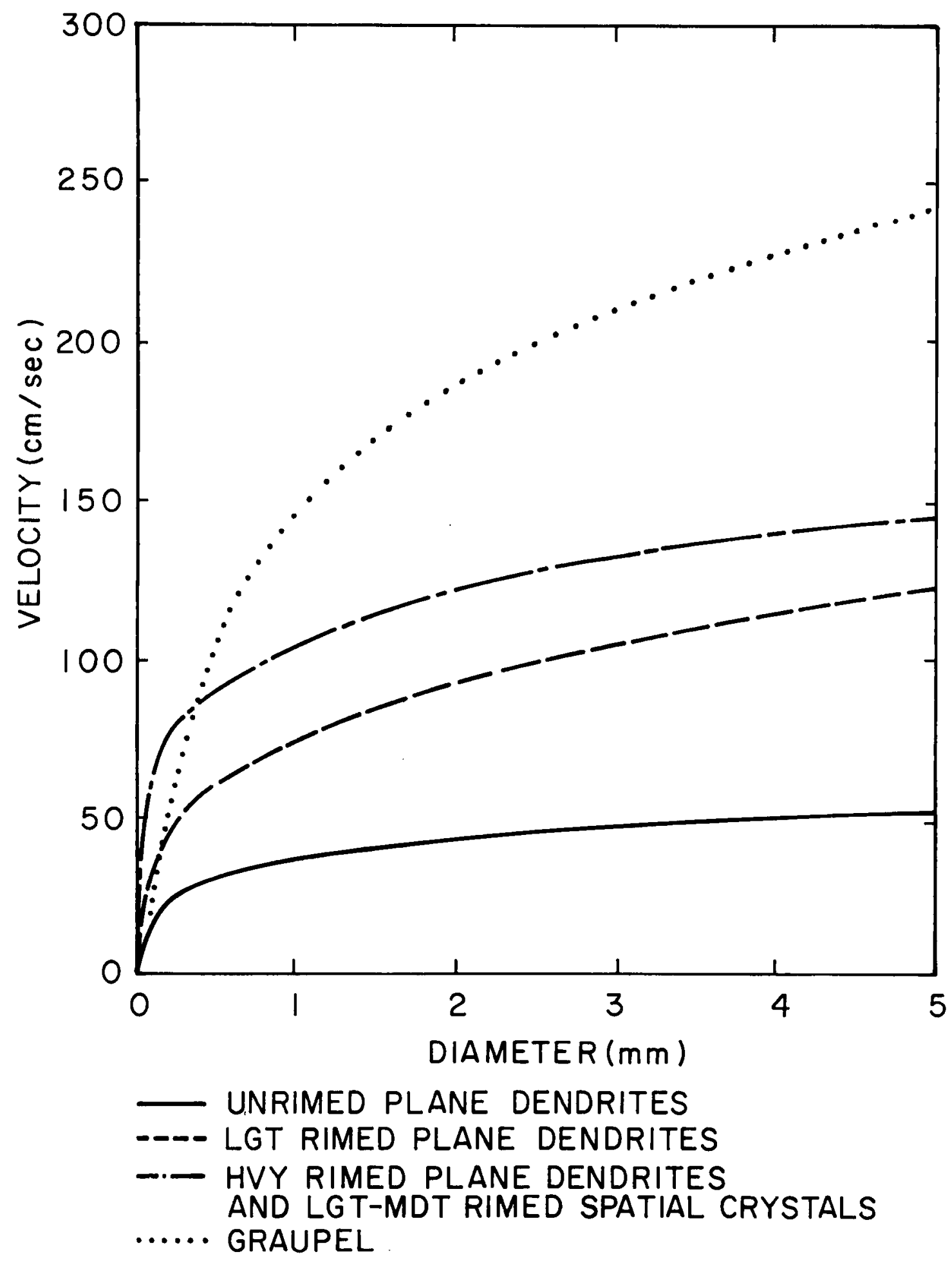

Figure 16. Terminal fall velocities as a function of crystal diameter for the five crystal types studied. 
The change in crystal concentration $\left(\frac{d C}{d t}\right)_{i j k l}$ for crysial type $i$ size $j$ when hit by crystal type $k$ - size 1 is then determined by evaluating Equation (11). Also, the total change in crystal concentration is determined from Equation (13). The determination of the change in the total crystal concentration involves four nested do loops. For two crystal types of 100 size categories, 10,000 passes through step $B$ are required. The total computation time for one time step on a CDC 6400 computer was approximately 15 secunds.

If only one time step was called for, the model wuld pulut the final total crystal concentration and final size distribution arrays and start again with new crystal combinatiuns wi size distrilutiuns. If however, additional time steps were called for, the or iglual size distributions were modified by the addition of fragments and the effects of accretion and diffusion. A size distributiun for the fragments is required to permit accurate wodeling of the regrowth of the fragments. Since the size distribution of the fiagments is not known in general, a specific case of graupel and havily-riued plane dendrites was treated because a fairly good distribution for these fragments was obtained in the fixed plate experiment.

A basic assumption which could have some effect on the model results should be mentioned at this point. Since little is known of the fragment sizes, it was assumed that the size uf fraguents produced by collisions in a cloud is the same as collisions with the fixed plate. This is probably not true as the size of fragments is most Iikely some function of the change in momentum, $\Delta M$. If the size of fragments is proportional to $\Delta M$, the model will give results 
which over estimates the generation rate of secondary particles and vice versa. It is difficult to say at this time which case is true. The effects of diffusion were modeled as linearly-dependent on size as shown by Hallett (1965), Marwitz and Auer (1968), Koenig (1971), Fukuta (1969), and Jayaweera (1971). Accretion on graupe1 was assumed linearly dependent on size also as Juisto (1968), Takeda (1968), and Hindman (1968) indicate in a crude manner. The rates of diffusional growth depend strongly on the temperature with the maximum rate of diffusional growth occurring at $-15^{\circ} \mathrm{C}$. The estimates of the rate of growth at this temperature range over an order of magnitude so no growth, moderate growth, and high growth rates were assumed. The moderate rate was assumed to be one micron per second and the high rate to be four microns per second. Growth by accretion in the model is even more crude. It depends on Iiquid water content, drop size distributions, and the collection efficiency. The rates assumed in this model were one micron per second for moderate growth and four microns per second for heavy growth on crystals larger than 300 microns. Once the original distributions were modified for fragmentation, diffusion, and accretion, the next time step was begun in the same manner as before. This process was repeated up to fifteen times. Different rates of growth and diffusion were used to evaluate the magnitude of secondary particle generation when $K(t)$ is not constant.

The model was found to be stable but did require small time steps for large initial crystal concentrations when $\mathrm{K}(t)$ was a1so large. This was due to the dependence of the collision frequency on $\mathrm{c}^{2}$. If the time step is too large, the change in $\mathrm{K}(\mathrm{t})$ is not sufficient to restrict the change in $C$. 


\section{B. Determination of Optimum Rate Constants}

The numerical model was run with combinations of the five crystal types. Including the combinations of each crystal type with itself, fifteen possible combinations existed. Within a given combination of two crystals, four size distributions for each type of crystals were studied giving sixteen values of $\mathrm{K}_{\mathrm{o}}$ for each of the fifteen combinations or a total of 240 values of $\mathrm{K}_{0}$. These values of $\mathrm{K}_{\mathrm{o}}$ are shown in Tables 5 through 19. Distribution 4 is not a physically-valid distribution but was included for mathematical interest. Distributions $1-4$ are progressively broader with means at greater sizes. The following features of crystal-crystal collisions may be seen in Tables 5 through 19 .

1. The broader the distribution the larger the value of $\mathrm{K}_{\mathrm{o}}$. Reviewing from Chapter II we recall that the 1 arger $\mathrm{K}_{0}$, the greater the generation of secondary particles for a given crystal concentration. Thus, we can say, the broader the crystal distribution the greater the secondary particle generation. This effect is most likely due to the greater concentration of crystals at the larger sizes for broad distributions. The larger the crystal size the larger the relative velocity and the more fragments produced in a collision. The collision frequency increases as the square of the concentration so that more crystals at large sizes repidly increases the secondary particle generation.

2. Unrimed plane dendrites should not generate secondary particles among themselves. Table 5 shows $\mathrm{K}_{\mathrm{o}}$ equal to zero for 
Table 5. Values of $\mathrm{K}_{\mathrm{o}}$ for various size distributions of unrimed plane dendrites colliding with unrimed plane dendrites.

\begin{tabular}{|c|c|c|c|c|c|}
\hline \multirow{5}{*}{ 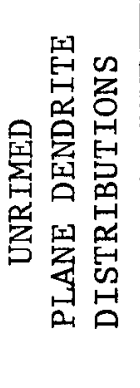 } & & 1 & 2 & 3 & 4 \\
\hline & 1 & 0 & 0 & 0 & 0 \\
\hline & 2 & 0 & 0 & 0 & 0 \\
\hline & 3 & 0 & 0 & 0 & 0 \\
\hline & 4 & 0 & 0 & 0 & 0 \\
\hline
\end{tabular}

Table 6. Values of $\mathrm{K}_{\mathrm{o}}$ for various size distributions of unrimed plane dendrites colliding with lightly-rimed plane dendrites.

UNRIMED PLANE DENDRITE DISTRIBUTIONS

\begin{tabular}{|c|c|c|c|c|c|}
\hline \multirow{5}{*}{ 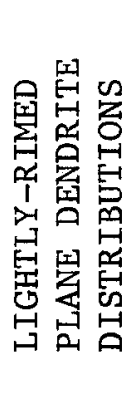 } & & 1 & 2 & 3 & 4 \\
\hline & 1 & $7.69 \times 10^{-11}$ & $1.76 \times 10^{-8}$ & $8.49 \times 10^{-7}$ & $6.95 \times 10^{-6}$ \\
\hline & 2 & $2.76 \times 10^{-8}$ & $5.09 \times 10^{-7}$ & $1.36 \times 10^{-5}$ & $8.87 \times 10^{-5}$ \\
\hline & 3 & $1.52 \times 10^{-5}$ & $2.28 \times 10^{-5}$ & $1.46 \times 10^{-4}$ & $7.05 \times 10^{-4}$ \\
\hline & 4 & $2.44 \times 10^{-4}$ & $2.95 \times 10^{-4}$ & $8.53 \times 10^{-4}$ & $2.93 \times 10^{-3}$ \\
\hline
\end{tabular}

Table 7. Values of $\mathrm{K}_{\mathrm{o}}$ for various size distributions of unrined plane dendrites colliding with heavily-rimed plane dendrites.

UNRIMED PIANE DENDRITE DISTRIBUTTONS

\begin{tabular}{|c|c|c|c|c|}
\hline \multirow{5}{*}{ 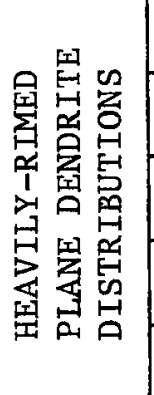 } & 1 & 2 & 3 & 4 \\
\hline & $1.80 \times 10^{-8}$ & $8.19 \times 10^{-7}$ & $1.47 \times 10^{-5}$ & $9.45 \times 10^{-5}$ \\
\hline & $2.02 \times 10^{-7}$ & $6.10 \times 10^{-6}$ & $1.04 \times 10^{-4}$ & $7.25 \times 10^{-4}$ \\
\hline & $7.41 \times 10^{-6}$ & $4.47 \times 10^{-5}$ & $6.56 \times 10^{-4}$ & $4.32 \times 10^{-3}$ \\
\hline & $2.99 \times 10^{-4}$ & $4.52 \times 10^{-4}$ & $2.68 \times 10^{-3}$ & $1.43 \times 10^{-2}$ \\
\hline
\end{tabular}


Table 8. Values of $K_{0}$ for various size distributions of unrimed plane dendrites colliding with light-moderately rinuil spatial crystals.

UNRIMED PLANE DENDRILE DISIRILIIIIUNS

\begin{tabular}{|c|c|c|c|c|c|}
\hline & & 1 & 2 & 3 & 4 \\
\hline 足恕 & 1 & $2.46 \times 10^{-6}$ & $2.09 \times 10^{-5}$ & $1.16 \times 10^{-16}$ & $3.29 \times 10^{-4}$ \\
\hline 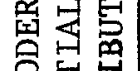 & 2 & $1.73 \times 10^{-5}$ & $1.20 \times 10^{-4}$ & $0.30 \times 10^{-4}$ & $1.84 \times 10^{-3}$ \\
\hline & 3 & $1.56 \times 10^{-4}$ & $6.62 \times 10^{-4}$ & $3.09 \times 10^{-3}$ & $8.97 \times 10^{-3}$ \\
\hline & 4 & $1.04 \times 10^{-3}$ & $2.71 \times 10^{-3}$ & $1.01 \times 10^{-3}$ & $2.74 \times 10^{-2}$ \\
\hline
\end{tabular}

Table 9. Values of $\mathrm{K}_{\mathrm{o}}$ for various size distributions of unrimed plane dendrites colliding with graupel.

UNR IMED PLANE DENDRTTE DISTK IBUTCONS

\begin{tabular}{|c|c|c|c|c|}
\hline \multirow{5}{*}{ 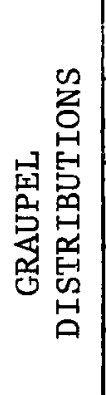 } & 1 & 2 & 3 & 4 \\
\hline & $2.38 \times 10^{-5}$ & $1.06 \times 10^{-4}$ & $5.31 \times 10^{-4}$ & $1.68 \times 10^{-3}$ \\
\hline & $2.14 \times 10^{-4}$ & $5.04 \times 10^{-4}$ & $1.86 \times 10^{3}$ & $.39 \times 10^{-3}$ \\
\hline & $1.81 \times 10^{-3}$ & $2.81 \times 10^{-3}$ & $6.83 \times 10^{-3}$ & $1.64 \times 10^{-2}$ \\
\hline & $7.15 \times 10^{-3}$ & $9.82 \times 10^{-3}$ & $1.88 \times 10^{-2}$ & $3.69 \times 10^{-2}$ \\
\hline
\end{tabular}

Table 10. Values of $\mathrm{K}_{\mathrm{o}}$ for various size distributions of lightly-rimed plane dendrites colliding with 1ightly riwed plane dendrites.

LIGHTLY-RIMED PLANE DENDRTTE DISTRIBUTIONS

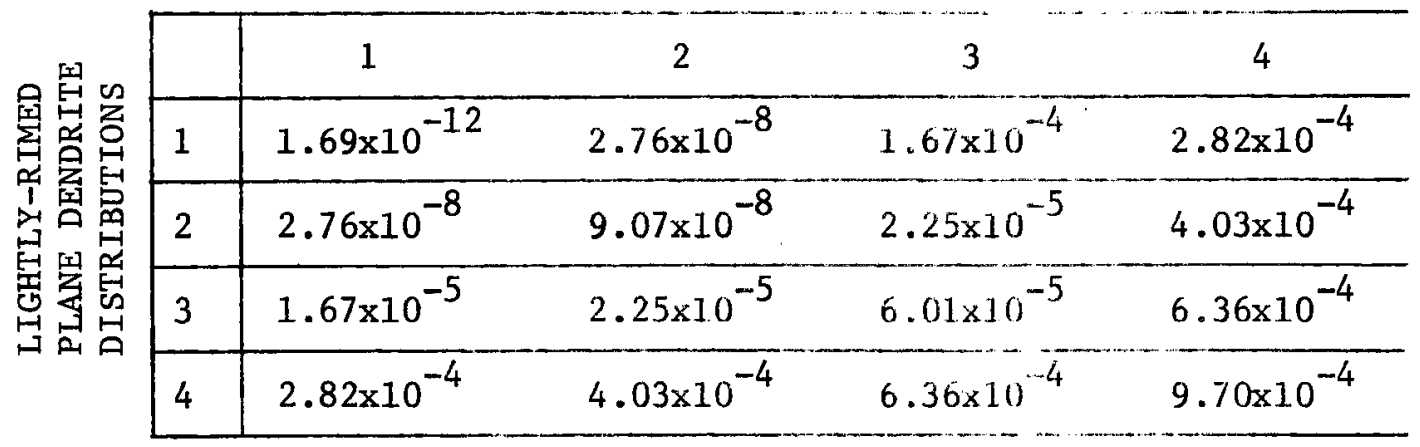




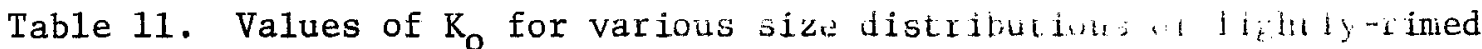
plane dendrites colliding with heavily-rina f iat whites.

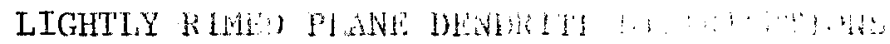

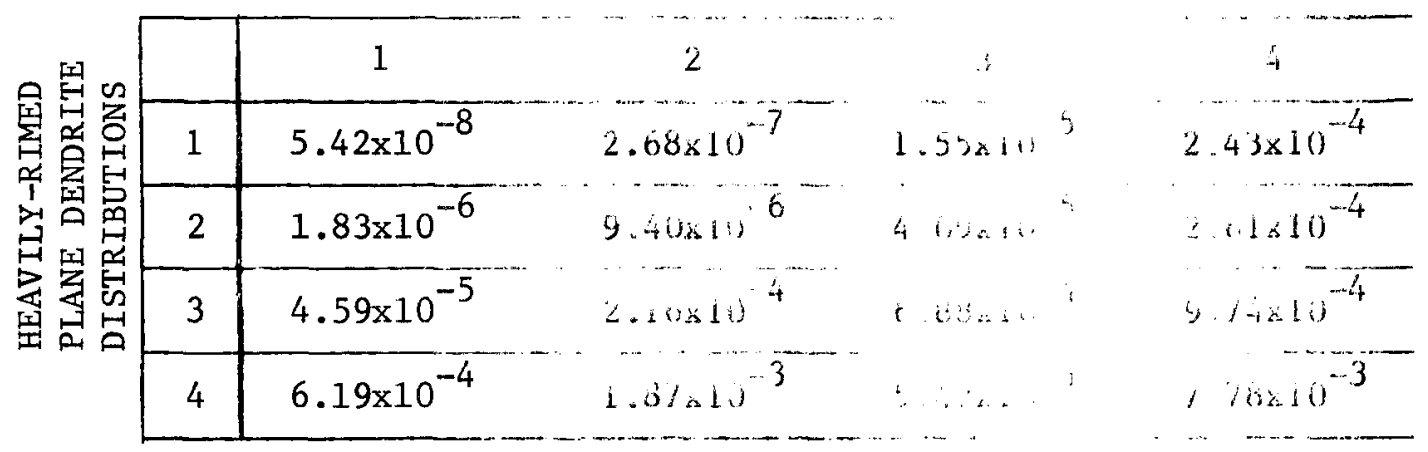

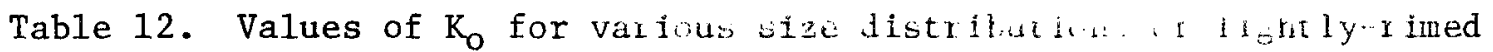

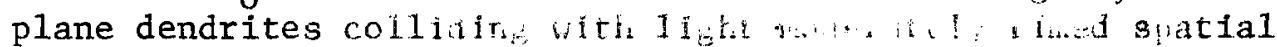
crystals.

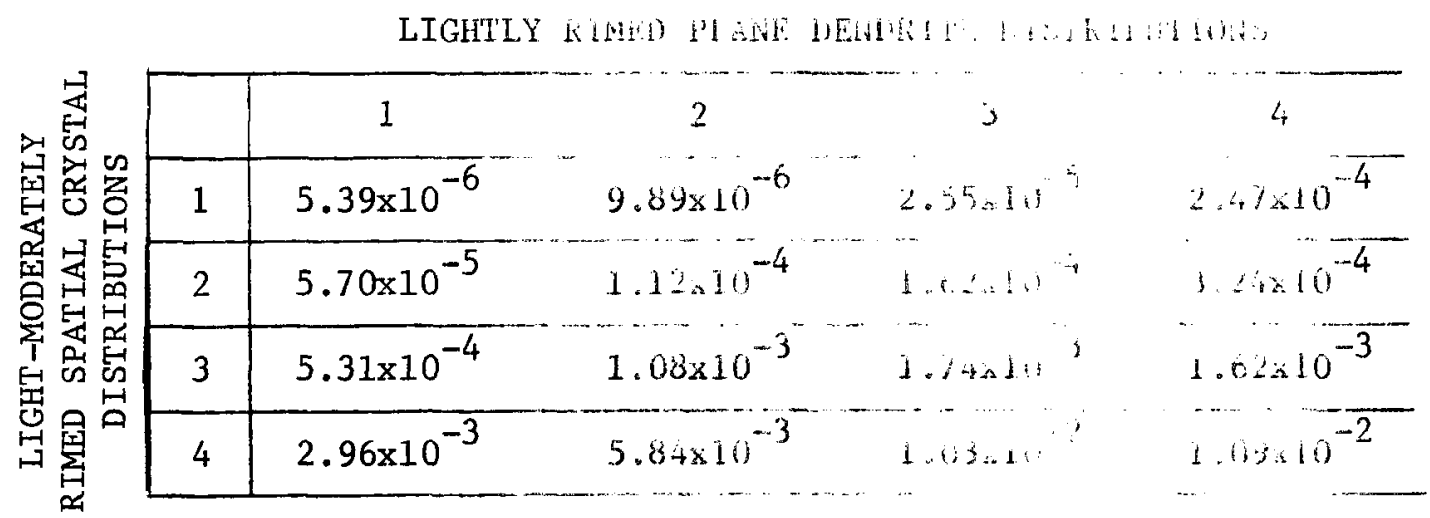

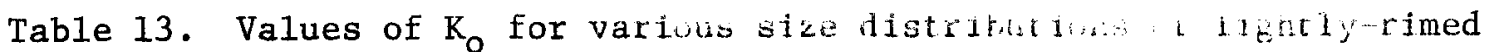
plane dendrites colliding with graniel.

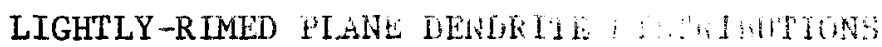

\begin{tabular}{|c|c|c|c|c|c|}
\hline \multirow{5}{*}{ 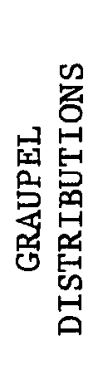 } & & 1 & 2 & 3 & 4 \\
\hline & 1 & $8.11 \times 10^{-5}$ & $1.90 \times 10^{-4}$ & $4.37 \ldots .6$ & is. $24 \times 10^{-4}$ \\
\hline & 2 & $4.91 \times 10^{-4}$ & $1.01 \times 10^{-3}$ & $2.22 n+11^{3}$ & $3.84 \times 10^{-3}$ \\
\hline & 3 & $3.10 \times 10^{-3}$ & $5.34 \times 10^{-3}$ & $\operatorname{lon}=0^{-2}$ & $1.86 \times 10^{-2}$ \\
\hline & 4 & $1.15 \times 10^{-2}$ & $1.81 \times 10^{-2}$ & $3.34 \times 10^{2}$ & $35 \% \times 10^{-2}$ \\
\hline
\end{tabular}


Table 14. Values of $\mathrm{K}_{\mathrm{o}}$ for various size distributions of heavily-rimed plane dendrites colliding with heavily-rimed plane dendrites.

HEAVILY-RIMED PIANE DENIRI'IE DISTRIBUTIONS

\begin{tabular}{|c|c|c|c|c|c|}
\hline \multirow{5}{*}{ 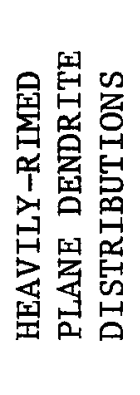 } & & 1 & 2 & 3 & 4 \\
\hline & 1 & 0 & $9.33 \times 10^{-11}$ & $5.74 \times 10^{-6}$ & $2.99 \times 10^{-4}$ \\
\hline & 2 & $9.33 \times 10^{-11}$ & $3.63 \times 10^{-10}$ & $7.04 \times 10^{-6}$ & $3.87 \times 10^{-4}$ \\
\hline & 3 & $5.74 \times 10^{-6}$ & $7.04 \times 10^{-6}$ & $2.26 \times 10^{-.5}$ & $6.86 \times 10^{-4}$ \\
\hline & 4 & $2.99 \times 10^{-4}$ & $3.87 \times 10^{-4}$ & $0.86 \times 10^{-4}$ & $1.16 \times 10^{-3}$ \\
\hline
\end{tabular}

Table 15. Values of $\mathrm{K}_{\mathrm{o}}$ for various size distributions of heavily-rimed plane dendrites colliding with light-moderately-rimed spatial dendrites.

\begin{tabular}{|c|c|c|c|c|c|}
\hline \multirow{2}{*}{\multicolumn{2}{|c|}{ 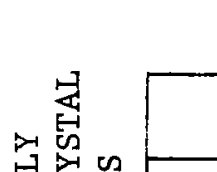 }} & \multicolumn{4}{|c|}{ HEAVILY-RIMED PLANE DENDRITE WISTRIBUTIONS } \\
\hline & & 1 & 2 & 3 & 4 \\
\hline 旲总怘 & 1 & $7.62 \times 10^{-9}$ & $4.71 \times 10^{-8}$ & $1.13 \times 10^{-5}$ & $3.78 \times 10^{-4}$ \\
\hline 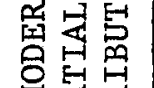 & 2 & $1.59 \times 10^{-6}$ & $2.74 \times 10^{-6}$ & $2.85 \times 10^{-5}$ & $5.86 \times 10^{-4}$ \\
\hline 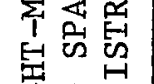 & 3 & $1.11 \times 10^{-4}$ & $1.61 \times 10^{-4}$ & $2.15 \times 10^{-4}$ & $1.02 \times 10^{-3}$ \\
\hline 吕鼠 & 4 & $1.19 \times 10^{-3}$ & $1.79 \times 10^{-3}$ & $2.33 \times 10^{-3}$ & $2.29 \times 10^{-3}$ \\
\hline
\end{tabular}

Table 16. Values of $\mathrm{K}_{\mathrm{o}}$ for various size distributions of heavily-rimed plane dendrites colliding with graupel.

HEAVILY-RIMED PLANE DENDRIIE DIST'RIBUTIONS

\begin{tabular}{|c|c|c|c|c|}
\hline \multirow{5}{*}{ 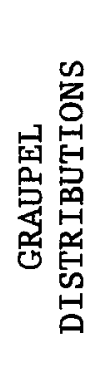 } & 1 & 2 & 3 & 4 \\
\hline & $3.13 \times 10^{-5}$ & $6.98 \times 10^{-5}$ & $1.61 \times 10^{-4}$ & $5.08 \times 10^{-4}$ \\
\hline & $3.15 \times 10^{-4}$ & $6.50 \times 10^{-4}$ & $1.59 \times 10^{-3}$ & $2.95 \times 10^{-3}$ \\
\hline & $2.65 \times 10^{-3}$ & $5.00 \times 10^{-3}$ & $1.18 \times 10^{-2}$ & $2.27 \times 10^{-2}$ \\
\hline & $1.10 \times 10^{-2}$ & $2.01 \times 10^{-2}$ & $4.60 \times 10^{-2}$ & $8.81 \times 10^{-2}$ \\
\hline
\end{tabular}


Table 17. Values of $\mathrm{K}_{\mathrm{o}}$ for various size distributions of lightmoderately rimed spatial crystals colliding with lightmoderately rimed spatial crystals.

LIGHT-MODERATELY RIMED SPATIAL CRYSTAL DISTRIBUTIONS

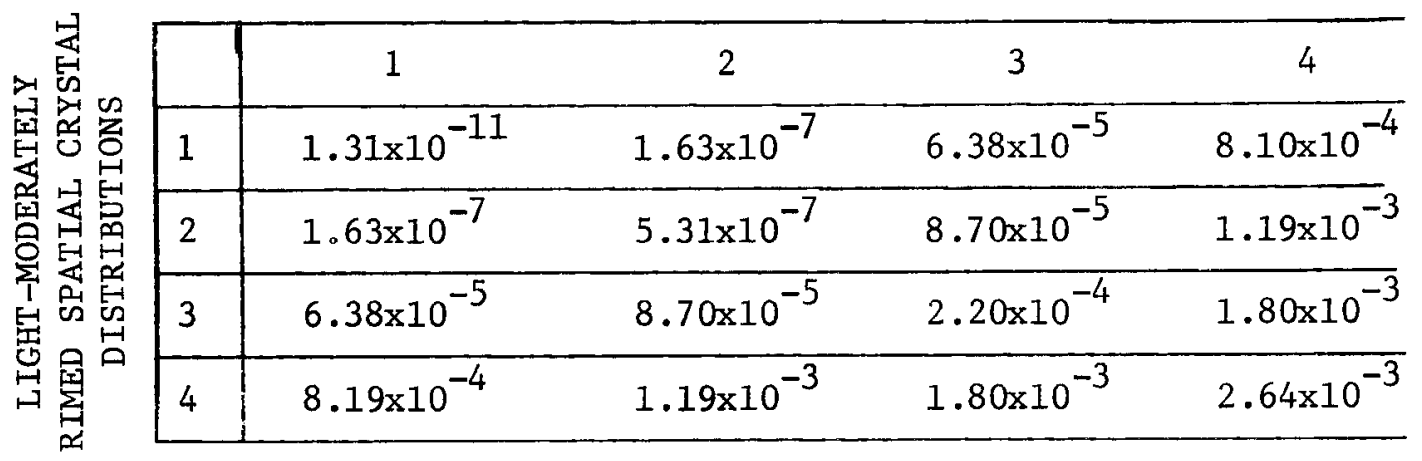

Table 18. Values of $\mathrm{K}_{\mathrm{o}}$ for various size distributions of lightmoderately rimed spatial crystals colliding with graupel.

LIGHT-MODERATELY RIMED SPATIAL CRYSTAL DISTRIBUTIONS

\begin{tabular}{|c|c|c|c|c|}
\hline \multirow{5}{*}{ 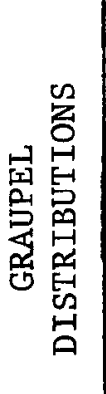 } & 1 & 2 & 3 & 4 \\
\hline & $2.71 \times 10^{-5}$ & $7.40 \times 10^{-5}$ & $2.51 \times 10^{-4}$ & $1.02 \times 10^{-3}$ \\
\hline & $2.91 \times 10^{-4}$ & $6.36 \times 10^{-4}$ & $1.69 \times 10^{-3}$ & $3.61 \times 10^{-3}$ \\
\hline & $2.48 \times 10^{-3}$ & $4.53 \times 10^{-3}$ & $1.06 \times 10^{-2}$ & $2.09 \times 10^{-2}$ \\
\hline & $1.02 \times 10^{-2}$ & $1.78 \times 10^{-2}$ & $3.85 \times 10^{-2}$ & $7.26 \times 10^{-2}$ \\
\hline
\end{tabular}

Table 19. Values of $\mathrm{K}_{\mathrm{o}}$ for various size distributions of graupel colliding with graupel.

\begin{tabular}{l}
\multicolumn{5}{c}{ GRAUPEL DISTRIBUTIONS } \\
\cline { 2 - 6 } \\
\cline { 2 - 6 }
\end{tabular}


all sizes distributions including distribution 4 . Since dendrites appear to be the most fragile unrimed type of crystal, this finding would seem to imply that no unrimed crystals may produce secondary particles by mechanical fracturing. However, plane dendrites also have the lowest terminal velocity for a given crystal size and other crystals which appear less fragile may still produce fragments because of their greater fall velocities. We find however, that the magnitude of $\mathrm{K}_{\mathrm{o}}$ for even rimed crystals is so small that a statement to the effect that unrimed crystals cannot generate secondary particles is probably correct.

3. The greater the rime the larger $\mathrm{K}_{\mathrm{o}}$ and consequently, the greater the secondary particle generation. This finding is similar to that obtained directly from the fixed-plate experiment. However, the result here is much more impressive. In the fixedplate experiment the effect of greater riming was to increase the fragment generation by a factor of two or three. Here, the generation of secondary particles may be increased by orders of magnitude. The reason is that riming not only increases the fragility of a crystal but also increases the fall velocity whereby the collision frequency is increased. Therefore, the model calculations take both effects into account and the influence of accretion is quite strong.

4. The magnitude of $\mathrm{K}_{\mathrm{o}}$ for the combination of crystal types and size distributions which are likely to occur in smooth winter orographic clouds or other cold stratiform clouds, is not large 
enough to cause secondary particle generation of great significance. Only convective cells which can generate heavilyrimed crystals with broad distributions can have large $\mathrm{K}_{\mathrm{o}}$ 's and thus generate secondary particles in large quantities. Even here the initial concentration of crystals must be greater than .1 crystals/1iter in rather extreme instances for secondary particle generation to occur. These findings are based on the assumption that $K(t)$ remains constant and equal to $K_{0}$. However, this assumption is not true in general and the effect of a change in $K(t)$ will be explored in the next section.

Before proceeding to the time dependent case, however, let us look at a few additional cases which were studied. The best cases found in the earlier set of crystal combinations and size distributions were those involving graupel and heavily-rimed plane dendrites. The crystal combination which had the greatest relative velocity was graupel and unrimed plane dendrites. However, neither graupel nor unrimed plane dendrites generate a large number of fragments. A greater effect was found between graupel and heavily-rimed dendrites, although there was little difference from that between moderatelyrimed plane dendrites and graupel or lightly-rimed plane dendrites and graupel. Apparently, the reduction in relative velocity is more than compensated for by the ability of more heavily-rimed crystals to produce fragments. What will happen then, when a fairly broad distribution of plane dendrites is bombarded by a shower of fairly large graupel? 
To answer this question the model was run again for one time step with unrimed, moderately-rimed, and heavily-rimed plane dendrites and spatial crystals, all with distribution 3 . They were bombarded by graupel with crystal distributions 6,7 , and 8 . The results are shown in Table 20. Under these extreme conditions $\mathrm{K}_{\mathrm{o}}$ reaches a maximum of $4.17 \times 10^{-2}$. Using Figure 2 or Equation (23) it can be shown that it would take over three minutes to increase the concentration by a factor of 10 if the initial concentration were .1 crystals/1iter. If the initial concentration were only .01 crystals/ liter the time would be over thirty minutes. We see, therefore, that even under extreme condtions mechanical fracturing of fragile crystals is important only when the concentration of crystals has reached a fairly high value.

\section{Time-Dependent Computations}

To go beyond the calculation of $K_{0}$ and find $K(t)$ as a function of time requires knowledge of the fragment distributions and diffusion and accretion rates. As discussed in Section $A$, the distributions for graupel fragments and heavily-rimed plane dendrite fragments were

Table 20. Values of $\mathrm{K}_{\mathrm{o}}$ for three relatively large distributions of graupel colliding with a broad distribution of four other crystal types.

CRYSTAL TYPE (DISTRIBUTION 3)

\begin{tabular}{|c|c|c|c|c|c|}
\hline \multirow{4}{*}{ 舁䝿 } & & $\begin{array}{l}\text { Unrimed } \\
\text { Plane } \\
\text { Dendrites } \\
\end{array}$ & $\begin{array}{l}\text { Lightly- } \\
\text { Rimed Plane } \\
\text { Dendrites }\end{array}$ & $\begin{array}{l}\text { Heavily- } \\
\text { Rimed Plane } \\
\text { Dendrites }\end{array}$ & $\begin{array}{l}\text { Light-Moderately } \\
\text { Rimed Spatial } \\
\text { Crystals }\end{array}$ \\
\hline & 6 & $1.89 \times 10^{-3}$ & $1.88 \times 10^{-3}$ & $8.14 \times 10^{-4}$ & $1.07 \times 10^{-3}$ \\
\hline & 7 & $7.38 \times 10^{-3}$ & $1.28 \times 10^{-2}$ & $1.37 \times 10^{-2}$ & $1.24 \times 10^{-2}$ \\
\hline & 8 & $1.51 \times 10^{-2}$ & $3.05 \times 10^{-2}$ & $4.17 \times 10^{-2}$ & $3.44 \times 10^{-2}$ \\
\hline
\end{tabular}


of sufficlent quality to allow modeling of this crystal combination. Since this combination gave the highest values of $\mathrm{K}_{0}$ it is appropriate that these crystals should be studied in greater depth. Unfortunately, the initial crystal distributions were not of the most favorable shape to give high values of $\mathrm{K}_{\mathrm{o}}$. Nevertheless, these distributions are actual observed distributions and lend credence to the findings. The fragment distributions for heavily-rimed plane dendrites and graupel are shown in Figures 17 and 18 respectively. The initial distributions for each crystal type are shown in frame (a) of Figures 20 and 21.

The model was run for 15 time steps of 60 seconds each for several different conditions. Figure 19 shows the results of these computations. The solid line is the case of $K(t)$ equal to a constant $\mathrm{K}_{\mathrm{o}}=.00081$. For an initial concentration of 1 crystal/1iter it would take over 20 minutes to increase the concentration by a factor of ten but only 6 minutes for an initial concentration of 3 crystals/liter. If one looks at the curve for no additional accretion and diffusion one notices that after a short period of time, it levels off and never reaches a factor of ten greater than the initial concentration. This was found to be true for all crystal types and size distributions studied. The result should not be surprising when one considers the fact that without additional growth by accretion and diffusion a single crystal will only produce so many. fragments. The calculations show that an average crystal will produce less than ten fragments unless additional grows occurs. In many cases fewer fragments will be produced because the fragments are too small to produce additional fragments at their reduced fall speed. 


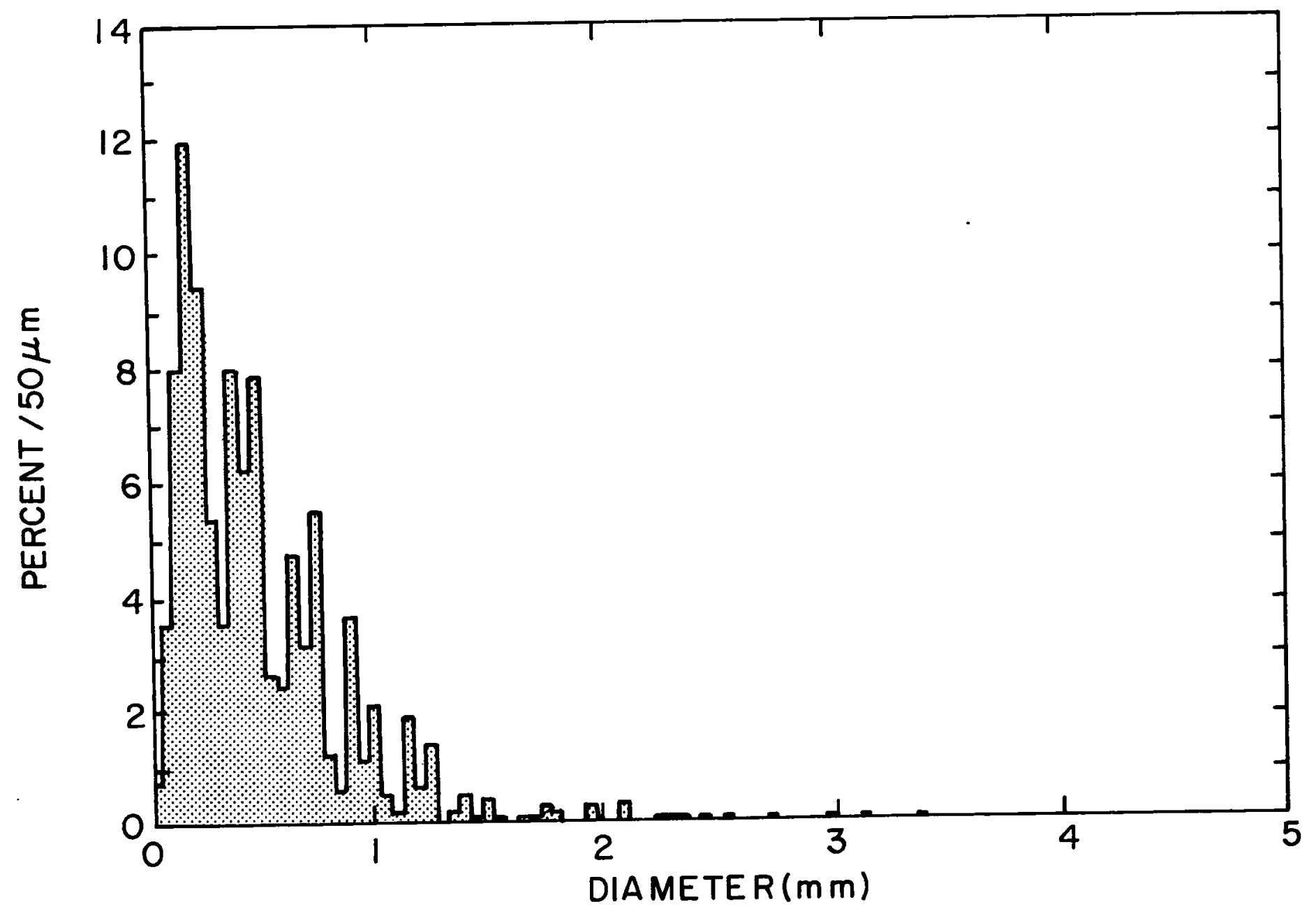

Figure 17. Size distribution of fragments from heavily-rimed plane dendrites. 


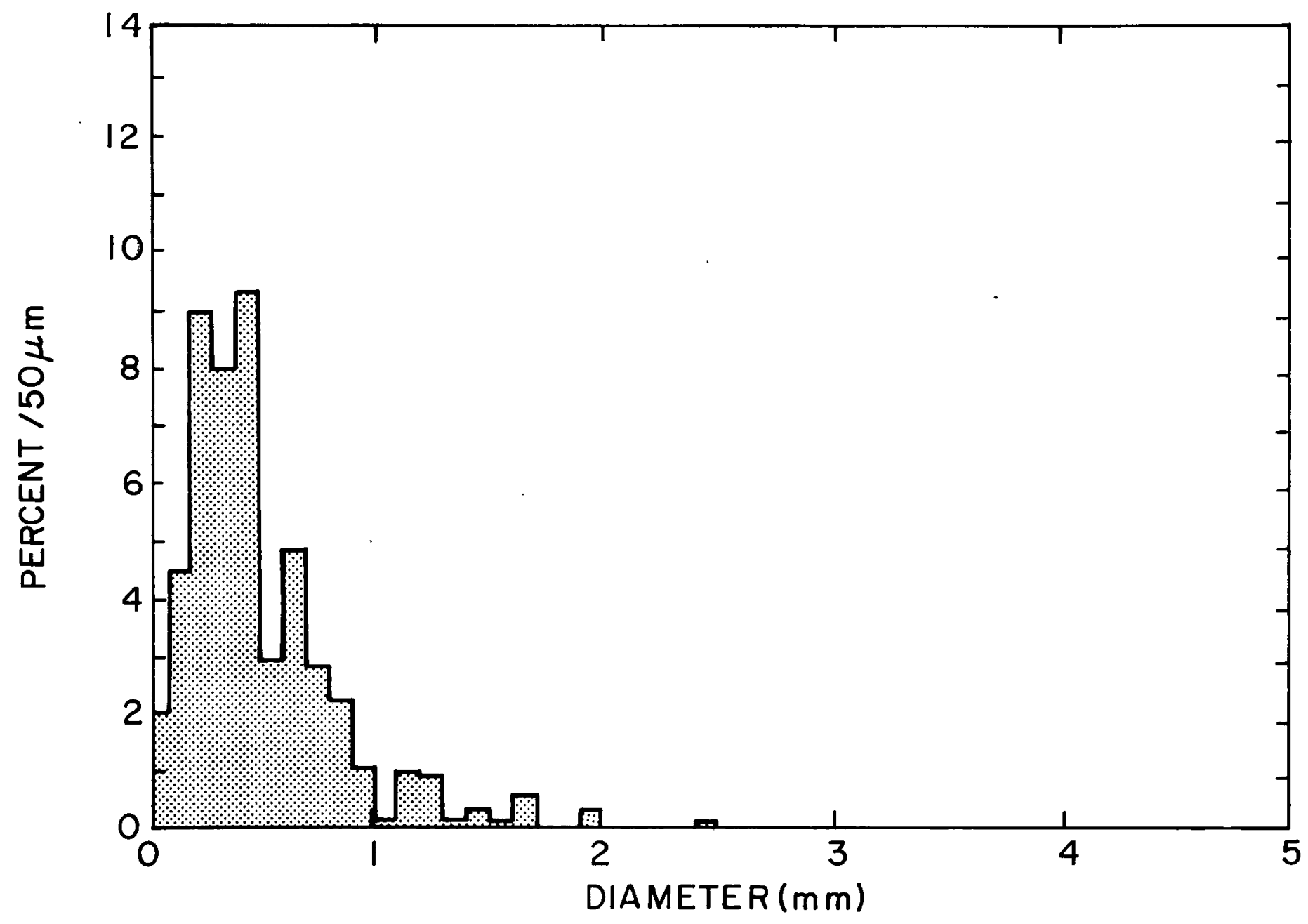

Figure 18. Size distributions of fragments from graupel. 


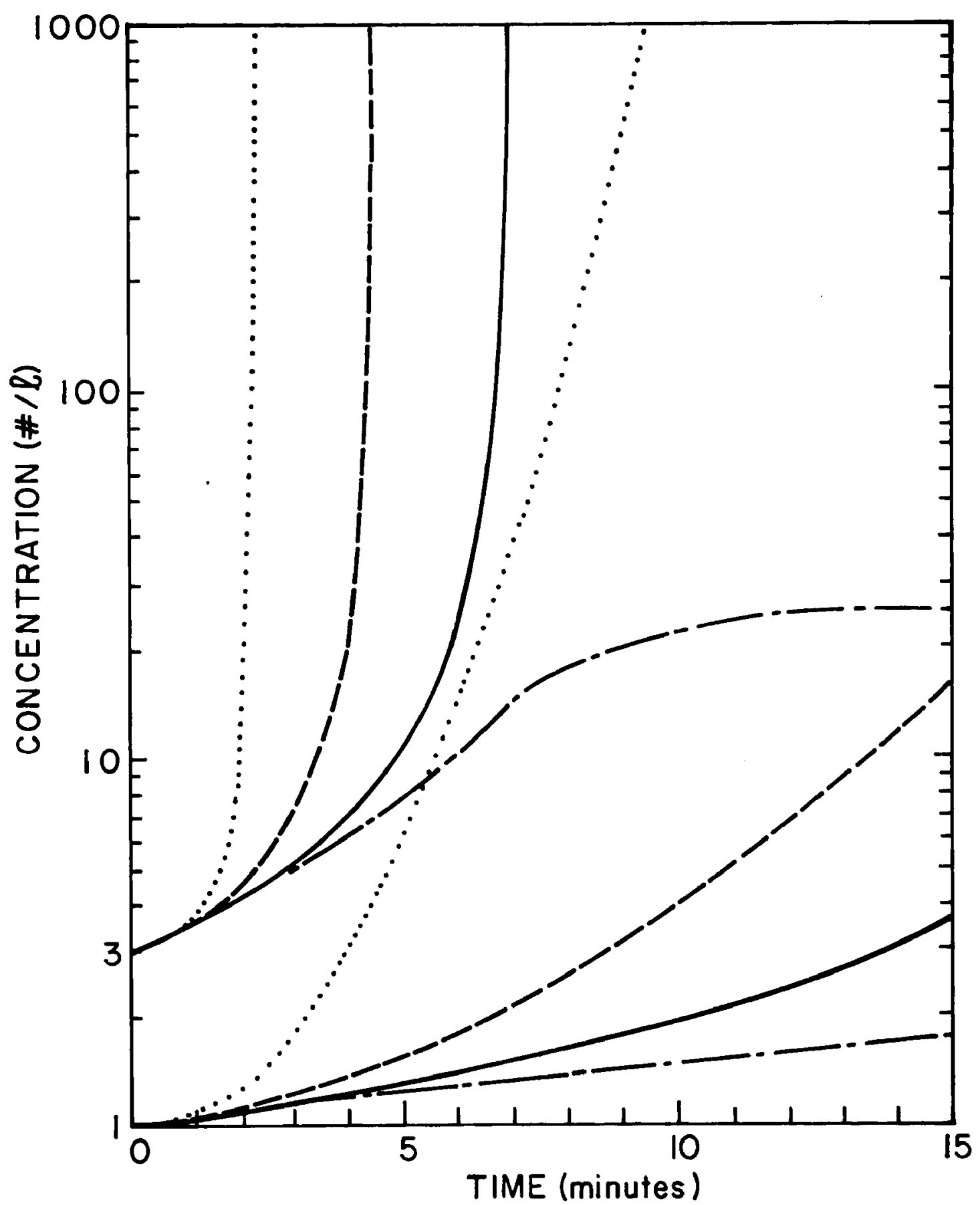

- NO ACCRETION OR DIFFUSION

$\longrightarrow K(t)=K_{0}$

- MODERATE ACCRETION AND DIFFUSION

.......... HEAVY ACCRETION AND DIFFUSION

Figure 19. Change of concentration of all crystals as a function of time for two different initial crystal concentrations and several different rates of accretion and diffusion. 

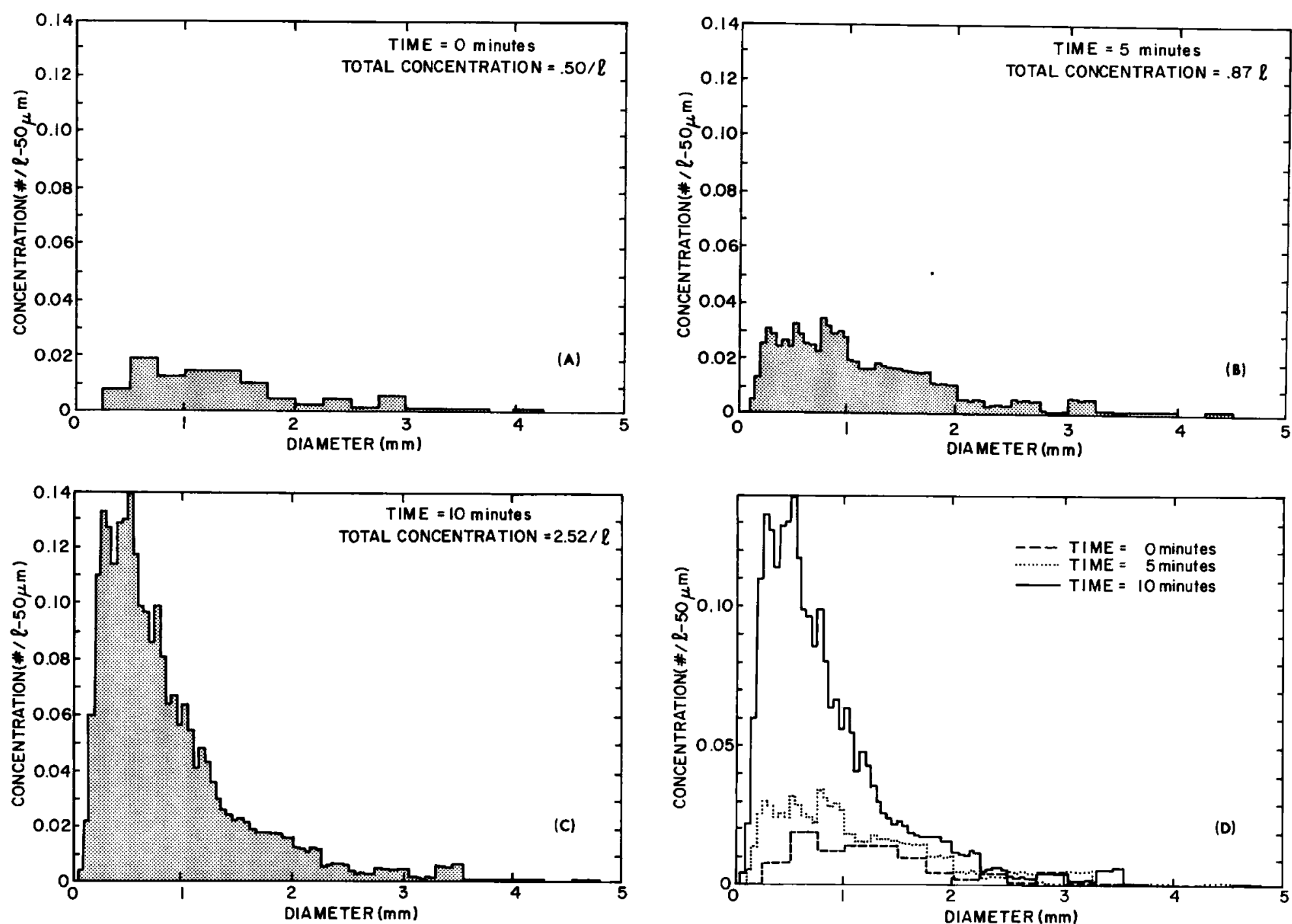

Figure 20. Change in the size distribution of heavlly-rimed plane dendrites due to collision with graupel. (a) Inttial size distribution (b) size distribution after five minutes (c) size distribution after ten minutes (d) composite of sizes distributions for all three time steps. 

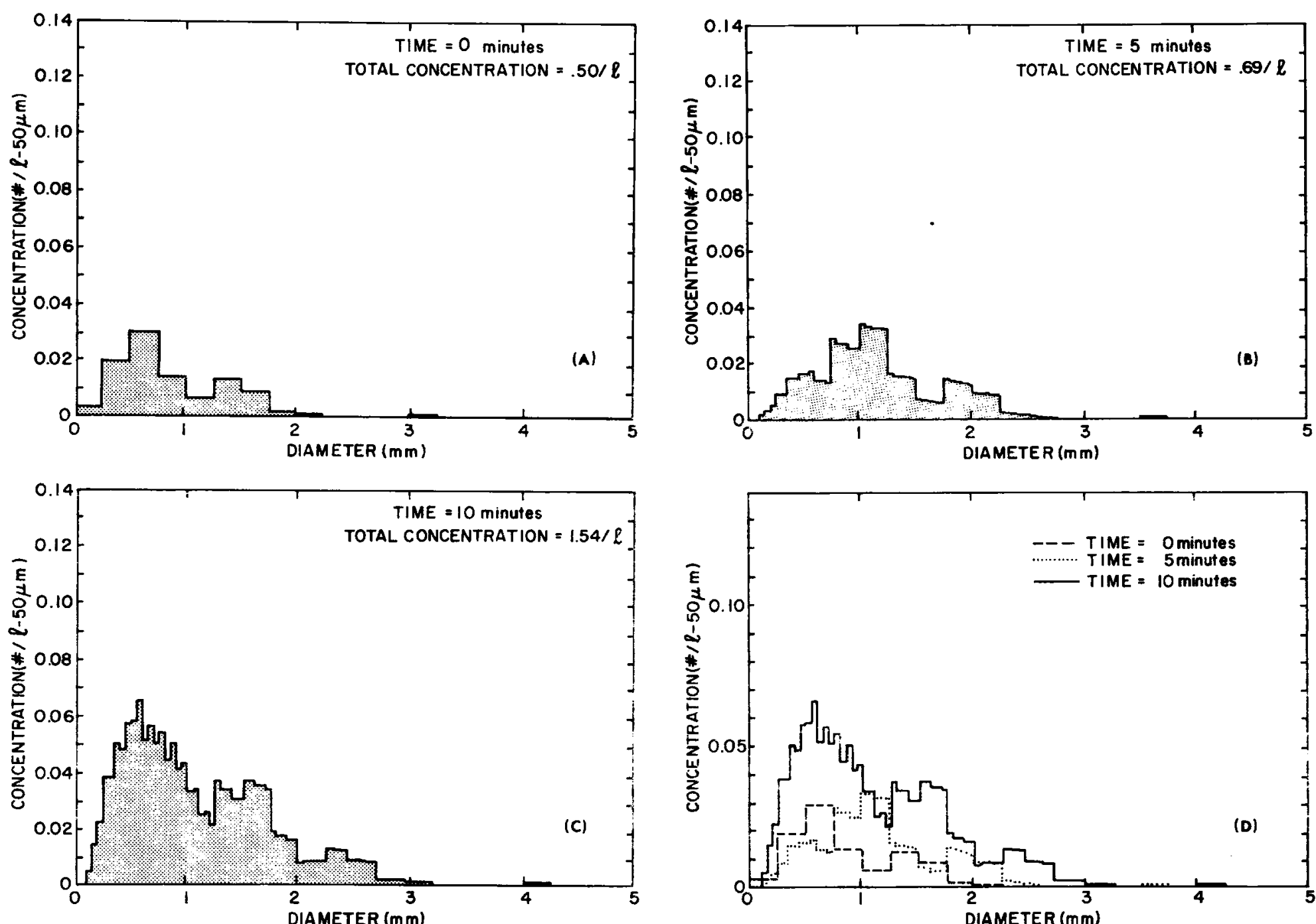

Figure 21. Change in the size distribution of graupel due to collision with heavily-rimed plane dendrites. (a) initial size distribution (b) size distribution after five minutes (c) size distribution after ten minutes (d) composite of size distributions for all three time steps. 
In a real cloud this is probably even more valid because a fragile crystal is less likely to produce fragments in a second collision of the same magnitude as the first. All or most of the fragile protrusions are broken off in the first collision.

The other curves show an increase in $C$ greater than that for $K(t)=K_{0}$ depending on the rate of accretional and diffusional growth. This effect seems physically valid because accretional and diffusional growth can maintain the size distributions and the fragility of the crystals such that $K(t)$ may actually increase. $K(t)$ was found to increase slightly at first with accretion and diffusion and then decrease but at a much slower rate than without accretion and diffusion and then decrease but at a much slower rate than without accretion and diffusion. Depending on the rate of growth by accretion and diffusion, then, the generation of secondary particles may be more or less than that estimated by assuming $K(t)=K_{0}$. For the largest growth rate likely the generation rate was found to be greater by a factor of about ten over that previously estimated. In the case of no accretion or diffusion the multiplication ratio is limited in all cases to less than a factor of ten.

It is quite informative to observe the change in crystal distribution with time as the fracturing and growth by accretion and diffusion occur. Figures 20 and 21 show the size distributions for the heavily-rimed plane dendrites and graupel respectively at 0,5 , and 10 minutes after fragmentation is assumed to begin. This example is the case for moderate accretion and diffusion with an initial concentration of 1 srystal/1iter in Figure 19. Notice the accelerating change in concentration of crystals at the small sizes and the 
regular progression of crystal concentration to larger sizes by accretion and diffusion. Apparently, the accretion and diffusion were able to cause an increase in $K(t)$ at first but the explosion of small particles eventually overwhelmed the accrelion and diffusion effects by changing the shape of the distribution drastically. In a real cloud this effect could be even more dominant because of the effect on the vapor pressure and liquid water as many small particles begin to grow. This model did not attempt to maintain a water balance. Another important restriction on the model results is the assumed diffusional growth rate at $-15^{\circ} \mathrm{C}$. If the air parcel containing the ice crystals rises or falls to another level the growth rate will fall and the secondary particle generation will be less effective. If accretional growth remains high, however, the effect could be small. 
CHAPTER V

MODEL VERIFICATION

\section{A. Introduction}

To verify the model predictions completely would require substantially more field data than is presently available. Only under special conditions can the available data be used to evaluate predictions from the model. This is true because most crystal data which have been collected are not correlated closely in time to crystal types and concentrations higher in a cloud and earlier in time relative to the collection site. A formvar replicator on the ground, for instance, collects a good sample of the crystals in cloud when no fragmentation is present. When fragmentation occurs in the cloud, however, the replicator "sees" the crystal distribution after-the-fact and does not relate the number of fragments to the conditions in the fragmentation region higher in the cloud or earlier in time.

It is even more difficult to use aircraft data because of the uncertainty in flying through the same position in the cloud at different times. In addition, when crystals are suitable for fragmentation by collision among themselves it is difficult to imagine collecting a sample by aircraft without extensive fragmentation in the collection process.

Nevertheless, some data are available from formvar replicator films taken in Colorado at the High Altitude Observatory (HAO) near Climax, Colorado, at Wolf Creek Pass in southern Colorado, and at Yellowstone National Park in Wyoming. These films have been reduced 
by projection onto a calibrated screen for size, and classified into crystal type and degree of rime. These representative samples of crystal distributions were difficult to obtain because the wind must be absolutely calm. Fragments from buildings, trees, and other surface sources can easily mask fragmentation effects in a cloud. If the crystals are rimed, even a light surface wind can cause them to collide with the entrance of the replicator and generate fragments on the film.

B. HAO and Wolf Creek Observations

Vardiman (1972) showed that ice crystal concentrations associated with convective elements embedded in winter orographic clouds frequently reach values $10^{3}-10^{4}$ greater than expected naturally from cloud top temperature and ice nucleus concentrations. In these convective elements large rimed dendrites and graupel were common, particularly at the warmer temperatures. In smooth orographic clouds without convection the crystals were much smaller and less rimed. Although only crude comparisons of observed crystal concentrations could be made to natural concentrations predicted by the model, the two concentrations appeared to agree to within a factor of ten. It is possible that the extreme concentrations observed beneath convective elements may be partly due to the increased wind speed and turbulence at the surface which causes contamination of the sample by ground sources and collection effects.

On the other hand, the model predictions are undoubtedly low due to an underestimate of the turbulent component to the collision frequency. Part of the fragmentation evident in the precipitation 
beneath convective elements must occur in the cloud however, because of the presence of regrown crystals. Regrown crystals exhibit marked changes in crystal habit or shape because of fracture and regrowth. An example of a regrown crystal is shown in Figure 22.

At Wolf Creek Pass the clouds are much wetter and frequently contain heavily-rimed crystals and graupel. Data taken near the summit of Wolf Creek Pass show fairly uniform precipitation suggesting little convection, at least near the summit. Vardiman, using a relatively sma11 number of cases, has shown that crystal concentrations agree within a factor of seven for all nonseeded storms. The crystals at Wolf Creek Pass average about 500 microns in diameter and are seldom larger than 2000 microns. Although the cry.tals are slightly larger at Wolf Creek Pass and are more heavily rimed, the fragmentation still seems to be small compared to that in convective elements.

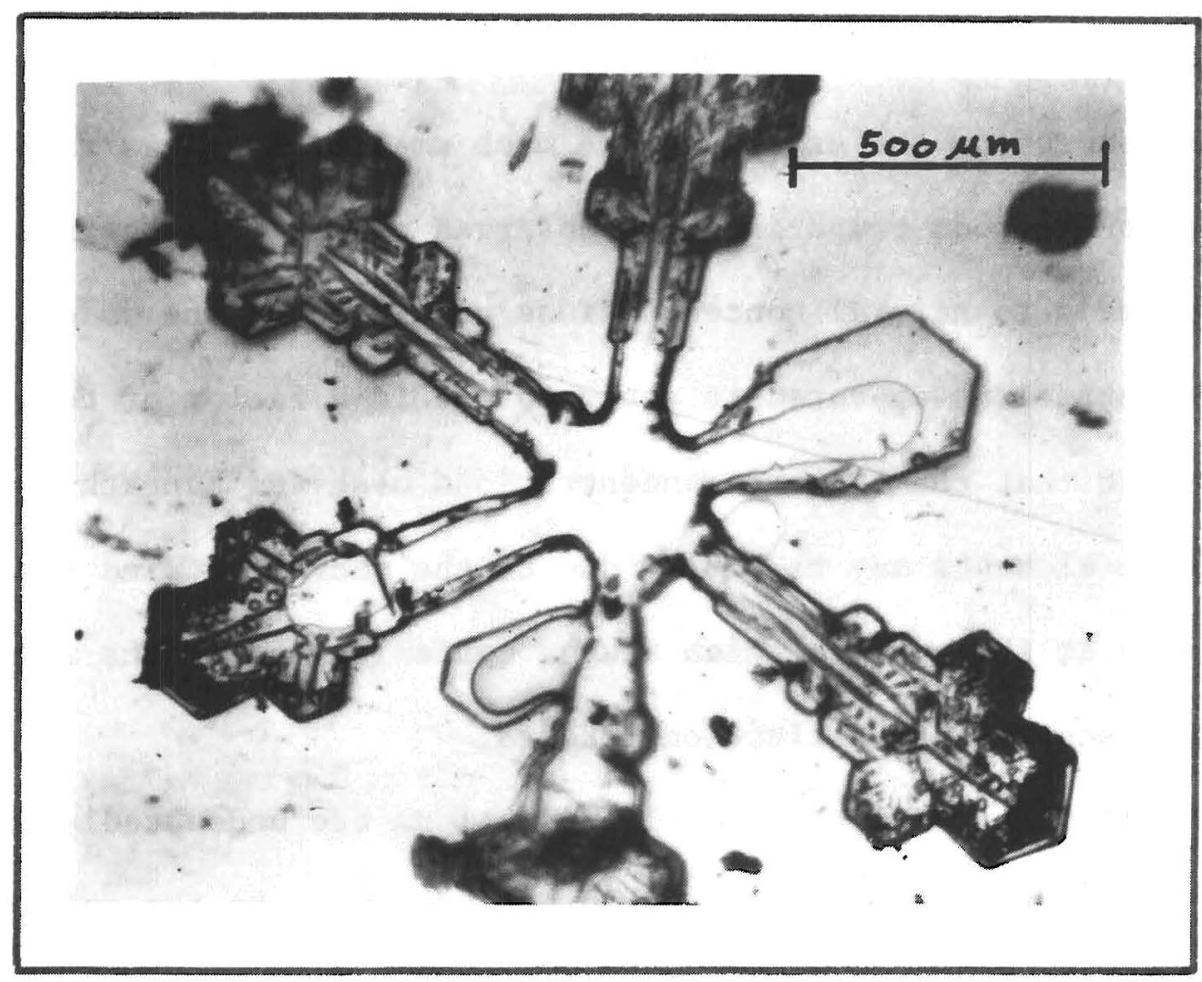

Figure 22. Regrown ice crystal collected at HAO near C1imax, Colorado. 


\section{Yellowstone Observations}

The clearest example of fragmentation in agreement with the model is a formvar replicator film taken on January 26, 1967, by the C.S.U. participating group during the Seventh Yellowstone Field Research Expedition. A short-wave trough was approaching lellowstone from the West with relatively warm, moist air being advected from the south at low levels. Cloud top was about 550 millibars with a temperature of $-16.5^{\circ} \mathrm{C}$, directly in the dendritic range. Meteorological data for this case may be found in Appendix D.

This case is a striking example because the replicator film was of top quality with a sequence of events which allows inferences to be drawn about conditions in the cloud. Figure 23 shows the concentration of different crystal types plotted with time. From 1200 MST to about 1500 MST the concentration of dendrites predominated but were below the critical value required for significant fragnentation as predicted by the model. The crystal size distribution for the model was obtained using the data between 1200 and 1500 MST. The critical concentration at which significant fragmentation would commence was found to be 10 crystals/1iter assuming half of the crystals were unrimed dendrites and half were heavily-rimed dendrites. At about 1500 MST a larger fraction of the dendrites became rimed and the concentration exceeded 10 crystals/1iter. At this point the concentration of fragments began to increase significantly. An interesting observation from the replicator film was a short five-minute period when large heavilyrimed dendrites were collected on the film. The crystals fragmented upon impact and left a fracture pattern of tens of pieces surrounding the main structure. 


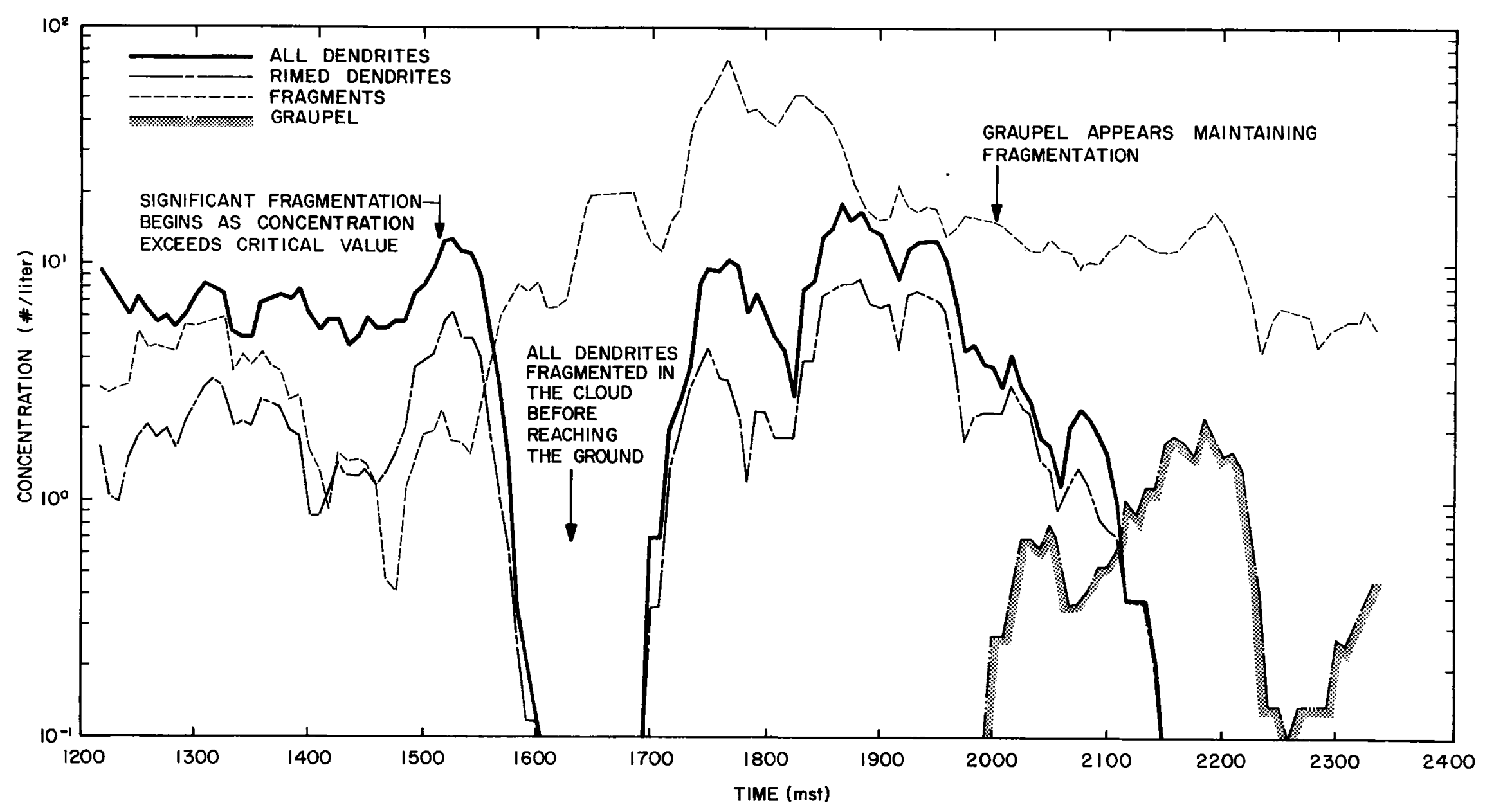

Figure 23. Plot of crystal concentration vs. time for January 26, 1967 at Yellowstone National Park, Wyoming. 
By 1600 MST the concentration of dendrites had reached zero but the concentration of fragments continued to rise to larger values. The implication of this is that the dendrites were being rimed and subsequently fragmented in the cloud before reaching the ground. of course, there are other possibilities but this explanation seems the most likely one. It is impossible to say what the maximum concentration of dendrites in the cloud was but it may have reached at least 18 crystals/liter as observed at 1840 MST. If this was the maximum concentration, then the fragmentation would have increased the concentration by a factor of four. This is consistent with the model and the observations at HAO and Wolf Creek Pass for relatively smooth clouds.

For the remainder of the period in Figure 23 inferences can not be drawn as clearly because fragmentation continues to occur in the cloud and the surface data are not completely representative. At 1700 MST the concentration of dendrites again increases suggesting that the fragmentation process has become less efficient for some reason. The trace for rimed dendrites seems to indicate that riming was somewhat less although this is not conclusive. Just before 2000 MST riming again appears to increase, even to the extent that graupel appear for the first time. As the graupel increase the concentration of dendrites again decreases inferring significant fragmentation again before the dendrites reach the ground. In this case, however, the concentration of fragments does not increase but remains uniform until the graupel concentration falls off at about $2230 \mathrm{MST}$. This is probably due to the general decline in snowfall 
intensity as the cold front approaches Yellowstone depleting the moisture and reducing the large-scale lifting.

D. Summary

These various case studies verify the model predictions quite well. The HAO and Wolf Creek Studies agree qualitatively but the Yellowstone study agrees quantitatively even to verifying the predicted critical concentration for significant fragmentation. Therefore, general conclusions about the occurrence of ice crystal fragmentation in various cloud types and conditions seem warranted. 
CHAPTER VI

\section{DISCUSSION OF RESULTS}

\section{A. General Comments}

The results of this study were somewhat different than had been expected. The presence of fragments and numerous irregular crystals beneath convective cells led to the belief that mechanical fracturing of unrimed dendrites would explain part of the observed excess in ice crystal concentrations. It was also thought that this process might possibly be general enough to explain high crystal concentrations observed in many other cloud conditions. The findings from the mode1, based on experimentally-derived fragment generation functions, eliminate further consideration of unrimed crystals as a source of more than minor numbers of in-cloud fragments. The model does predict, however, that under certain cloud conditions, significant fragmentation can occur - namely when relatively large concentrations of rimed crystals are present. Since relatively large concentrations of rimed crystals are required before secondary particle generation can proceed, this mechanism can not explain the occurrence of excess crystal concentrations at warm temperatures, as observed by Mossop. Even though mechanical fracturing of rimed crystals by crystalcrystal collision can not explain ice multiplication in general, it may still be important in certain cloud situations. Examples of likely cloud conditions would be precipitation zones and embedded convective clouds. 
B. Implications for Natura1 and Seeded Clouds

1. Stratiform Clouds

Changes in crystal concentration for natural stratiform clouds due to mechanical fracturing appear to be limited to less than a factor of ten. A stratiform cloud is probably highly self-limiting in this process. If the cloud top is not sufficiently cold to generate enough crystals from natural ice nuclei and utilize all of the condensate, the crystals will become rimed and begin to generate secondary particles by mechanical fracturing. Since the growth time is limited in the slow updraft of a normally shallow stratiform cloud, the generation of secondary particles should reach peak efficiency only near the base, and only a small fraction of the cloud will be affected by this mechanism.

Recirculation currents in a stratiform cloud such as eddies in and around mountains or embedded convection could enhance the effect of secondary particle generation. If recirculation currents are present many of the fragments generated at low levels in a cloud could be carried up to higher levels and the process amplified. Since the mechanical fracturing process is so highly dependent on the concentration of colliding particles the recirculation of fragments to higher levels could be a powerful means to increase the efficiency. Seeding a stratiform cloud which is generating secondary particles naturally by mechanical fracturing should be moderately effective in increasing the precipitation. Ice multiplication by this process should only affect the lowest portion of the cloud while seeding could affect a much larger volume. 


\section{Isolated Convective Clouds}

Convective clouds contain several features which would at first appear to make them very efficient in generating secondary particles by mechanical fracturing compared to stratiform clouds. The turbulence in a convective cloud should increase the collision frequency over that of a stratiform cloud and the collisions should be more forceful. Convective clouds normally have higher liquid water contents which allow accretion and diffusion to proceed at an accelerated pace. Crystal sizes are normally larger and many convective cells contain large graupel.

On the other hand, the updraft is sufficiently strong so that crystals do not reside in a favored growth region very long unless they are falling at the same speed as the updraft. In addition, most of the fragments are probably blown out the top and sides of a convective cloud and sublimate before being reincorporated into the cloud. The results of this study on secondary particle generation should be put into a convective cloud model before definite conclusions can be drawn, but the characteristic features of an isolated convective cloud seem to indicate that the generation of secondary particles by mechanical fracturing has little effect on the main portion of the cloud.

Seeding of an isolated convective cell would probably be effective even when secondary particle generation due to mechanical fracturing is occurring. An isolated cell lacks ice crystals at lower regions of the updraft. Seeding can provide these crystals, whereas mechanical fracturing cannot, unless there is recirculation. 


\section{Embedded Convective Clouds}

Embedded convective clouds should contain the same favorable features for secondary particle generation that isolated convective cells contain, but should also be able to retain the fragments before sublimation in the surrounding environment. Fragments generated near the sides and top of an embedded convective cell will be continually mixed into the surrounding stratiform deck or into new cells. As the fragments grow, rime, and generate new fragments in turn, the background concentration of ice crystals in the cloud will rise above that expected from natural ice nuclei. As the concentration increases, the collision frequency increases. When a relatively high crystal concentration is reached the reduced liquid water content of the cloud limits further mechanical fracturing. Crystal concentrations could reach 100 to 1000 times that expected from natural nuclei. The precipitation efficiency for this situation should be considerably higher than when no secondary particle generation occurs.

Seeding of a convective cell embedded in a stratiform cloud should be considerably less effective when ice crystal multiplication is occurring. It is conceivable that if a sufficient number of convective cells are embedded in a stratiform layer they could generate sufficient ice crystals in the stratiform deck to remove most of the available condensate. If this is the case seeding would probably not be advisable. However, if few cells are present or they are not generating sufficient crystals because of any number of reasons, then seeding could be effective. In any case, the effect of seeding should be reduced significantly when fragmentation is occurring is this cloud situation. 
C. Summary

It would seem, then, that secondary particle production by mechanical fracturing would be least important in isolated convective cells and most important in convective cells embedded in a stratiform cloud deck. Effects in a smooth stratiform cloud would be intermediate with greater effects for recirculation. Increases in crystal concentration appear to be limited to less than a factor of ten in smooth stratiform clouds but could reach 100 to 1000 in the case of embedded convection.

Because of the strong dependence of the fragment generation rate on crystal concentration, light to moderate seeding in some situations might actually initiate the fragmentation process where it would not have occurred naturally. If such opportunities exist, procedures for seeding clouds need to be restudied where the possibility of multiplication processes may be triggered. 
CHAPTER VII

\section{CONCLUSIONS AND RECOMMENDATIONS}

\section{A. Conclusions}

The purpose of this study was to experimentally determine fragment generation functions for a number of different crystal types and integrate these fragment generation functions with the respective theoretical collision frequencies. The magnitude of ice particle generation was to be estimated for various cloud conditions and the effects on natural and seeded clouds predicted. These goals have been accomplished from numerical and experimental approaches and the results are consistent with observed field measurements and concepts of cloud structure. The main conclusions of this study are:

1. Unrimed crystals do not generate significant secondary particles by mechanical fracturing.

2. The greater the degree of rime the greater the rate of secondary particle generation.

3. The broader the crystal distributions the greater the rate of secondary particle generation.

4. The combination of ice crystals which most easily produces fragments is rimed dendrites and graupel.

5. The magnitude of $\mathrm{K}$ required to generate secondary particles appears to be insufficient to generate more than a ten-fold increase in crystal concentration in most stratiform clouds.

6. Convective clouds may have $\mathrm{K}$ 's large enough to generate many more secondary particles due to larger crystals and high rates of accretion and diffusion. 
7. Continued accretion and diffusion is required to obtain ice multiplication ratios greater than ten.

\section{B. Implications for Natural and Seeded Clouds}

Isolated convective cells should not be strongly affected by the fragmentation process because the fragments would be generated near the top of the cloud and would probably be evaporated at the top or edges without being reincorporated into the cloud circulation. Unless there is recirculation of the fragments, requirements for seeding of these clouds should not be greatly altered by this process.

Smooth stratiform clouds should be moderately affected by this process near cloud base if riming is present. Increases in crystal concentration appear to be limited to less than a factor of ten unless recirculation of the fragments to higher levels of the cloud can occur. Seeding requirements should be reduced by this process but probably not greatly in most cases.

Convective cells embedded in a stratiform layer appear to provide the greatest opportunity for secondary particle generation by mechanical fracturing. The fragments would be generated at the top of a convective cell which could then be recirculated in the cell or dispersed out into the surrounding stratiform deck. By continued riming, fragmentation, and recirculation the crystal concentration could reach 100 to 1000 times the natural concentration. Where the process is operating efficiently, seeding should add very little additional precipitation over that which occurs naturally. 


\section{Recommendations}

Field verification of secondary particle generation by mechanical fracturing should be continued. The most promfsing avelus if investigation would seem to be in alycraft probing or the liswo:

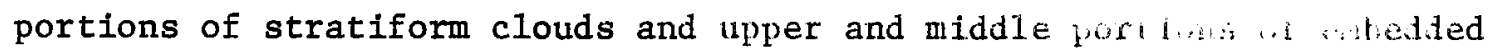
convective clouds. If the ice crystal concentration, lyos, ant rince could be mapped in time and space in and around these regions of the clouds, it is likely that the source region for crystal fragrents could be identified. This region of the cloud is very difficul $\ldots$ rly, however, because of the heavy rime. A specially modified aircraft must be used for this type of study. In addition, the instruncilation for collecting or observing ice crystals must be inproved t: feitult as little fragmentation as possible in the collection provesi.

Ground observations are of limited usefulness becalus they require so many inferences to be drawn about conditions in th: a l.w. Observations taken prior to the beginning of fragmentation ate the only reliable indicators of conditions necessary for fragtiental isu. After fragmentation begins the primary crystal types, sizes, degree of rime, and concentrations in the cloud cannot be deternined.

A statistical study of the precipitation efficitery in sliatiform clouds with and without convection should be conducted ro deterijne the role of embedded convection on natural precipitation. Hon wla wio ice multiplication the embedded convection should increase the precipitation efficiency by increased mixing of ice crystals and supercooled cloud. However, the generation of secondary particles should greatly increase the efficiency. A stratification into seeded 
and nonseeded classes should also be quite interesting. The increase in precipitation by seeding should be considerably less for embedded convection in stratiform clouds. 
REFERENCES

Abbas, M. A., and J. Latham, 1969: The Electrofreezing of Supercooled Water Drops. Journal of the Meteorological Society of Japan, 47, $65-74$.

Auer, A.H., Jr., D.L. Vea1, and J.D. Marwitz, 1969: Observations of Ice Crystal and Ice Nuclei Concentrations in Stable Cap clouds. Journal of the Atmospheric Science, 26, 1342-1343.

Austin, P.M., and M.J. Kraus, 1968: Snowflake Aggregation - A Numerica1 Model. Proceedings of the International Conference on liloud Physics, Toronto, 300-304.

Bergeron, T., 1933: On the Physics of Clouds and Precipitcition. Proceedings of the Fifth Assembly U.G.G.I. Lisbon, $156-1 \% 8$.

Berry, E.X., 1967: Cloud Droplet Growth by Collection. Journal of the Atmospheric Sciences, 24, 688-701.

Braham, R.R., Jr., 1967: Cirrus Cloud Seeding as a Trigger for Storm Development. Journal of the Atmospheric Sciences, 24, 311-312.

Brewer, A.W., and H.P. Palmer, 1949: Condensation Processes at Low Temperatures and the Production of New Sublimation Nuslei by the Splintering of Ice. Nature, 164, 312-313.

Brown, S.R., 1970: Terminal Velocities of Ice Crystals. Atmospheric Science Paper No. 170, Colorado State University, Furt Collins, Colorado.

Brownscomb, J.L., and N.S.C. Thorndike, 1968: Freezing and shattering of Water Droplets in Free Fall. Nature, 220, 687-689.

Campbel1, N., 1952: What is Science? Dover Publications, Inc.

Cross, J.D., 1969: Scanning of Electron Microscopy of Evaporating Ice, Science, $164,174-175$.

DeMichelli, S.M., and A.R., Licenblat, 1967: Ice Whiskers Grown in Substrated Atmospheres. Journal of Atmospheric Science, 24, 312-315.

Findeisen, W., 1943: Untersuchungen uber die Eissplitterbildung an Reifschichten. Meteorologische Zeitschenft, 5, 145-154.

Fletcher, N.H., 1962: The Physics of Rainclouds, Cambridge University Press.

Fukuta, N., 1969: Experimental Studies on the Growth of Sma11 Ice Crystals. JAS, 26, 522 . 
Gagin, A., 1971: Studies of the Factors Governing the Colloidal Stability of Continental Cumulus Clouds. International Conference on Weather Modification, Camberra, 5-11.

Gokhale, N.R., and F. Goold, Jr., 1968: Droplet Freezing by Surface Nucleation. Journal of Applied Meteorology, 7, 870-874.

Grant, L.0., 1968: The Role of Ice Nuclei in the Formation of Precipitation. Proceedings of the International Conference on Cloud Physics, Toronto, 305-310.

, and R.E. Elliott, 1974: The Cloud Seeding Temperature Window. Journal of Applied Meteorology, 13, 355-363.

Hallett, J., 1965: Field and Laboratory Observations of Ice Crystal Growth from the Vapor. JAS, 22, 64 .

, and S.C. Mossop, 1974: Production of Secondary ice Particles During the Riming Process. Nature, 294-323.

Henmi, T., 1974: Secondary Ice Particle Production from Rimed Ice. Ph.D Dissertation, Colorado State University, Fort Collins, Colorado.

Hindman, E.E., II, and D.B. Johnson, 1972: Numerical Simulation of Ice Particle Growth in a Cloud of Supercooled Water Droplets. JAS, 29, 1313.

Hobbs, P.V., 1969: Ice Multiplication in Clouds. Journal of the Atmospheric Sciences, 26, 315-318.

, and A.J. Alkezweeny, 1968: The Fragmentation of Freezing Water Droplets in Free Fall. Journal of Atmospheric Science, 25, 881-888.

, and R.J. Farber, 1972: Fragmentation of Ice Particles in Clouds. H. Dessens Memorial Volume, Journal of Atmospheric Recherches, 6, 245-258.

Jayaweera, K.0.L.F., 1971: Calculations of Ice Crystal Growth. JAS, 28,728 .

Juisto, J., 1968: Snow Crystal Development in Supercooled Clouds. Proceedings of the First National Conference on Weather Modification, Albany, 287.

Johnson, D.A., 1972: The Production of Ice Splinters by the Freezing of Accreted Water Drops. The International Cloud Physics Conference, London, 27-28.

, and J. Hallett, 1968: Freezing and Shattering of Supercooled Water Drops. Quarterly Journal of the Royal Meteorological Society, 94, 463-482. 
Kepler, J., 1611: The Six-Cornered Snowflake. Oxford at the Clarendon Press.

Koenig, L.R., 1963: The Glaciating Behavior of Small Cumulonimbus Clouds. Journal of Atmospheric Science, 20, 29-47.

, 1968: Some Observations Suggesting Ice Multiplication in the Atmosphere. Journal of Atmospheric Science, 25, 460-463.

226 . , 1971: Numerical Modeling of Ice Deposition. JAS, 28,

Langmuir, I., 1948: The Production of Rain by a Chain Reaction in Cumulus Clouds at Temperatures Above Freezing. Journal of Meteorology, 5, 175.

Marwitz, J.D., and A.H. Auer, Jr., 1968: Ice Crysta1 Growth by Diffusion and Accretion. Proceedings of the International Conference on Cloud Physics, Toronto, 249.

Mason, B.J., 1955: The Physics of Natural Precipitation Processes. Arch. Met. Geophys. Bioklim., A8, 159-207.

, 1971: The Physics of Clouds, Clarendon Press.

Mossop, S.C., 1968: Comparisons Between Concentration of Ice Crysta1s in Cloud and Concentration of Ice Nuclei. Journal de Recherches Atmospheriques, 4, 119-124.

, 1971: The Multiplication of Ice Crystals in Clouds, Proceedings of the International Conference on Weather Modification, Canberra, Australia, 1-4.

A. Ono, and K.J. Heffernan, 1967: Studies of Ice Crystals in Natural Clouds. Journal de Recherches Atmospheriques, $3,45-64$.

, and 1969: Measurements of Ice Crystal Concentration in Clouds. Journal of Atmospheric Science, 26, 130137 .

, Maritime Clouds Near Tasmania. Quarterly Journal of the Royal Meteorological Society, 96, 487-508.

, R.E. Cottis, and B.M. Bartlett, 1972: Ice Crysta1 Concentration in Cumulus and Stratocumulus. Quarterly Journal of the Roya1 Meteorologica1 Society, 98, 487-508.

, R.E. Ruskin, and K.J. Wishart, 1968: Glaciation of a Cumulus at Approximately $-4^{\circ} \mathrm{C}$. Journal of Atmospheric Science, 25, 889-899. 
Nakaya, U., 1954: Snow Crystals. Harvard University Press.

Newton, I., 1686: Philosophiae Naturalis Principia Mathematica. University of California Press.

Ono, A., 1973: Some Aspects of the Ice Phase Development in Relatively Warm Supercooled Maritime Cumulus Clouds with Special Attention to Small Regular Ice Crystals. Paper presented at the Seminar on Cumulonimbus Modification of Tropical Nature, Miami.

Roberts, P., and J. Hallett, 1968: A Laboratory Study of the Ice Nucleating Properties of Some Mineral Particulates. Quarterly Journal of the Royal Meteorological Society, 94, 25-34.

Ruskin, R.H., 1969: Multiplication of Ice Embryos by Ice Whisker Shedding, Science, 166, 906.

Schaeffer, V.J., and R.J. Cheng, 1971: The Production of Ice Crystal Fragments by Sublimination and Electrification. Journal de Recherches Atmospheriques, 5, 5-10.

Sears, F.W., and M.W. Zemansky, 1957: University Physics, Addison Wesley Publishing Company, Inc., p. 149.

Takahashi, C. and A. Yamashita, 1970: Shattering of Frozen Water Drops in a Supercooled Cloud. Journal of the Meteorological Society of Japan, 48, 373-376.

Takeda, T., 1968: Solid Prescipitation in Supercooled Cloud: Part 2Growth of a Solid Precipitation Particle. J. Meteor. Soc. Japan, $46,4,255$.

, 1968: The Effect of the Time Lag in the Activation of Atmospheric Ice Nuclei on the Number of Ice Crystals in Clouds. Journal of the Meteorological Society of Japan, 46, 69-76.

Twomey, S., 1966: Computations of Rain Formation by Coalescence. Journal of the Atmospheric Sciences, 23, 405-411.

Vardiman, L., 1972: Ice Crystal Multiplication in Convective Elements of Winter Orographic Clouds. Atmospheric Science Paper No. 191, Department of Atmospheric Science, Colorado State University, Fort Collins, Colorado.

, G. Mulvey, and C. Hartze11, 1974: An Investigation of Precipitating Ice Crystals from Natural and Seeded Winter Orographic Clouds. Proceed. Fourth Weather Modification Conference, Fort Lauderdale.

Warner. J., and T.D. Newnham, 1958: Time Lag in Ice Crystal Nucleation in the Atmosphere. Bulletin de l'Observatoire du Puy de Dome, 1, $1-10$. 
Zikmunda, J. and G. Val1, 1972: Fall Patterns and Fall Velocities of Rimed Ice Crystals. J. Atmos. Sci., 29, 1334. 


\section{APPENDIX A}

\section{DERIVATION OF AVERAGE CHANGE IN MOMENTUM}

When two particles collide in a cloud each particle experiences a change in momentum dependent on the masses of the two particles, the relative velocities, the coefficient of restitution, and the collision configuration. The first three variables have been treated in the main text but here the effect of collision configuration will be investigated.

The collision configuration is a function of the crystal shapes and the distance between the centers of mass upon impact. The crystal shapes will be assumed to be of secondary importance for this deviation and will be assumed spherical. Figure A-1 shows the importance of parameter $X$, the horizontal distance between the centers of mass.

The parameter $\mathrm{X}$, in Figure $\mathrm{A}-1$ is zero when the two particles collide center-to-center and a maximum, equal to $r_{1}+r_{2}$, when the particles collide at a grazing blow. The direction of impact is vertical for a center-to-center collision and horizontal for a grazing blow. Figure A-I shows the separation of the terminal velocities into components relative to the direction of impact. The angle between the vertical and the direction of impact, $\theta$, may be expressed as follows:

$$
\operatorname{Cos} \theta=\frac{\sqrt{\left(r_{1}+r_{2}\right)^{2}-x^{2}}}{r_{1}+r_{2}}=\sqrt{1-\frac{x^{2}}{\left(r_{1}+r_{2}\right)^{2}}}
$$

where $r_{1}$ and $r_{2}$ are the radii of the two particles and $X$ is the horizontal distance between the center of masses. The relative 


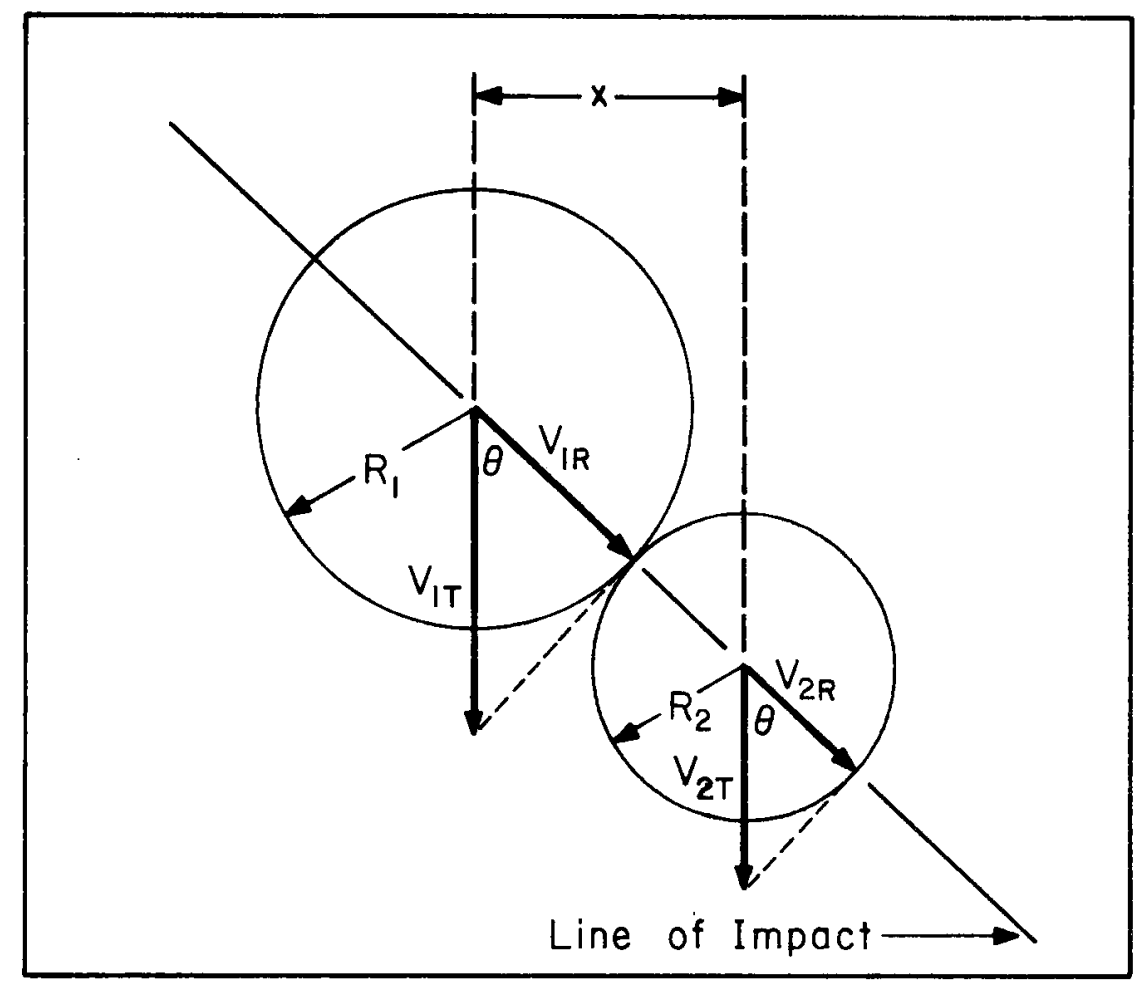

Figure A-1. Collision configuration of two crystals used to determine the most-1ikely change of momentum.

velocities of the two particles along the direction of impact may be expressed:

$$
\begin{aligned}
& \mathrm{v}_{1 \mathrm{R}}=\mathrm{v}_{1 \mathrm{~T}} \cos \theta=\mathrm{v}_{1 \mathrm{~T}} \sqrt{1-\frac{\mathrm{x}^{2}}{\left(\mathrm{r}_{1}+\mathrm{r}_{2}\right)^{2}}} \\
& \mathrm{v}_{2 \mathrm{R}}=\mathrm{v}_{2 \mathrm{~T}} \cos \theta=\mathrm{v}_{2 \mathrm{~T}} \sqrt{1-\frac{\mathrm{x}^{2}}{\left(\mathrm{r}_{1}+\mathrm{r}_{2}\right)^{2}}}
\end{aligned}
$$

where $V_{1 R}$ and $V_{2 R}$ are the velocities of the two particles in the direction of impact and $V_{1 T}$ and $V_{2 T}$ are the terminal velocities of the two particles. 
The change in momentum may be expressed as in Equation (8) of Chapter II using different notation and velocities relative to the direction of impact rather than center-to-center.

$$
\Delta M=\frac{m_{1} m_{2}}{m_{1}+m_{2}}\{1+e\}\left\{v_{2 R}-v_{1 R}\right\}
$$

where $e$ is the coefficient of restitution. Substituting (A-2) and $(A-3)$ into $(A-4)$,

$$
\begin{aligned}
\Delta M= & \frac{m_{1} m_{2}}{m_{1}+m_{2}}\{1+e\}\left\{v_{2 T} \sqrt{1-\frac{x^{2}}{\left(r_{1}+r_{2}\right)^{2}}}\right. \\
& \left.-v_{1 T} \sqrt{1-\frac{x^{2}}{\left(r_{1}+r_{2}\right)^{2}}}\right\}
\end{aligned}
$$

Simplifying Equation (A-5) gives:

$$
\Delta M=\sqrt{1-\frac{x^{2}}{\left(r_{1}+r_{2}\right)^{2}}}\left\{\frac{m_{1} m_{2}}{m_{1}+m_{2}}(1+e)\left(v_{2 T}-v_{1 T}\right)\right\}
$$

The portion of Equation $(A-6)$ in brackets was shown to be the change in momentum due to a center-to-center collision and therefore the maximum change possible. Define:

$$
\Delta M_{M A X}=\frac{m_{1} m_{2}}{m_{1}+m_{2}}\{1+e\}\left\{v_{2 T}-v_{1 T}\right\}
$$

Therefore:

$$
\Delta M=\sqrt{1-\frac{x^{2}}{\left(r_{1}+r_{2}\right)^{2}}} \Delta M_{M A X}
$$


Now, the expected value of $\Delta M$ given two particles of radii $r_{1}$ and $r_{2}$ is:

$$
<\Delta M>=\int_{0}^{X} \Delta M(X) P(X) d X
$$

where $P(X)$ is the probability density function of $X$. For ordered collisions where no wake effects are present $P(X)$ is uniform over the interval $r_{1}+r_{2}$. Although $P(X)$ is not uniform in a real cloud, we have already argued that for small crystals and small relative velocities where the wake effects are most important, the generation of crystal fragments is the smallest. Therefore $P(X)$ will be assumed uniform.

$$
P(X)=\frac{1}{r_{1}+r_{2}}
$$

Equation $(A-9)$ becomes:

$$
\langle\Delta M(X)\rangle=\int_{0}^{r_{1}+r_{2}} \sqrt{1-\frac{x^{2}}{\left(r_{1}+r_{2}\right)^{2}}} \Delta M_{M A X}\left(\frac{1}{r_{1}+r_{2}}\right) d X \cdot(A-11)
$$

Let:

$$
a=r_{1}+r_{2}
$$

Then:

$$
\left\langle\Delta M(X)>=\frac{\Delta M M A X}{a^{2}} \int_{0}^{a} \sqrt{a^{2}-x^{2}} d x\right.
$$

Finally:

$$
\langle\Delta M(X)\rangle=\frac{\pi}{4} \Delta M_{M A X}
$$


Therefore, the average change in momentum for all possible collision configurations is simply $\pi / 4$ times the momentum change for a center-to-center collision. 
APPENDIX B

DETERMINATION OF THE COEFFICIENT OF RESTITUTION

IN A COLLISION WITH A FIXED PLATE

Equation (29) of Chapter II gives the basic formula for finding the coefficient of restitution in a collision with a fixed plate. This equation can be simplified further under special conditions. Assuming a particle approaches the fixed plate with a trajectory perpendicular to the surface, then only the vertical or $w$ component is present. For this special condition the formula for obtaining e may be written:

$$
e=-\frac{w_{f}}{w_{o}}
$$

where $w_{o}$ and $w_{f}$ are the vertical velocities of the particle before and after the collision respectively. The same equation may be used for the case where the particle approaches the plate in a nearlyvertical direction or where the change in velocity in directions other than vertical are negligible. The experiments to obtain e were designed to provide nearly vertical trajectories in most cases and in all cases to minimize the horizontal change in momentum. Therefore, Equation $(B-1)$ is a good approximation and simplifies the determination of $e$.

The high-speed camera used to observe the collisions was operated at $\sim 100$ frames per second. This speed did not allow the observation of the crystal velocity immediately after impact in most cases. The retarding effect of gravity and drag slowed the particle before the camera was able to take a picture after the collision. The retarding 
effect depended on the speed of the particle, its size, shape, and mass, and the time elapsed between the collision and the picture. However, the velocity of the particle could be obtained by integrating back in time given two positions and velocities of the particle after the collision.

The basic equation for integrating the trajectory is the equation of motion for the particle:

$$
m \frac{d \vec{v}}{d t}=\vec{F}_{g}+\vec{F}_{D}
$$

where $m$ is the mass of the particle, $\vec{v}$ is the total velocity of the particle, and $\vec{F}_{\mathrm{g}}$ and $\overrightarrow{\mathrm{F}}_{\mathrm{D}}$ are the retarding forces on the particle due to gravity and drag respectively. Assuming a Cartesian frame of reference and no components of velocity in the Y-direction the gravitation force may be expressed:

$$
\overrightarrow{\mathrm{F}}_{\mathrm{g}}=-\mathrm{mg \hat {k }}
$$

where $\mathrm{g}$ is the gravitational constant and $\hat{\mathrm{k}}$ is the unit vector in the vertical direction, positive upward. The drag force may be written:

$$
\overrightarrow{\mathrm{F}}_{D}=-\frac{1}{2} C_{D} \rho A|\vec{v}-\vec{c}|(\vec{v}-\vec{c})
$$

where $C_{D}$ is the drag coefficient, $A$ is the cross sectional area of the particle in the direction of the motion, and $\vec{c}$ is the wind velocity. The drag force only acts when there is motion relative to the air, thus Equation $(B-4)$ is written in terms of $(\vec{v}-\vec{c})$ rather than $\vec{v}$. Equation $(B-4)$ may be simplified by assuming that the 
particle motion is in the Stoke's regime. This is not valid for the larger particles but is a reasonable approximation for the majority of particles and nearly all of the fragments. With this assumption:

$$
C_{D}=\frac{K^{\prime}}{R e}
$$

where $K^{\prime}$ is a constant and $R e$ is the Reynold's number. But, the Reynold's number may be written:

$$
\operatorname{Re}=\mathrm{D}|\overrightarrow{\mathrm{v}}-\vec{c}| \rho / \mu
$$

where $D$ is the particle diameter, $\rho$ is the air density and $\mu$ is the viscosity. The drag force then becomes:

$$
\vec{F}_{D}=-K^{\prime \prime} D(\vec{v}-\vec{c})
$$

where $K^{\prime \prime}$ is a new constant composed of the previous constants and the viscosity, $\mu$. Equation (B-2) finally becomes:

$$
\frac{d \vec{v}}{d t}=-g \hat{k}-\frac{K^{\prime \prime} D}{m}(\vec{v}-\vec{c})
$$

Breaking this vector equation into its component equations, assuming no component in the Y-direction:

$$
\begin{aligned}
& \frac{d u}{d t}=-\frac{K^{\prime \prime}}{m} D(u-c) \\
& \frac{d w}{d t}=-g-\frac{K^{\prime \prime} D}{m} w
\end{aligned}
$$

where $\mathrm{u}$ is the horizontal speed, $\mathrm{w}$ is the vertical speed, and $\mathrm{c}$ is the horizontal wind speed. 
The u-equation may be solved to obtain $\mathrm{K}^{\prime \prime}$.

$$
K^{\prime \prime}=\frac{m}{D\left(t_{2}-t_{1}\right)} \ln \left(\frac{u_{1}-c}{u_{2}-c}\right)
$$

where the subscripts refer to points in the trajectory after the collision, shown in Figure $B-1$.

The horizontal wind speed, $c$, is assumed constant during the collision and may be obtained by:

$$
c=v_{0} \cos \phi_{0}
$$

Once $\mathrm{K}^{\prime \prime}$ has been obtained from the u-equations, it may be substituted back into the w-equation and the time dependence for $w$ obtained. The vertical velocity immediately after the collision, $w_{f}$, is the desired variable.

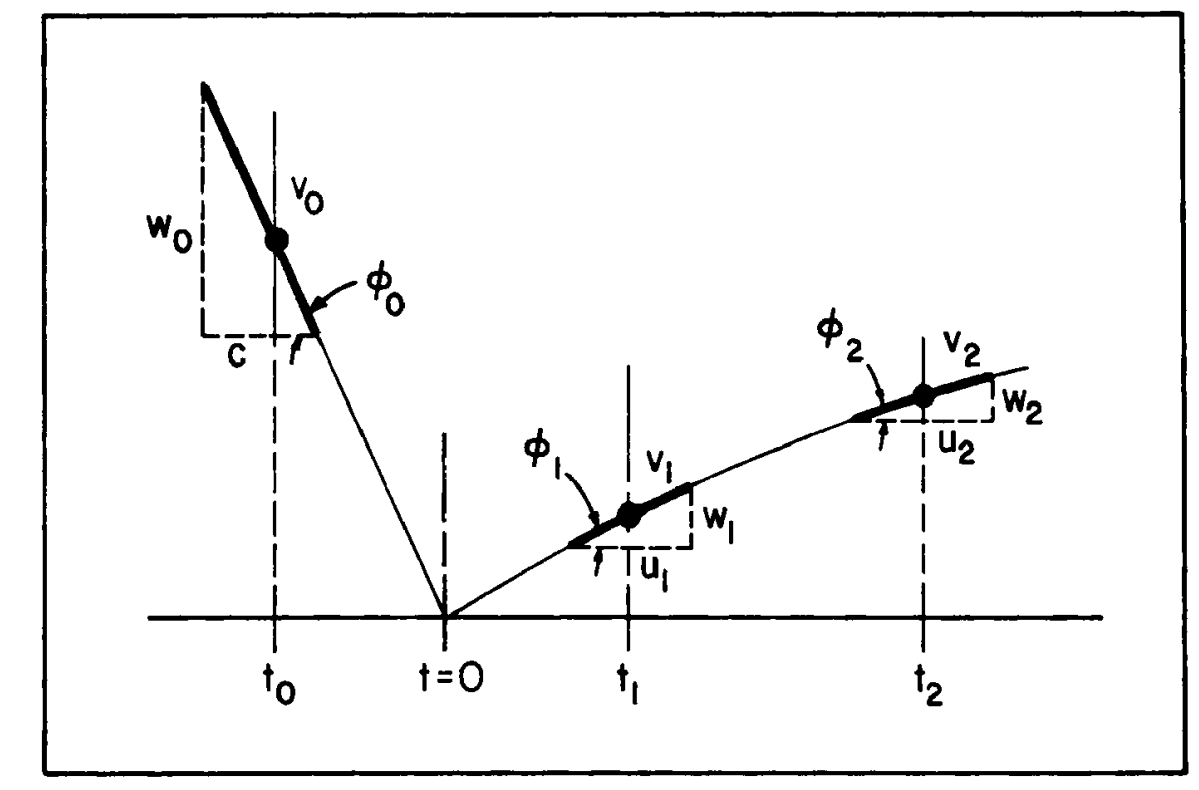

Figure B-1. Collision trajectory with times, angles, and velocities before and for two frames after collision with a fixed plate. 


$$
w_{f}=\frac{m}{K^{\prime \prime} D}\left\{-g+\left(g+\frac{K^{\prime \prime} D}{m} w_{1}\right) e^{\frac{K_{1}}{m}}\right\}
$$

The vertical velocity before collision is simply:

$$
\mathrm{w}_{0}=\mathrm{v}_{0} \sin \phi_{0}
$$

If a particle remained in one piece after the collision, the determination of e would be simply the division of $w_{f}$ by $w_{o} \cdot$ However, from one to thirteen fragments were observed after the collision for graupe1. Therefore, a valid scheme must be found to account for the fragmentation.

The first adjustment is in the estimation of mass after the collision. The sum of the masses for individual particles after the collision should equal the mass of the initial particle. However, due to errors in measuring the particle diameters the masses do not normally balance. To correct for this error, the mass of the initial particle is assumed correct and the masses of the particles after collision weighted so that the sum equals the initial mass.

The second adjustment is to obtain a mass-weighted final velocity which is equivalent to a single-particle velocity of the same mass. The formula used for this computation is:

$$
\overline{\mathrm{w}}_{\mathrm{f}}=\sum_{i=1}^{\mathrm{N}} \frac{\mathrm{m}}{\mathrm{m}}_{\mathrm{m}} \mathrm{w}_{\mathrm{fi}}
$$

where $\bar{w}_{f}$ is a mass-weighted final vertical velocity, $m_{1}$ is the adjusted mass of an individual fragment after collision, $m_{0}$ is the mass of the initial particle, $w_{f i}$ is the final vertical velocity 
of a fragment after collision, and $\mathrm{N}$ is the number of fragments for a given collision.

The coefficient of restitution, e, for a single collision of a particle with a fixed plate, is then:

$$
e=-\frac{\bar{w}_{f}}{w_{o}} \text {. }
$$

These computations were done for 88 collisions of graupel with the fixed plate and an average e of .37 was obtained. It ranged from .08 to .96 with a standard deviation of .22 . 


\section{APPENDIX C}

\section{DETERMINATION OF FALL VELOCITIES}

The fall velocity of an ice crystal is one of the most fundamental parameters used in the microphysics of clouds. However, reliable equations relating fall velocity to crystal size have yet to be determined for many crystal types. This is particularly true of rimed crystals. Nakaya (1954) provided some data for different degrees of riming on a few crystal types, but the number of data points were so few, and the classification of rime so ill-defined that I decided to use recent data obtained in association with the determination of the fragment generation functions.

Vertical velocities were required in computing the change in momentum when a crystal underwent collision with the fixed plate. These crystals were falling at or near terminal velocity. The crystals were divided into four categories depending on the general amount of rime in a given sample. The crystals were not classified on an individual basis, therefore considerable scatter would be expected in the results.

The results for 1ight-moderate rimed plane dendrites is shown in Figure C-1. A least-squares polynomial was fitted to the data and a correlation coefficient of .59 was found. The equation was:

$$
v=9.395 \mathrm{D}^{.301}
$$

The same analysis was done for heavily-rimed plane dendrites shown in Figure $(\mathrm{C}-2)$. The correlation coefficient in this case was quite low at .36 . The equation was: 


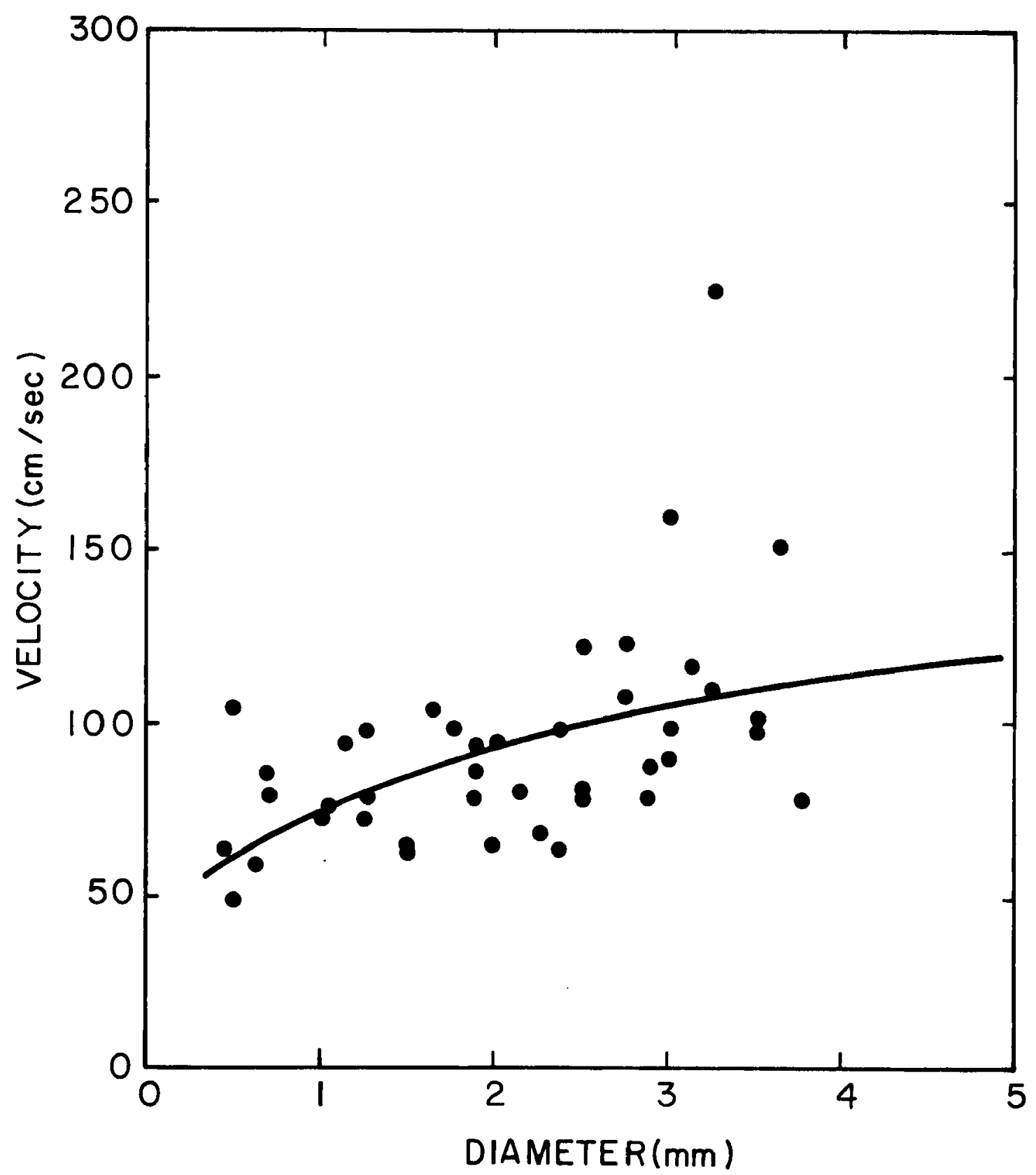

Figure C-1. Observed terminal fall velocities for lightly-rimed plane dendrites. The correlation coefficient for the leastsquares fit was .59 . 


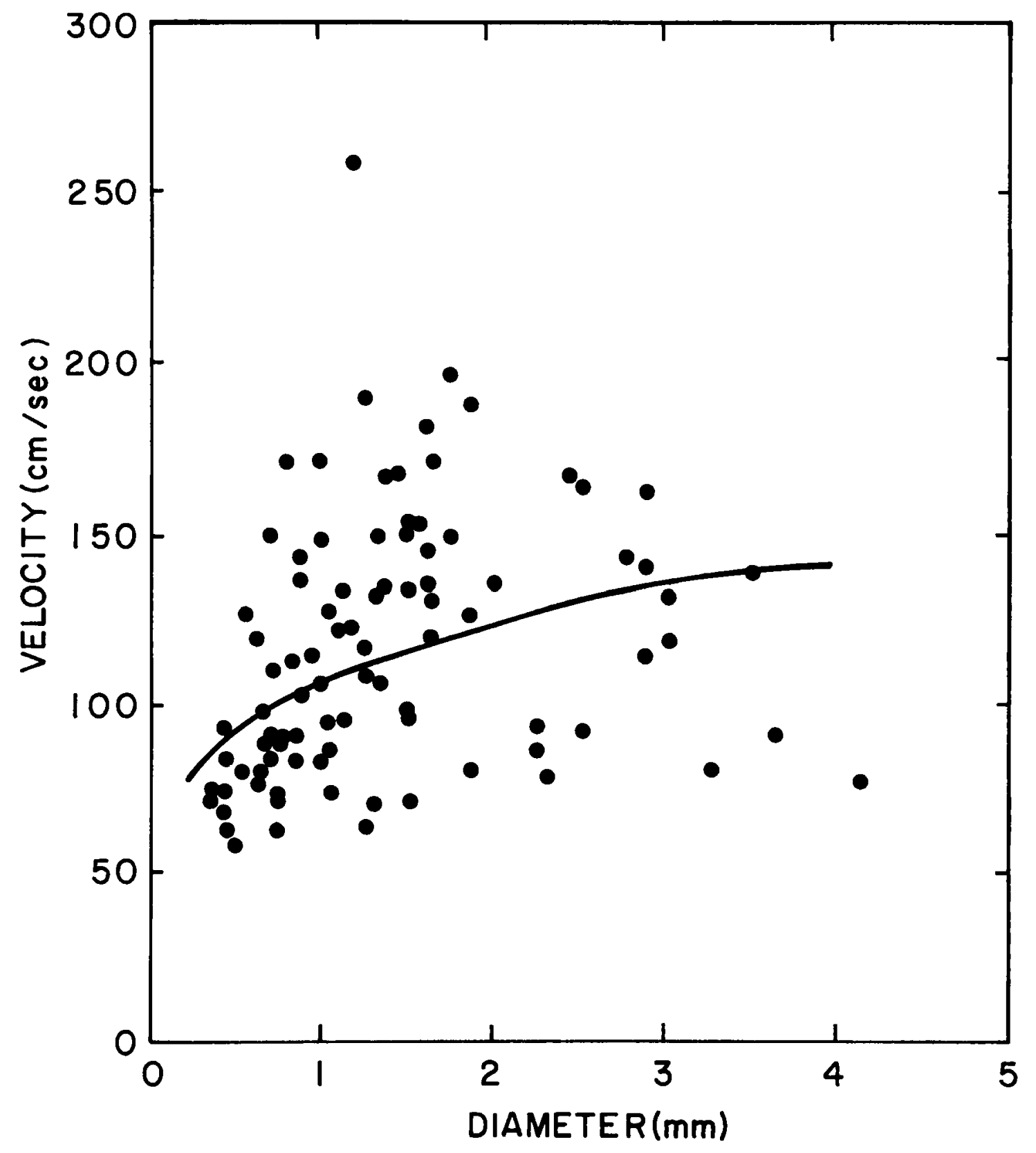

Figure C-2. Observed terminal fall velocities for heavily-rimed plane dendrites. The correlation coefficient for the leasesquares fit was . 36 . 


$$
v=25.533 \mathrm{D}^{.206}
$$

When the analysis was done for light-moderate rimed spatial crystals, the scatter was so bad and the correlation coefficient so low that a curve fit to the data was considered useless. Since the data did not appear to be unreasonably fitted by the curve fitted t, heavily-rimed plane dendrites, the fall velocity equations were assumed to be the same in both cases. This seems reasonable physically since a given rimed category of spatial crystals would generally be expected to fall at a rate equal to a greater-rimed category of plane dendrites.

Fall velocity equations for unrimed plane dendrites and graupel were adopted from Brown (1970) and Zikmumda and Vali (1972) respectively, since these studies were adequate in terms of sample size and scatter in the data. 
APPENDIX D

METEOROLOGICAL DATA FOR A CASE STUDY AT YELLOWSTONE NATIONAL PARK 


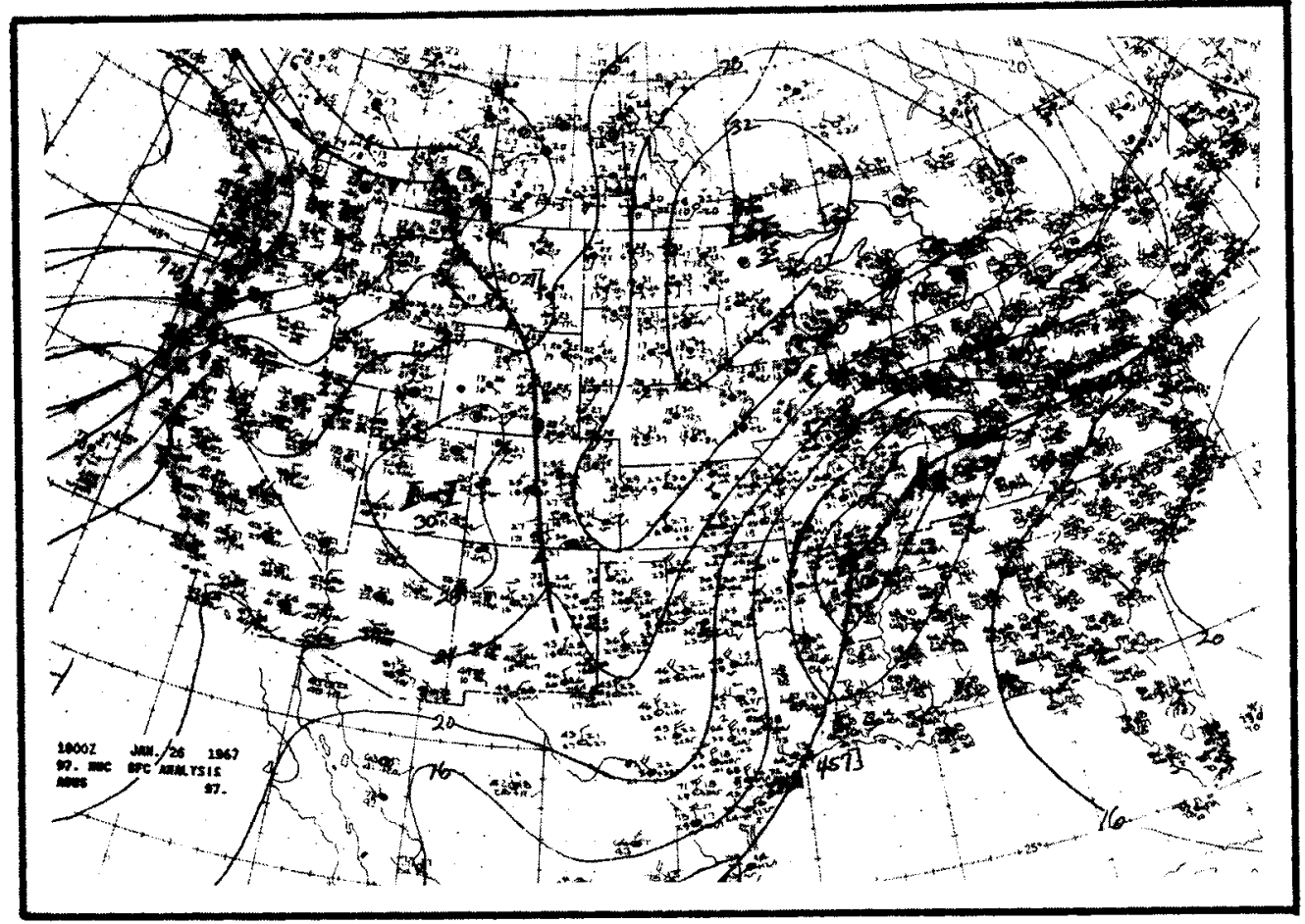

Figure D-1. Surface map for 18Z on 26 January 1967.

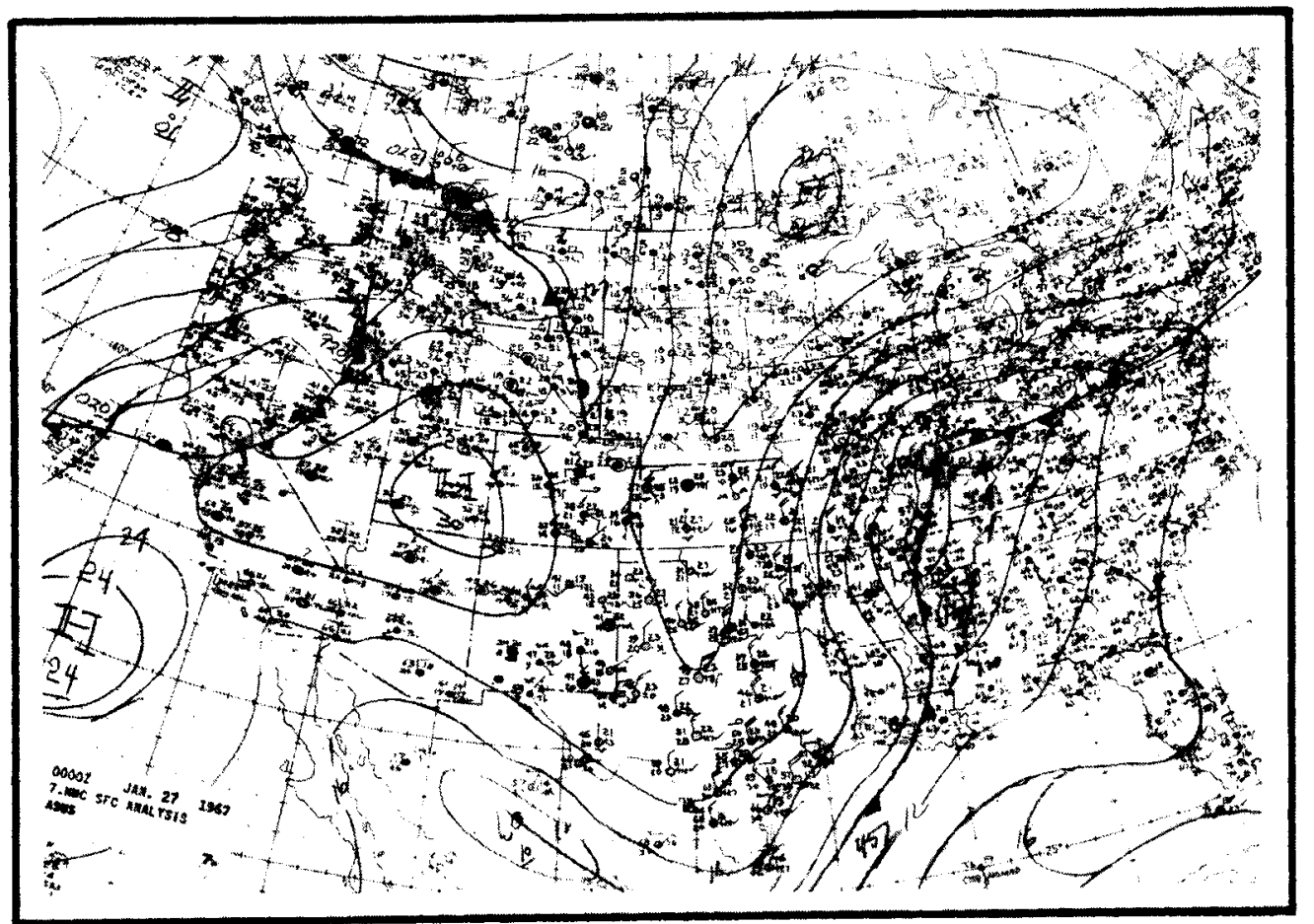

Figure D-2. Surface Map for 00Z on 97 January 1967. 


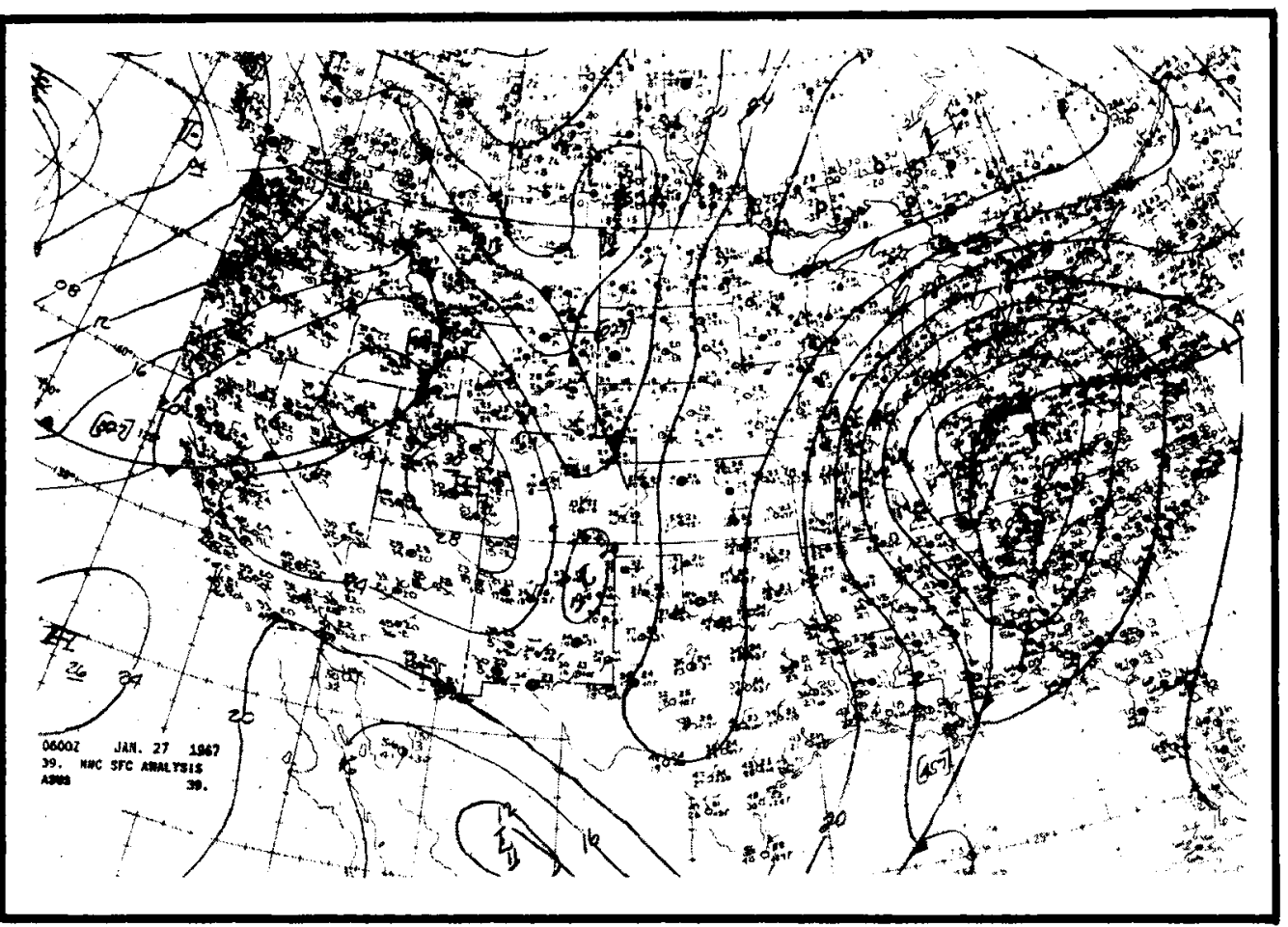

Figure D-3. Surface map for 06Z on 27 January 1967.

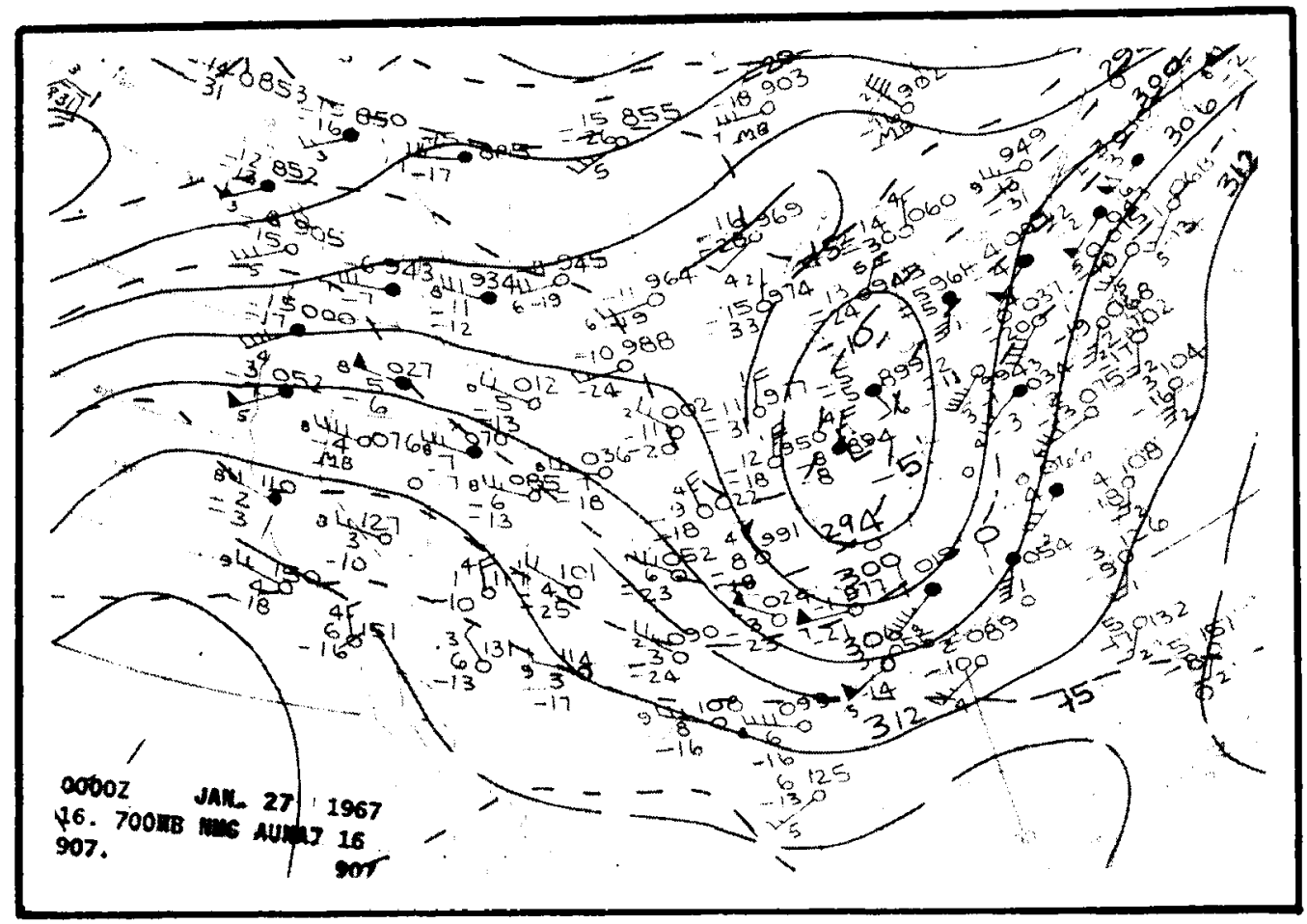

Figure D-4. $700 \mathrm{mb}$ chart for $00 \mathrm{Z}$ on 27 January 1967. 


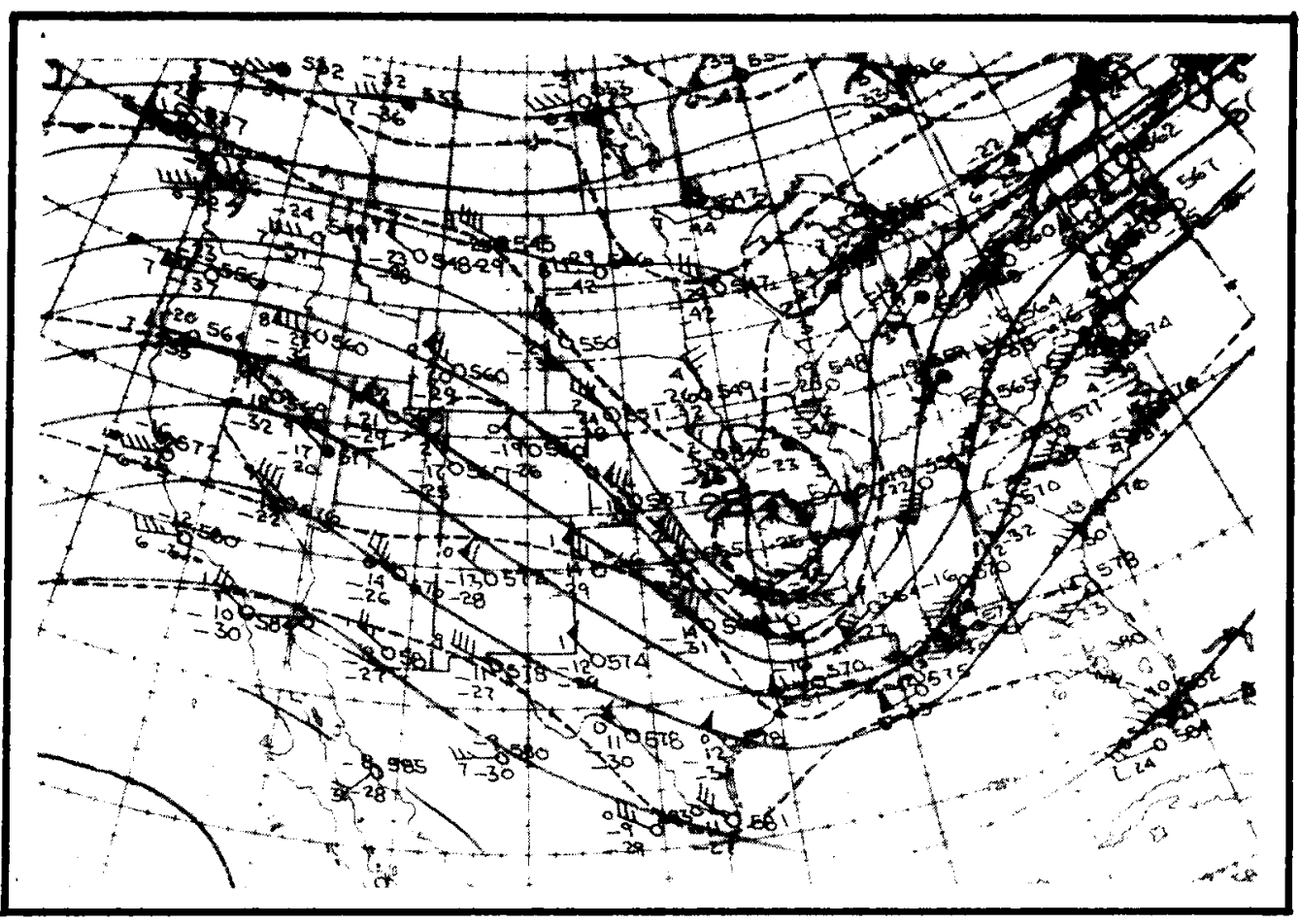

Figure D-5. $500 \mathrm{mb}$ chart for $00 \mathrm{Z}$ on 27 January 1967.

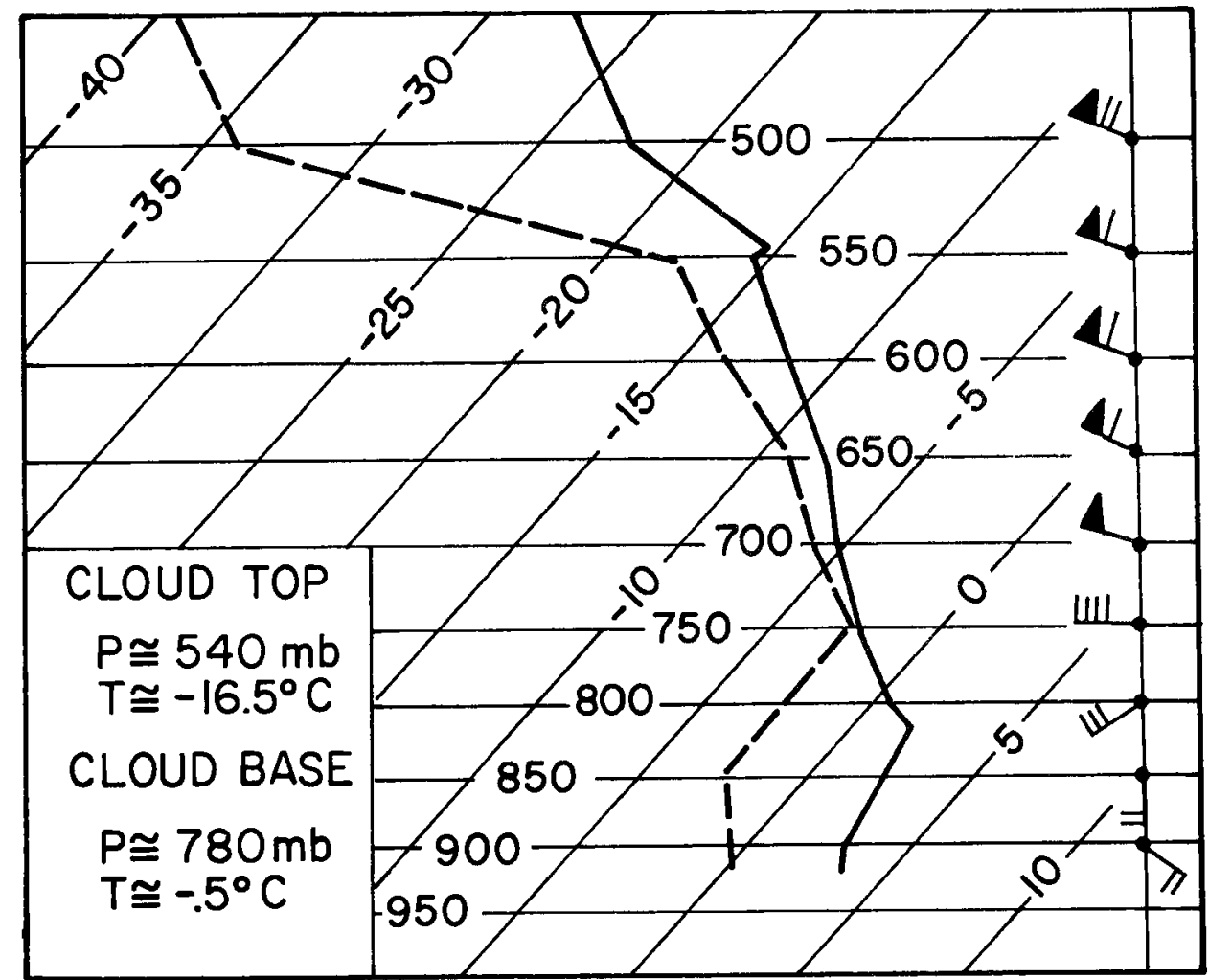

Figure D-6. Upper-air sounding for Boise, Idaho, at $00 \mathrm{Z}$ on 27 January 1967. 


\begin{tabular}{|c|c|c|}
\hline $\begin{array}{l}\text { BIBLIOGRAPHIC DATA } \\
\text { SHEET }\end{array}$ & $\begin{array}{l}\text { 1. Report Nio. } \\
\text { CSU-ATSP-230 }\end{array}$ & 3. Recipient's Accession ho. \\
\hline \multirow{3}{*}{\multicolumn{2}{|c|}{$\begin{array}{l}\text { 4. Title and subtitle } \\
\qquad \begin{array}{l}\text { THE GENERATION OF SECONDARY ICE PARTICLES IN CLOUDS } \\
\text { BY CRYSTAL-CRYSTAL COLLISION }\end{array}\end{array}$}} & 5. Report Date \\
\hline & & November 1974 \\
\hline & & 6. \\
\hline \multicolumn{2}{|c|}{ Larry Vardiman } & $\begin{array}{l}\text { 8. Performing Otganization Rept. } \\
\text { No.CSU-ATSP-230 }\end{array}$ \\
\hline \multirow{2}{*}{\multicolumn{2}{|c|}{$\begin{array}{l}\text { 9. Performing Organization hame and Address } \\
\text { Department of Atmospheric Science } \\
\text { Colorado State University } \\
\text { Foothills Campus }\end{array}$}} & 10. Project/Task/thork Lnit tio. \\
\hline & & \\
\hline Fort Collins, & Colorado 80523 & GI -31460 \\
\hline \multirow{2}{*}{\multicolumn{2}{|c|}{$\begin{array}{l}\text { Atmospheric Sciences Section } \\
\text { National Science Foundation } \\
\text { Washington, D. C. } 20550\end{array}$}} & $\begin{array}{l}\text { 13. Type of Reporc \& Period } \\
\text { Covered } \\
\text { Ph.D. dissertation }\end{array}$ \\
\hline & & 14. \\
\hline
\end{tabular}

15. Supplementary Notes

16. Abstracts

The number of ice crystal fragments generated in a cloud is a function of the collision frequency between crystals and the number of fragments produced per collision. The number of fragments generated per collision is determined experimentally in this paper by observing the fragmentation of various types of ice crystals upon impact with a fixed plate. This fragmentation rate is combined with the collision frequency in a numerical model to determine the optimum cloud conditions for secondary particle generation.

The generation of secondary particles by mechanical fracturing appears to be unimportant in isolated convective clouds. The additional crystals generated in smooth stratiform clouds may reach a maximum of ten times the expected natural crystal concentration at or near cloud base. Secondary crystal concentrations in stratiform clouds with embedded convection could reach 100 to 1000 times the expected natural concentrations.

\section{Key hords and Document Analysis. 17a. Descriptors}

Ice Multiplication

Ice Crystals

Cloud Physics

Weather Modification

Crystal Fragmentation

Secondary Particles

Ice Nuclei

17b. Identifiers/Open-Ended Terms

17e. Cost T! Field/Group

\begin{tabular}{|c|c|c|}
\hline \multirow[t]{2}{*}{ 18. Availubility jtatement } & $\begin{array}{l}\text { 19. Security Class (This } \\
\text { Report) } \\
\text { (YCH ASIFIFD }\end{array}$ & 21. Xo. of Pages \\
\hline & $\begin{array}{l}\text { 20. Securicy Class llinis } \\
\text { Page } \\
\text { PCl ASIFIFD }\end{array}$ & 22. Price \\
\hline
\end{tabular}

